AUTARQUIA ASSOCIADA À UNIVERSIDADE DE SÃO PAULO

\title{
USO DE MACRÓFITAS PARA REMOÇÃO DE METAIS EM EFLUENTES LÍQUIDOS
}

\author{
JULIANA DE ALMEIDA SILVA OLIVEIRA
}

Dissertação apresentada como parte dos requisitos para obtenção do Grau de Mestre em Ciências na Área de Tecnologia Nuclear - Aplicações

\#

Prof. Dr. PAULO SERGIO CARDOSO DA SILVA 
INSTITUTO DE PESQUISAS ENERGÉTICAS E NUCLEARES

Autarquia associada à Universidade de São Paulo

USO DE MACRÓFITAS PARA REMOÇÃO DE METAIS EM EFLUENTES LÍQUIDOS

JULIANA DE ALMEIDA SILVA OLIVEIRA

Dissertação apresentada como parte dos requisitos para obtenção do Grau de

Mestre em Ciências na Área

de Tecnologia Nuclear - Aplicações

Orientador:

Prof. Dr. PAULO SERGIO CARDOSO DA SILVA

\#

Versão Corrigida

Versão Original disponível no IPEN

São Paulo

2018 


\section{DEDICATÓRIA}

Dedico esse trabalho ao meu marido Bruno ao meu pequeno filho que deixei de acompanhar por diversos momentos por estar me dedicando a esse trabalho.

Dedico ao meu irmão Junior (in memorian), que não pode me acompanhar de maneira física nessa jornada, mas sei que esteve todos os momentos comigo, principalmente nos momentos de fraqueza onde pensei em desistir. 


\section{AGRADECIMENTO}

Agradeço primeiramente a Deus, por ter me proporcionado essa magnifica oportunidade de estudar e poder ter passado por essa imensa transformação.

Agradeço imensamente ao meu orientador Dr. Paulo Sergio Cardoso da Silva, por toda paciência e horas dedicadas a esse trabalho, agradeço também por em nenhum momento ter desistido de mim, até quando eu mesma já estava desistindo.

Agradeço aos meus colegas que dividiram a sala durante o período do mestrado em especial ao Bruno, Nicole, Renata, Uanda.

Agradeço a ajuda no laboratório dos colegas Eliel e Marcio, dos alunos de iniciação cientifica Isis e Alan.

Agradeço a CNEN pela concessão de bolsa de mestrado e ao IPEN pelos recursos financeiros para ida em congressos.

Agradeço ao CCTM e a Dra Larissa Otubo e a técnica Dra Flavia R. O. Silva pela realização das análises de microscopia eletrônica de varredura.

Agradeço também a equipe de apoio que fazem a limpeza, vigilância serviços de portaria e manutenção, que fazem sempre um importante trabalho, sem eles fazendo o trabalho deles, todos os dias eu não teria conseguido realizar o meu.

Agradeço todos aqueles que me ajudaram e estiveram ao meu lado por todo esse percurso em especial a Viviane Américo minha grande amiga.

Agradeço ao meu orientado, meu marido e minha mãe pelas ajudas com a coletas das macrófitas, que nem sempre foram fáceis.

Agradeço e sem palavras para agradecer a minha sogra, dona Lúcia por toda ajuda em cuidar do meu filho para que pudesse realizar esse projeto.

Por fim agradeço a todos do CRPq pelo trabalho e ajuda sempre que precisei, em especial a Regina Beck pela ajuda sempre que precisei. 
Sem sonhos pedras do caminho se tornam montanhas, os pequenos problemas são insuportáveis, as decepções se tornam golpes fatais e os desafios em fonte de medo. Os sonhos são como o vento, sentimo-los, mas não sabemos de onde vêm nem para onde vão. Eles inspiram o poeta, animam o escritor, arrebatam o estudante, abrem a inteligência do cientista. Eles nascem como flores nos terrenos da inteligência e crescem nos vales secretos da mente. 
(Augusto Cury)

\section{USO DE MACRÓFITAS PARA REMOÇÃO DE METAIS EM EFLUENTES LÍQUIDOS}

\section{JULIANA DE ALMEIDA SILVA OLIVEIRA}

\section{RESUMO}

Nesse trabalho foi avaliada a capacidade de adsorção da biomassa da com macrófita Eichhornia crassipes (aguapé) em efluente sintético contendo íons de metais $\mathrm{Cd}, \mathrm{Pb}, \mathrm{Cr}, \mathrm{Zn}$ e Co. Primeiramente foram determinadas as áreas superficiais específicas de cada uma das partes da planta (caule, folha e raiz) separadamente. A raiz foi a parte selecionada e em seguida foi ativada quimicamente com $\mathrm{HCl}$ e $\mathrm{NaOH} 0,1 \mathrm{~mol} \mathrm{~L}^{-1}$. A raiz ativada com $\mathrm{HCl}$ foi utilizada para os estudos dos parâmetros de adsorção: influência do $\mathrm{pH}$, do tempo de contato e da concentração inicial dos íons em solução. Para as determinações propostas, foram utilizados como métodos analíticos de análise por ativação neutrônica instrumental para os íons do Co, $\mathrm{Zn}$ e $\mathrm{Cr}$ e análise por absorção atômica com forno de grafite para determinação da concentração dos íons de $\mathrm{Cd}$ e $\mathrm{Pb}$. Nas duas técnicas, foram analisadas amostras de biomassa antes e após os experimentos de adsorção. Tanto a ativação ácida quanto a básica provocam um aumento da área superficial, porém o tratamento ácido produziu um material de mais fácil moagem. A eficiência de remoção e porcentagem de adsorção do íon $\mathrm{Cr}$ não foi satisfatória nas condições de realização deste trabalho. Para os demais íons verificou-se um aumento da eficiência de adsorção com o aumento do $\mathrm{pH}$, do tempo de contato e da concentração inicial. Pode-se concluir que a biomassa ativada da raiz de Eichhornia crassipes é uma alternativa rápida, barata e eficiente para remoção dos íons metálicos considerados neste trabalho, sendo que a eficiência de remoção presentou a seguinte ordem decrescente: $\mathrm{Pb}>\mathrm{Cd}>\mathrm{Zn}>\mathrm{Co}>\mathrm{Cr}$. 


\title{
USE OF MACROPHITES FOR REMOVAL OF METALS IN LIQUID EFFLUENTS
}

\section{JULIANA DE ALMEIDA SILVA OLIVEIRA}

\begin{abstract}
In this work the adsorption capacity of the macrophyte Eichhornia crassipes (aguapé) biomass was evaluated in synthetic effluent containing $\mathrm{Cd}$, $\mathrm{Pb}, \mathrm{Cr}, \mathrm{Zn}$ and $\mathrm{Co}$ metal ions. At first, the specific surface areas of each part of the plant (stem, leaf and root) were determined. The root was the selected part and then chemically activated $\mathrm{HCl}$ and $0.1 \mathrm{~mol} \mathrm{~L}^{-1} \mathrm{NaOH}$. The $\mathrm{HCl}$ activated root was used for the studies of the adsorption parameters: $\mathrm{pH}$, contact time and initial concentration of the solution influence. In order to determine the concentration of the $\mathrm{Cd}$ and $\mathrm{Pb}$ ions the analytical method graphite furnace atomic absorption was used and to analyze $\mathrm{Co}, \mathrm{Zn}$ and $\mathrm{Cr}$, instrumental neutron activation analysis was applied. The analysis was made in the biomass samples before and after the adsorption experiments. Both acid and basic activation caused an increase in surface area, but the acid treatment produced a material easier to grind. The adsorption efficiency and adsorption percentage of the $\mathrm{Cr}$ was not satisfactory under the conditions of this work. For the other ions, an increase of the adsorption efficiency with the increase of $\mathrm{pH}$, contact time and initial concentration was verified. It was possible to conclude that the activated biomass of Eichhornia crassipes roots is a fast, cheap and efficient alternative for the removal of the metal ions considered in this work, and the removal efficiency had the following decreasing order: $\mathrm{Pb}>\mathrm{Cd}>\mathrm{Zn}>\mathrm{Co}>\mathrm{Cr}$.
\end{abstract}




\section{SUMÁRIO}

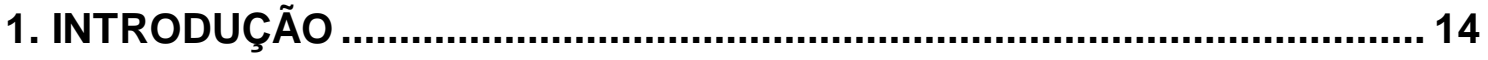

1.1 Aspectos históricos e importância da água e tratamento de efluentes ... 14

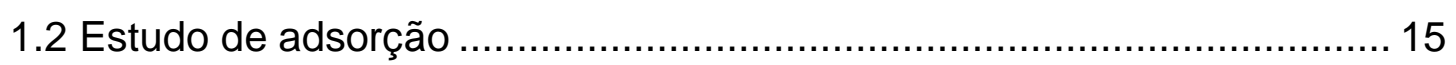

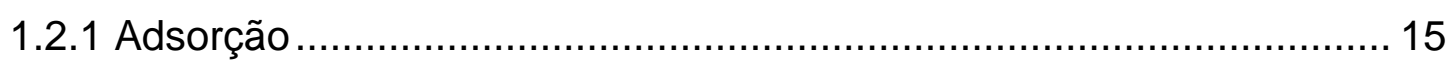

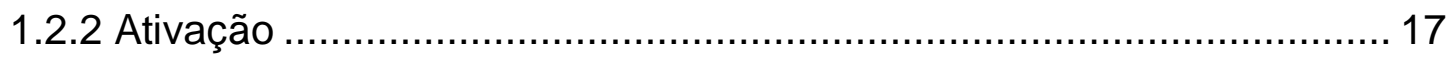

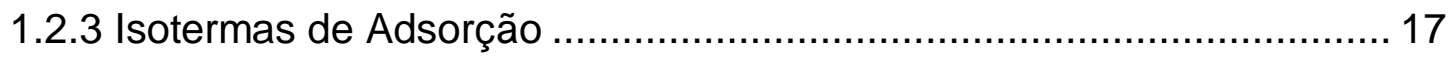

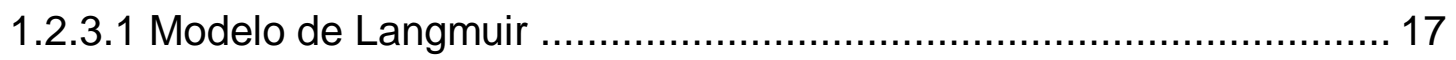

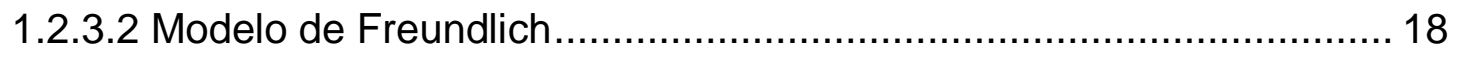

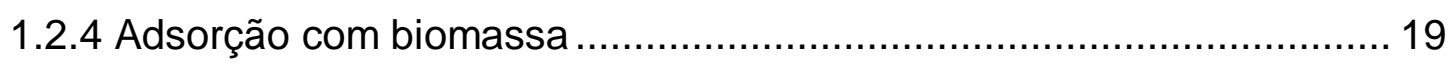

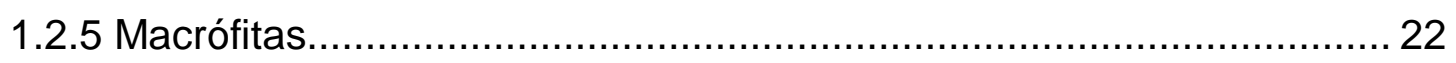

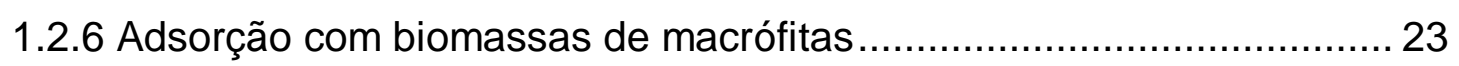

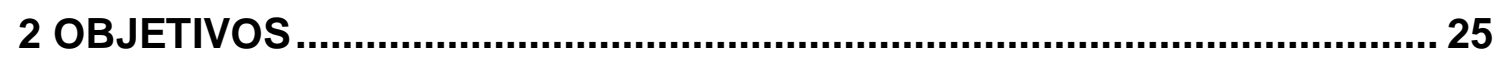

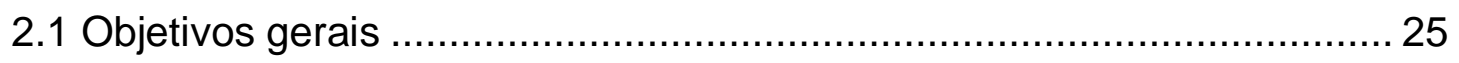

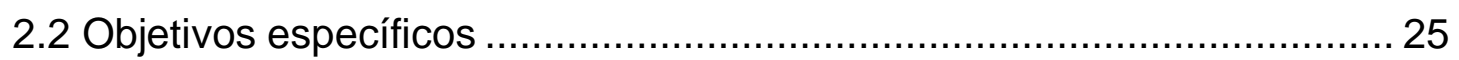

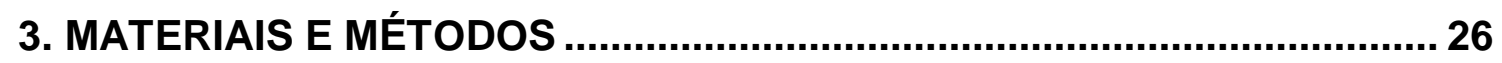

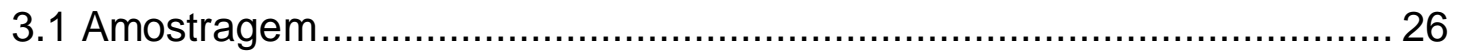

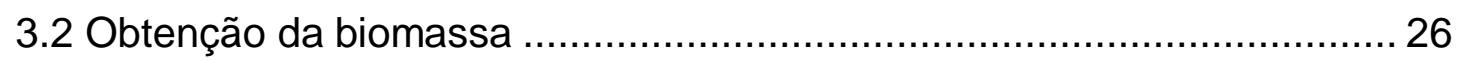

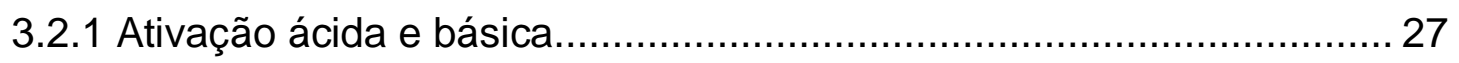

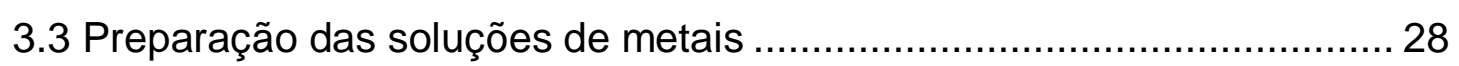

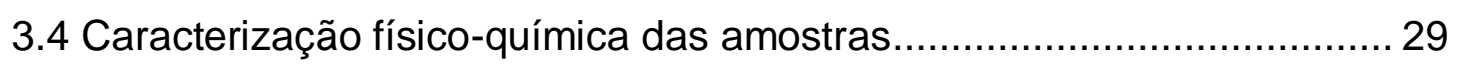

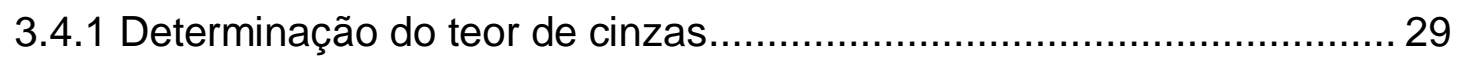

3.4.2 Analise de área superficial específica por titulação............................... 29

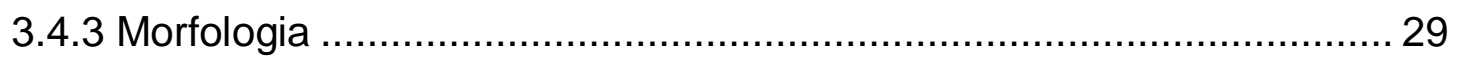

3.4.4 Análise por ativação neutrônica instrumental (INAA) ……….............. 30

3.4.4.1 Preparação das amostras para irradiação ........................................ 33

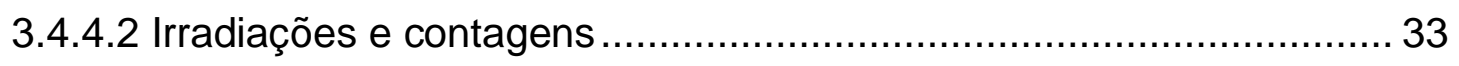

3.4.5 Espectrometria de Absorção Atômica por Forno de Grafite (GF AAS) 34

3.4.5.1 Procedimento experimental para as analise de $\mathrm{Cd}$ e $\mathrm{Pb}$................. 35

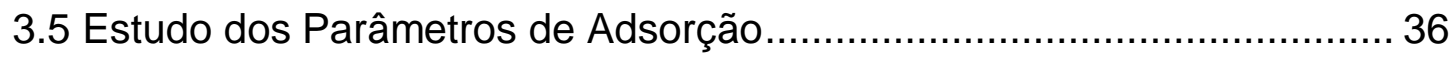

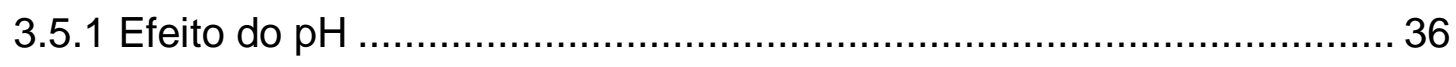




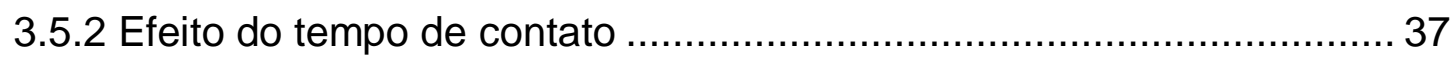

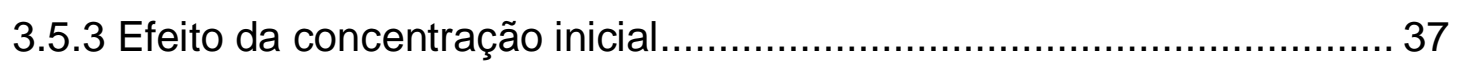

3.5.4 Determinação da Capacidade de Adsorção e porcentagem de remoção

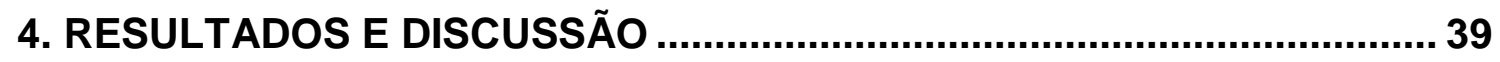

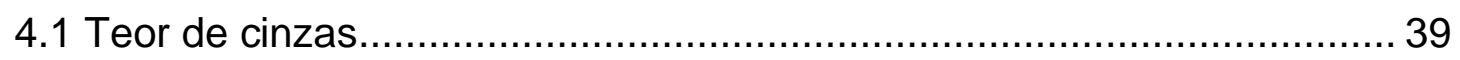

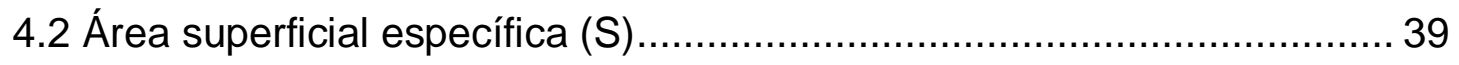

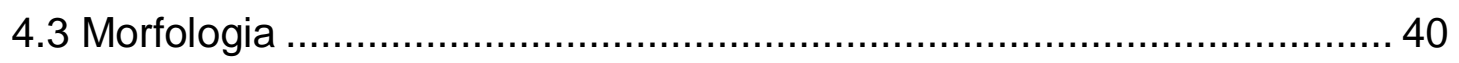

4.4 Caracterização elementar da biomassa .............................................. 43

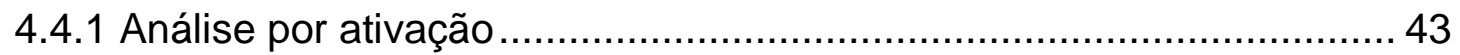

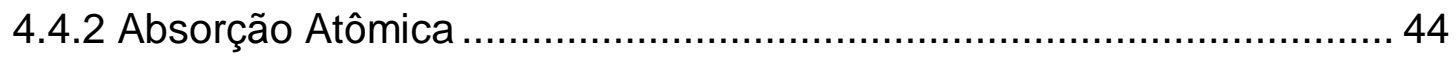

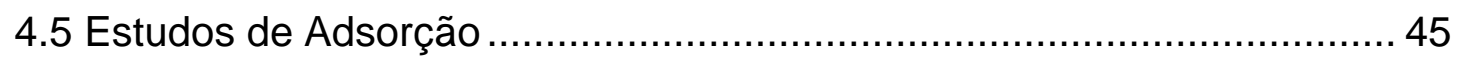

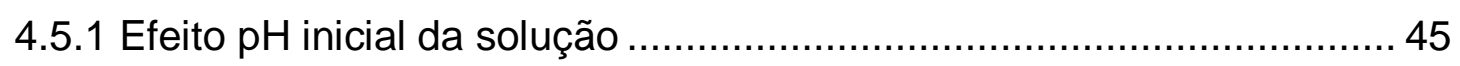

4.4.2 Efeito do tempo de contato ........................................................ 53

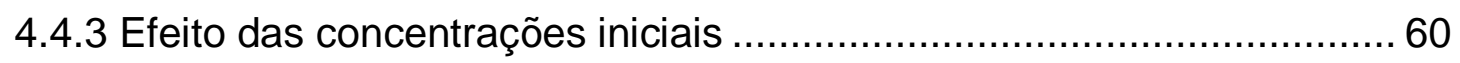

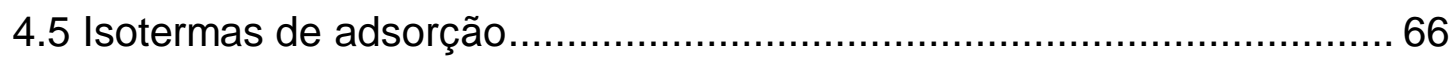

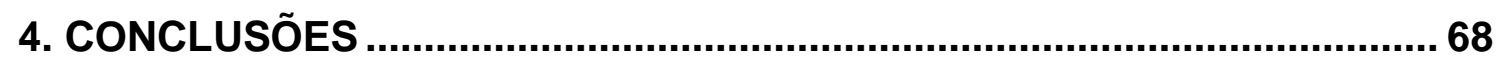

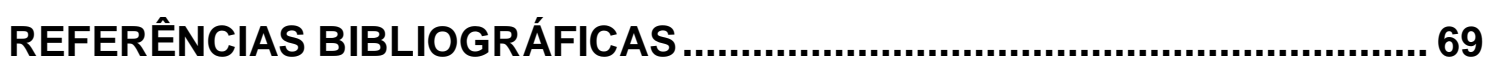




\section{LISTA DE FIGURAS}

Figura 1 - Representação dos fenômenos de absorção e adsorção em sistema

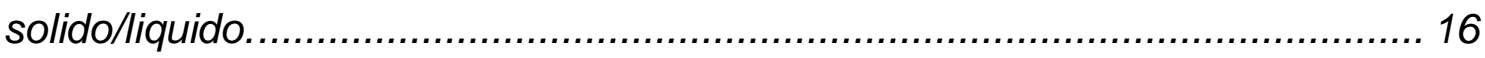

Figura 2 - macrófitas Eichhornia crassipes..............................................22

Figura 3 - Vista aérea dos locais de coleta................................................. 26

Figura 4 - Etapas do processo de divisão da planta (raiz, caule e folha). ........ 27

Figura 5 - Equipamento de microscopia eletrônica de varredura (SEM), modelo $X L-30$, marca Phillips, com detector de espectroscopia de energia dispersiva (EDS) acoplado.

Figura 6 - Ilustração da sequência de eventos para uma reação $(n, \gamma)$.

Figura 7 - llustração dos processos para preparação das amostras para irradiação: acondicionamento das amostras em saquinhos de polietileno (etapa 1), invólucros selados (etapa 2), embalados em lâmina de alumínio e acondicionados em cápsula de alumínio para irradiação (etapa 3). 33

Figura 8 - Ilustração do sistema com detector de Germânio Hiperpuro e eletrônica associada do Laboratório de Análise por Ativação Neutrônica.

Figura 9- Equipamento de GF AAS modelo AAnalyst 800 da Perkin Elmer para determinação de $\mathrm{Cd}$ e $\mathrm{Pb}$.

Figura 10- Curva de calibração obtida para análise de Cd e Pb por GF AAS.36

Figura 11- Morfologia da raiz sem tratamento.

Figura 12- Morfologia da raiz com tratamento com HCl, $1 \mathrm{~mol}^{-1}$.

Figura 14 - Capacidade de adsorção $\left(q_{e}, \mathrm{mg} \mathrm{g}^{-1}\right)$ em função do $\mathrm{pH}$ para o íon cobalto.

Figura 15 - Eficiência de remoção (\%) em função do $\mathrm{pH}$ para o íon cobalto... 46 Figura 16 - Capacidade de adsorção $\left(q_{e}, \mathrm{mg} \mathrm{g}^{-1}\right)$ em função do $\mathrm{pH}$ para o íon zinco.

Figura 18 - Capacidade de adsorção $\left(q_{e}, \mathrm{mg} \mathrm{g}^{-1}\right)$ em função do $\mathrm{pH}$ para o íon cromo.

Figura 19 - Eficiência de remoção (\%) em função do pH para o íon cromo..... 49 Figura 20 - Capacidade de adsorção em $\mathrm{mg} \mathrm{g}^{-1}$, em função do $\mathrm{pH}$ inicial da solução de íons de cádmio.

Figura 21 - Eficiência de remoção (\%) em função do pH para os íons da solução de cádmio. 
Figura 22 - Capacidade de adsorção, em $\mathrm{mg} \mathrm{g}^{-1}$, de chumbo em função do $\mathrm{pH}$ inicial da solução.

Figura 23 - Eficiência de remoção (\%) em função do pH inicial para solução de íns de chumbo.

Figura 24 - Capacidade de adsorção (qe, $\mathrm{mg} \mathrm{g}^{-1}$ ) em função do tempo de contato para o íon cobalto.

Figura 25 - Eficiência de remoção, em \%, em função do tempo de contato para o íon cobalto.

Figura 26 - Capacidade de adsorção $\left(q_{e}, m g^{-1}\right)$ em função do tempo de contato para o íon de zinco.

Figura 27 - Eficiência de remoção, em \%, em função do tempo de contato para o íon de zinco.

Figura 28 - Capacidade de adsorção, em mg g ${ }^{-1}$, de Cd em função do tempo de contato.

Figura 29 - Eficiência de remoção, em \%, de Cd em função do tempo de contato

Figura 30 - Capacidade de adsorção, em $\mathrm{mg} \mathrm{g}^{-1}$, de $\mathrm{Pb}$ em função do tempo de contato.

Figura 31 - Eficiência de remoção, em \%, de Pb em função do tempo de contato.

Figura 32 - Capacidade de adsorção, em $\mathrm{mg} \mathrm{g}^{-1}$, de cobalto em função da variação concentração.

Figura 33 - Eficiência de remoção, em \%, em função da variação da concentração para os íons cobalto.

Figura 34 - Capacidade de adsorção, em mg g ${ }^{-1}$, de zinco em função da concentração.

Figura 35 - Eficiência de remoção, em \%, em função da variação de concentração para íons de Zinco.

Figura 36 - Capacidade de adsorção, em $\mathrm{mg} \mathrm{g}^{-1}$, de cádmio em função da concentração.

Figura 37 - Eficiência de remoção, em \%, em variação de concentração para íons de cádmio.

Figura 38 - Capacidade de adsorção, em $\mathrm{mg} \mathrm{g}^{-1}$, de Pb em função da concentração. 
Figura 39 - Eficiência de remoção em (\%) em função da variação de concentração íons de chumbo.

\section{LISTA DE TABELAS}

Tabela 1- Concentração permitida (coluna 1), duas (coluna 2) e seis (coluna 3) vezes o valor permitido para descarte em corpos hídricos que foram usadas neste trabalho.

Tabela 2 - Elementos de interesse e suas concentrações (valor \pm incerteza), em $\mathrm{mg} \mathrm{kg}^{-1}$ e valores calculados dos materiais de referência e dos padrões pipetados (P.P), utilizados para INAA.

Tabela 3 - Elementos de interesse e suas concentrações (valor \pm incerteza), em $\mathrm{mg} \mathrm{kg}^{-1}$ e valores calculados dos materiais de referência utilizados para FGASS. 36

Tabela 4 - Teor de cinzas de amostras de biomassa.

Tabela 5 - Área superficial específica, em $\mathrm{m}^{2} \mathrm{~g}^{-1}$, das biomassas não ativadas.

Tabela 6: Área superficial, em $\mathrm{m}^{2} \mathrm{~g}^{-1}$, da biomassa (raiz) avaliada após tratamento de $\mathrm{HCl}$ e $\mathrm{NaOH}$. 40

Tabela 7 - Concentrações determinadas por NAA, em mg kg-1, para os elementos de interesse, nas amostras utilizadas para estudo do efeito do $\mathrm{pHe}$ do tempo de contato.

Tabela 8 - Concentrações de Cd e Pb, em $\mathrm{mg} \mathrm{kg}^{-1}$, obtidas por absorção atômica. 45

Tabela 9 - Valores de $q_{e}$ obtidos para o efeito de $\mathrm{pH}$ para o Co. 45

Tabela 10 - Valores de $q_{e}$ obtidos para o efeito de $\mathrm{pH}$ para o $\mathrm{Zn}$. 47

Tabela 11 - Valores de $q_{e}$ obtidos para o efeito de $\mathrm{pH}$ para o $\mathrm{Cr}$. 48

Tabela 12 - Valores de $q_{e}$ obtidos para o efeito de $\mathrm{pH}$ para o Cd. 50

Tabela 13 - Valores de $q_{e}$ obtidos para o efeito de $p H$ para o $P b$. 52

Tabela 14 - Valores de $q_{e}$ obtidos para o efeito de TC para o Co. 53

Tabela 15 - Valores de qe obtidos para o efeito de TC para o Zn. 55

Tabela 16 - Valores de qe obtidos para o efeito de TC para o Cd. 57

Tabela 17 - Valores de $q_{e}$ obtidos para o efeito de TC para o Pb. 58 
Tabela 18 - Valores de qe obtidos para o efeito de Concentração para o Co... 60 Tabela 19 - Valores de qe obtidos para o efeito de Concentração para o Zn... 61 Tabela 20 - Valores de $q_{e}$ obtidos para o efeito de Concentração para o Cd... 63 Tabela 21 - Valores de $q_{e}$ obtidos para o efeito de Concentração para o Pb... 64 Tabela 22 - Parâmetros das isotermas de Langmuir e Freundlich. 66 


\section{INTRODUÇÃO}

\subsection{Aspectos históricos e importância da água e tratamento de efluentes}

A água, sendo o elemento mais difundido no globo terrestre, é um recurso indispensável à manutenção da vida no planeta, estando em constante renovação, por meio do ciclo hidrológico. Encontra-se no ambiente nos estados líquido (mares, represas, lagos, riachos, cachoeiras), sólido (gelo) e gasoso. De acordo com Braga et al. (2010), estima-se que a massa de água total existente no planeta seja aproximadamente a 265.400 trilhões de toneladas, distribuídas não uniformemente, sendo deste total, apenas 3\% de água doce e deste, somente $0,3 \%$ disponível para consumo nas atividades humanas. Deve-se considerar ainda que diversos processos alteram a qualidade e quantidade da água disponível (BRAGA et al., 2010).

A decorrente preocupação com o saneamento básico acompanha as civilizações desde as épocas mais remotas. Aristóteles, já na antiga Macedônia, relatava interesse no assunto. Com o decorrer do tempo, as necessidades humanas e o crescimento da população passaram a exigir quantidade cada vez maior de água e facilidades às fontes existentes. Na tentativa de evitar a escassez, principalmente nas estações de seca, os povos antigos desenvolveram projetos avançados de engenharia para condução e armazenamento da água. Ao mesmo tempo, procuravam novas fontes de suprimento, inclusive no subsolo. Os romanos criaram obras grandiosas destinadas ao transporte de água (aquedutos) e ao afastamento de esgoto (cloaca). Embora, com o passar dos tempos, a humanidade tenha aperfeiçoado muitas técnicas para coletar água e afastar os detritos, o problema permanece até os dias atuais (CAVINATTO, 1994).

Além de todos os prejuízos conhecidos causados pelo estresse hídrico, aos seres humanos, existe também o dano causado ao meio ambiente, devido às fontes poluidoras difusas e pontuais de efluente industriais e domésticos (BRAGA et al., 2010).

$\mathrm{Na}$ resolução CONAMA no 430 são estabelecidos diversos parâmetros para quantificar elementos nos efluentes. Para cada elemento é estabelecido o valor máximo permitido (VMP), que não deve ser ultrapassado no despejo em corpos de água. A resolução CONAMA no 430 também estabelece quantidades especificas 
para metais de efeitos cumulativos e íons de metais pesados. Efluente líquido deve ser tratado antes de ser despejado em corpos receptores.

ĺons metálicos ocorrem na natureza e muitos deles são essenciais à vida, entretanto, quando presentes em elevadas concentrações, podem ser tóxicos ao meio aquático e à vida humana (SCHVARTSMAN, 1985). Esses íons podem ser removidos de soluções aquosas por processos como troca iônica, extração com solvente, flotação, coagulação, eletrodeposição, precipitação química, separação por membranas e adsorção (DEMIRBAS, 2008).

Recentemente, um novo campo de estudo referente à remoção de íons metálicos de solução de efluentes baseia-se no uso de espécies de plantas, as quais possuem habilidade natural para biorremediação do ambiente. Além do uso de plantas vivas, alguns estudos têm demonstrado que o uso de biomassa pode, efetivamente, adsorver íons metálicos e, portanto, ser utilizada para remoção de metais de soluções (SEKI et al., 1998, SARIN e PANT, 2006; SINGH et al., 2006; HASHEM et al., 2007; KAHRAMAN et al., 2008).

\subsection{Estudo de adsorção}

\subsubsection{Adsorção}

No estudo de adsorção é necessário entender a diferenças entre os fenômenos que ocorrem.

Ao fenômeno da aderência e penetração de partículas (íons, átomos, moléculas e etc.) dá-se o nome de sorção interface sólido/gás ou sólido/líquido. O efeito inverso, isto é, de liberação das partículas para o fluido, é denominado dessorção.

São fenômenos de sorção a absorção e adsorção. Na absorção ocorre difusão, penetração, incorporação do soluto através de matérias sólidos. Na adsorção, temse adesão, fixação de partículas de natureza orgânica ou inorgânica na superfície solida, sendo um fenômeno superficial acontecendo apenas na superfície do adsorvente (HYPOLITO et al., 2011). Na figura 1 é mostrada uma representação dos fenômenos de absorção e adsorção. 
Figura 1 - Representação dos fenômenos de absorção e adsorção em sistema solido/liquido.

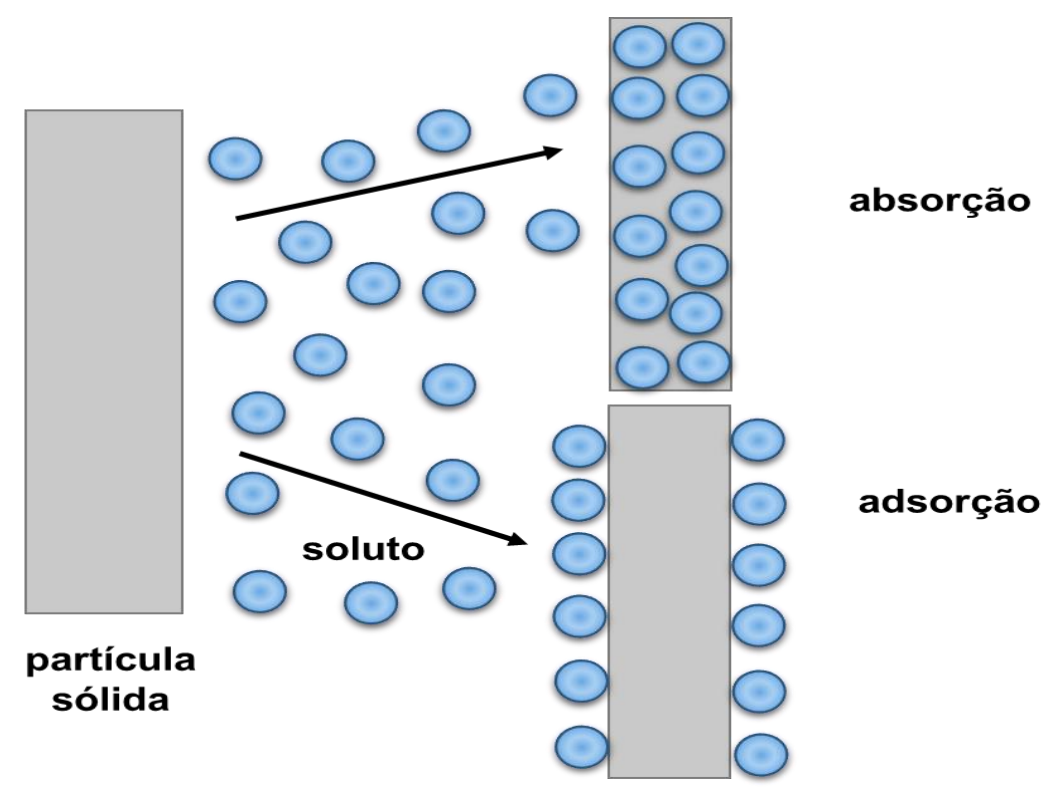

Fonte: adaptado (HYPOLITO et al., 2011)

No fenômeno de adsorção, adsorvato é a espécie que no meio aquoso é adsorvida (soluto) e o substrato sólido no qual ocorre a adsorção é denominado adsorvente (HYPOLITO et al., 2011).

No fenômeno de adsorção, levando em conta a natureza da ligação, tem-se adsorção não especifica ou física (fisiossorção) e específica ou química (químiossorção).

A fisiossorção está relacionada à interação com a superfície e íons ligados por pontes de hidrogênio e por forças de van der Waals, sendo sua principal característica a reversibilidade. Neste tipo de adsorção podem se formar camadas moleculares sobrepostas, sendo que a força de adsorção diminui com o aumento do número de camadas.

A químiossorção (adsorção química) ocorre em temperaturas elevadas ao contrário da fisiossorção os fenômenos são na maioria das vezes irreversíveis, e por ser uma interação específica ocorre em uma só camada. A adsorção química ocorre através de ligações fortes entre soluto e adsorvente, como as covalentes e iônicas, e 
dificilmente sofrem dessorção. Na quimissorção, são necessários longos períodos de tempo para atingir o equilíbrio, especialmente a baixas temperaturas. (HYPOLITO et al., 2011; SCHMAL, 2009)

\subsubsection{Ativação}

Em estudos de adsorção é comum a utilização da ativação do adsorvente. O propósito desta ativação é aumentar a área superficial do sólido aumentado sua porosidade (Hussein et al., 2004). A ativação pode produzir defeitos estruturais no adsorvente que, por sua vez, podem tornar favorável o processo de adsorção.

No processo de ativação, têm-se a ativação física e ativação química.

A ativação física consiste em tratamentos térmicos, com temperaturas relativamente elevadas por períodos prolongados, produz uma estrutura de poro tipo fenda bastante fina, tornando o material obtido apropriado para o uso em processo de adsorção.

$\mathrm{Na}$ ativação química utilizam-se agentes químicos como $\mathrm{HCl}, \mathrm{H}_{2} \mathrm{SO}_{4}, \mathrm{H}_{3} \mathrm{PO}_{4}, \mathrm{ZnCl}_{2}$, $\mathrm{K}_{2} \mathrm{CO}_{3}, \mathrm{NaOH}$, para promover a ativação do material. A ativação química gera materiais com poros maiores (FOO e HAMEED, 2011; SAI e KRISHNAIAH, 2005).

\subsubsection{Isotermas de Adsorção}

Foram propostos modelos teóricos diversos procurando interpretar os fenômenos de adsorção-desorção. Os modelos mais importantes são descritos pelas isotermas de adsorção-desorção que foram introduzidos por Langmuir e Freundlich.

\subsubsection{Modelo de Langmuir}

O primeiro modelo teórico quantitativo da adsorção de gases em sólidos foi proposto por Irving Langmuir em 1916 (SCHMAL, 2009). A isoterma de Langmuir permite que se estimem a capacidade máxima de adsorção e a energia de ligação soluto/sólido para as superfícies de sólidos, admitidas como homogêneas e uniformes (HYPOLITO et al., 2011).

A adsorção ocorre com cobrimento por monocamadas, só cessando quando o valor máximo for atingido, isto é, quando todos os sítios de adsorção estiverem ocupados. No desenvolvimento do modelo, Langmuir admitiu as seguintes hipóteses: 
- A superfície de um sólido contém um número definido de sítios para a adsorção;

- Cada sítio pode adsorver somente uma molécula;

- Todos os sítios são energeticamente equivalentes, i.e., todos possuem a mesma entalpia de adsorção;

- A adsorção independe da presença ou ausência de espécies adsorvidas na sua vizinhança, i.e., a entalpia de adsorção independe do grau de cobertura;

- No equilíbrio, a taxa de adsorção é igual à taxa de desorção;

Equação de Langmuir é dada por:

$$
\frac{x}{m}=\frac{K_{L} M C e}{1+K_{L} C e}
$$

Sendo:

$\mathrm{X}=$ Massa de soluto adsorvido nos sítios de adsorção de adsorvente (mg ou $\mu \mathrm{g}$ )

$\mathrm{m}=$ massa de adsorvente $(\mathrm{g})$

$\mathrm{K}_{\mathrm{L}}=$ Constante de Langmuir - indica a energia de ligação soluto-substrato. Maior valor de $\mathrm{K}_{\mathrm{L}}$ indica íons mais fortemente ligados ao adsorvente, sugerido predomínio do fenômeno de químiossorção.

M = capacidade máxima de adsorção. Valor elevado de M significa alta capacidade de adsorção.

$\mathrm{C}_{\mathrm{e}}=$ concentração de soluto no equilíbrio $\left(\mathrm{mg} \mathrm{dm}^{-3}\right)$ (HYPOLITO et al., 2011).

\subsubsection{Modelo de Freundlich}

O modelo proposto por Freundlich equaciona a relação entre a quantidade de material adsorvido e a concentração do material na solução em um modelo aplicado a sistemas não padrões, em superfícies heterogêneas e adsorção em multicamada (NASCIMENTO et al., 2014). 
O modelo considera o sólido heterogêneo, ao ponto que se aplica uma distribuição exponencial para caracterizar os vários tipos de sítios de adsorção, os quais possuem diferentes energias adsortivas (NASCIMENTO et al., 2014).

Para aplicação da equação de Freundlich adota-se a formação de multicamadas de soluto nos sítios de adsorção. Ela é válida somente dentro de limites de concentrações e pode ser expressa através da equação 2 .

$$
\frac{x}{m}=K_{F} C_{e}^{\frac{1}{n}}
$$

Na forma logarítmica produz a equação da reta, (expressão linear). $\log \frac{x}{m}=$

$$
\log _{K_{F}}+\frac{1}{n} \log C_{e}
$$

$\mathrm{X}=$ massa de soluto adsorvido nos sítios de adsorção do adsorvente (mg ou $\mu \mathrm{g}$ )

$\mathrm{m}=$ massa de adsorvente $(\mathrm{g})$

$C_{e}=$ concentração do material na solução final em equilíbrio com o sólido.

$\mathrm{K}_{\mathrm{F}}$ = coeficiente de adsorção - indica a capacidade adsorvida. Refere-se a uma medida da distribuição de equilíbrio entre as fases sólidas e líquidas; quanto maior o valor de KF mais elevada será a capacidade máxima adsorvida.

$\frac{1}{n}=$ coeficiente angular da reta. É um parâmetro adimensional e indica reatividade ou intensidade dos sítios de adsorção (HYPOLITO et al., 2011).

\subsubsection{Adsorção com biomassa}

Os seres vivos e materiais de origem biológica são capazes de remover íons de metais pesados do meio aquoso, entre eles bactérias, microalgas, fungos e vegetais (SCHNEIDER, 1995). Muitos estudos de remoção de íons metálicos com biomassa de subprodutos agroindustriais e vegetais estão sendo realizados, como exemplos 0 uso casca de amendoim para remoção de $\mathrm{Cu}$, Pb e Cd (Randall et al., 1978), mesocarpo de maracujá para remoção $\mathrm{Cr}$ (Costa et al., 2015), pó de casca de coco verde para sorção de $\mathrm{Zn}, \mathrm{Ni}$ e $\mathrm{Cr}$, Cd e As (Pino, 2005), biomassa de macrófitas para remoção de $\mathrm{Cr}, \mathrm{Ni}, \mathrm{Cu}, \mathrm{Zn}, \mathrm{Cd}$ e Pb (SCHNEIDER, 1995). 
No estudou Casarin, (2014) estudou o uso de resíduo de castanha do Brasil (castanha do Pará), como biossorvente na remoção dos íons metálicos $\mathrm{Cd}, \mathrm{Pb}, \mathrm{Cr}$, $\mathrm{Cu}$ e $\mathrm{Zn}$, em função da variação do $\mathrm{pH}$, de 4, 5 e 6, do tempo de contato, com variação de 5 a 180 minutos, e com variações de temperatura de $15^{\circ}$ a $55^{\circ} \mathrm{C}$. Constatou que os modelos matemáticos Langmuir, Freundlich e DubininRadushkevich se ajustaram a adsorção de $\mathrm{Cr}$. Para $\mathrm{Pb}(\mathrm{II})$ o melhor ajuste foi obtido apenas pelo modelo de Langmuir e para o Cd(II) Langmuir e Freundlich.

MIMURA et al. (2010) utilizaram biomassa de casca de arroz previamente tratada com $\mathrm{NaOH} 0,5 \mathrm{~mol} / \mathrm{L}^{-1}$ a $50^{\circ} \mathrm{C}$ durante 4 horas, seca e triturada até atingir uma granulometria de 0,5 mm. Esta biomassa foi aplicada ao tratamento de efluente contendo $\mathrm{Cu}(\mathrm{II}), \mathrm{Al}(\mathrm{III}), \mathrm{Ni}(\mathrm{Il})$ e $\mathrm{Zn}(\mathrm{II})$, com variação de $\mathrm{pH}$ de 1 a 12 e tempo de contato 30 a 660 minutos. Os melhores resultados de adsorção ocorreram em pH 5. Os resultados mostraram que a eficiência da casca de arroz como biossorvente. no tratamento de efluentes líquidos contendo os íons metálicos é afetada pela competitividade entre eles. A capacidade de adsorção da casca de arroz é modificada pela presença de $\mathrm{Al}(\mathrm{III})$, que forma filme de óxido-hidróxidos na superfície do biossorvente, impedindo que íons de outras espécies metálicas tenham acesso aos sítios ligantes.

SILVA et al. (2016) utilizaram casca de banana nanica como biossorvente aplicado aos íons de $\mathrm{Cr}(\mathrm{IV})$. As cascas foram secas e trituradas a uma granulometria de 35 mesh, verificou-se também efeito $\mathrm{pH}$, tempo de contato e agitação para identificar, dentre esses parâmetros, que iriam fornecer melhor resultado. A maior biossorção foi obtida em pH 2,5 e velocidade de agitação de 400 rpm.

No estudo de Pino (2005), utilizando pó da casca de coco Verde (Cocos nucifera) para biossorção de íons de metais $\mathrm{Cd}$, $\mathrm{Cr}$ (III), $\mathrm{Cr}(\mathrm{VI})$, Ni e Zn foi aplicada uma variação de $\mathrm{pH}$ de 1 a 12, sendo que os valores ótimos encontrados foram de 7 para o Cd e Cr(III) e de 2 para o $\mathrm{Cr}(\mathrm{VI})$. Em concentrações iniciais inferiores a $100 \mathrm{mg} / \mathrm{L}$ foram obtidas percentagens de remoção superiores a 95\%, 85\% e 80\% para o Cd, $\mathrm{Cr}(\mathrm{III})$ e $\mathrm{Cr}(\mathrm{VI})$, respectivamente. Em concentrações iniciais menores que $1000 \mathrm{mg} / \mathrm{L}$, a percentagem de remoção para o $\mathrm{Cd}$ e o $\mathrm{Cr}$ (III) foi de $80 \%$ e $85 \%$, respectivamente. Foram utilizados os modelos de Langmuir e Freundlich para avaliar a capacidade de adsorção desses íons metálicos pela casca de coco. O modelo de Langmuir 
mostrou-se mais adequado para o $\mathrm{Cd}$ e o $\mathrm{Cr}(\mathrm{VI})$, enquanto que para o $\mathrm{Cr}(\mathrm{III})$ o modelo de Freundlich foi o mais adequado.

FONTANA et al. (2016) utilizaram casca de urucum (Bixa orellana) para biossorção de $\mathrm{Pb}(\mathrm{II})$ em soluções aquosas. Nesse estudo foram verificadas a variação de $\mathrm{pH}$ (1,0 - 4,5), velocidade de agitação (0 - 150 rpm), dosagem de biossorvente (0,8 - 5,0 $\left.\mathrm{g} \mathrm{L}^{-1}\right)$, temperatura $\left(20-40^{\circ} \mathrm{C}\right)$ e tempo de contato $(0-120 \mathrm{~min})$. A isoterma de Langmuir foi o modelo mais apropriado para descrever o equilíbrio de biossorção do $\mathrm{Pb}(\mathrm{II})$, sendo a capacidade de biossorção de $43,6 \mathrm{mg} \mathrm{g}^{-1}$ a $30 \pm 2{ }^{\circ} \mathrm{C}$.

Um estudo de COSTA et al. (2015), teve como objetivo avaliar a potencialidade do mesocarpo de maracujá (Passiflora edulis) como biossorvente no tratamento de soluções aquosas com $\mathrm{Cr}(\mathrm{VI})$. A influência do $\mathrm{pH}$, tempo de contato e a concentração inicial de cromo na remoção de $\mathrm{Cr}(\mathrm{VI})$ das soluções foram os parâmetros investigados. O biomaterial (pó de mesocarpo de maracujá) foi obtido através de tratamento térmico a $400{ }^{\circ} \mathrm{C}$. O tempo de contato necessário para atingir o equilíbrio foi de 3 horas e o $\mathrm{pH}$ ótimo foi 2. Os dados de equilíbrio químico foram analisados usando os modelos de Langmuir e Freundlich e os parâmetros foram determinados através de programação matemática não-linear. O processo de sorção foi melhor representado pelo modelo de Freundlich, indicando que a superfície do biossorvente é heterogênea. Os resultados mostraram que o biossorvente removeu em média $74 \%$ de $\mathrm{Cr}(\mathrm{VI})$ em 180 minutos.

KHORAMZADEH et al. (2013) investigaram a biossorção de íons de mercúrio a partir de soluções aquosas utilizando bagaço de cana-de-açúcar. O pré-tratamento do biossorvente foi feito com $\mathrm{NaOH}$ e $\mathrm{HCl}$. Foram investigados os parâmetros que afetam a biossorção, como $\mathrm{pH}$ da solução, tempo de contato e temperatura. Os dados de equilíbrio de adsorção foram analisados pelos modelos das isotermas de Freundlich e Langmuir. De acordo com os resultados, ambos os modelos foram adequados para descrever o equilíbrio da biossorção. A capacidade máxima de adsorção foi de $35,71 \mathrm{mg} \mathrm{g}^{-1}$. Foi observada a remoção máxima de mercúrio de $97,6 \%$ a um $\mathrm{pH}$ de 4 . Tratamentos químicos adicionais do biosorbente não tiveram efeito significativo na biosorção de mercúrio.

FLORES-CANO et al. (2013) estudaram o mecanismo e a capacidade da casca de ovo para sorção de Cd (II) a partir de solução aquosa. Para obtenção do adsorvente, 
a casca de ovo de galinha foi moída e passada em uma peneira granulométrica para atingir um diâmetro de partícula médio de 0,95 mm, lavada repetidamente com água deionizada, seca num forno eléctrico a $100^{\circ} \mathrm{C}$ durante $24 \mathrm{~h}$. A variação de $\mathrm{pH}$ estudada foi de 3 a 10 e pode-se notar que a capacidade de adsorção aumentou com o aumento do $\mathrm{pH}$ da solução, e a capacidade máxima de adsorção ocorreu em $\mathrm{pH}$ 6, com uma concentração de Cd (II), no equilíbrio, de $350 \mathrm{mg} \mathrm{g}^{-1}$. A massa de Cd (II) adsorvido foi de 3,67, 1,83 e 1,95 $\mathrm{mg} \mathrm{g}^{-1}$ para os valores e $\mathrm{pH}$ de 6, 5 e 4, respectivamente. Em outras palavras, a capacidade de sorção da casca do ovo foi aumentada 1,88 vezes o aumento do pH da solução de 4 a 6 .

\subsubsection{Macrófitas}

Macrófita é a denominação que caracteriza vegetais que habitam desde brejos até ambientes verdadeiramente aquáticos. Estes vegetais, especialmente as macrófitas flutuantes, são capazes de produzir grande quantidade de biomassa. Estas plantas são consideradas "agentes purificadores", por sua intensa absorção de nutrientes, por seu rápido crescimento, e pelas características que as adequa a utilização, facilidade de sua retirada de lagoas e pelas amplas possibilidades de aproveitamento de sua biomassa (ESTEVES, 1998; POMPÊO, 2008). Macrófita da espécie Eichhornia crassipes (aguapé) apresentada na figura 2.

Figura 2 - macrófitas Eichhornia crassipes.

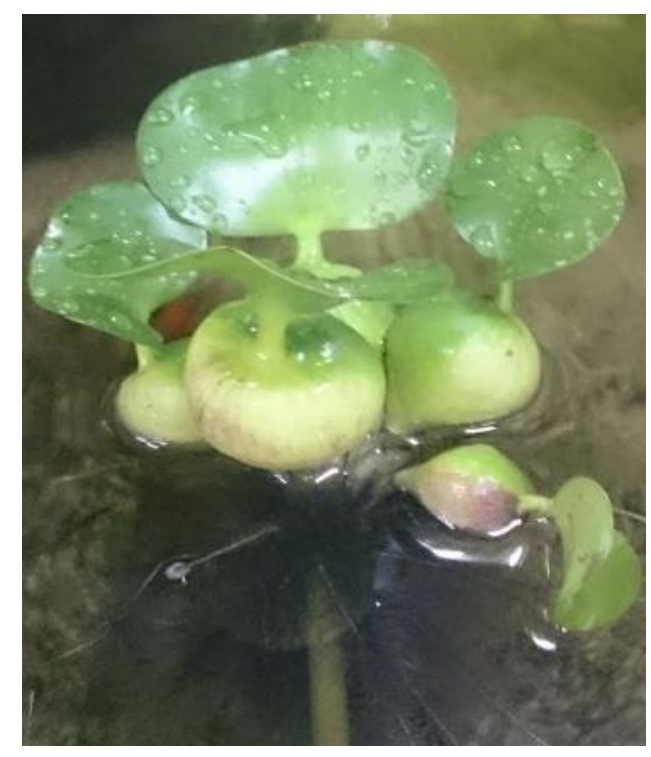




\subsubsection{Adsorção com biomassas de macrófitas}

SARASWAT e RAI (2010) utilizaram biomassa de aguapé (Eichhornia crassipes) tratada com NaOH 0,1 mol.L-1 . A partir desse tratamento estudaram a remoção dos íons metálicos $\mathrm{Zn}(\mathrm{II}), \mathrm{Cd}$ (II) e $\mathrm{Cr}(\mathrm{VI})$, em valores de $\mathrm{pH}$ de 2, 3, 4, 5, 6 e 7, e variações de tempo de contato de 30 a 240 minutos. A melhor adsorção para $\mathrm{Cd}$ e $\mathrm{Cr}$ foi em $\mathrm{pH} 5$ e para $\circ \mathrm{Zn}$ em pH 6. A adsorção máxima para $\mathrm{Zn}$ e $\mathrm{Cd}$ se deu no tempo de 120 minutos e para $\mathrm{Cr}$, em 180 minutos.

ZHANG et al. (2015) utilizaram a Eichhornia crassipes para produzir biocarvão (Biochar) por pirólise de biomassa seca. $O$ aquecimento foi realizado nas temperaturas de $250^{\circ}, 350^{\circ}, 450^{\circ}$ e $550^{\circ} \mathrm{C}$ durante 1 hora. A partir desse carvão realizou-se estudo de sorção de $\mathrm{Cd}$. Considerado sua maior capacidade de sorção de $\mathrm{Cd}$, o biochar que teve aquecimento de $450^{\circ} \mathrm{C}$ em relação com outras amostras de biochar.

MAHAMADI e NHARINGO (2010) utilizaram biomassa de aguapé, ativada quimicamente com $\mathrm{HNO}_{3} 0,1 \mathrm{~mol}$. $\mathrm{L}^{-1}$ e com temperatura de $30{ }^{\circ} \mathrm{C}$, para realizarem os ensaios de biossorção dos metais $\mathrm{Pb}^{2+}, \mathrm{Cd}^{2+}$ e $\mathrm{Zn}^{2+}$. O modelo de Langmuir mostrou-se mais eficiente nesse estudo, ocorrendo a biossorção dos metais na ordem de $\mathrm{Pb}^{2+}>\mathrm{Cd}^{2+}>\mathrm{Zn}^{2+}$.

SARKAR, RAHMAN e BHOUMIK (2017) utilizaram biomassa de aguapé, seca e triturada a uma granulometria de 150 micrômetros. Esta biomassa foi utilizada para adsorção de $\mathrm{Cr}$ e Cu por coluna de filtração que teve um tempo operacional de 180 minutos, sendo que para o $\mathrm{Cr}$ houve maior capacidade de remoção nos 10 primeiros minutos e para o $\mathrm{Cu}$, ocorreu nos primeiros 14 minutos.

No estudo de ROCKER (2015) foi utilizada a biomassa de Eichhornia crassipes da planta inteira, que foi seca e peneirada a uma granulometria de 0,300 $\mathrm{mm}$. Os ensaios foram realizados tanto com a biomassa in natura (não submetida a nenhum tratamento) quanto com a biomassa tratada com hidróxido de sódio $(\mathrm{NaOH})$ e ácido cítrico na proporção de 1:20 para $\mathrm{NaOH}$ e 1:8 para o ácido cítrico. A partir dessa biomassa realizou-se os testes de adsorção de $\mathrm{Cr}$ (III) em efluente de curtume. Foram aplicadas variações de $\mathrm{pH}$ de 3 a 6 e tempo de contato de 200 a 1600 minutos. Os resultados indicaram uma melhor capacidade de adsorção na biomassa modificada. 
No estudo MISHRA e TRIPATHI, (2008) foi testado a eficácia de três macrófitas: Pistia stratiotes (alface de água), Spirodela polyrrhiza Koch (lentilha de água) e Eichhornia crassipes. As três macrófitas foram testadas para a remoção simultânea de cinco íons de metais $\mathrm{Fe}, \mathrm{Cu}, \mathrm{Zn}, \mathrm{Cr}$ e $\mathrm{Cd}$. Estes autores concluíram que a biomassa das macrófitas mostrou-se altamente eficaz na sorção dos íons metálicos. Os resultados revelaram que a E. Crassipes apresentou a melhor eficiência para a remoção de metais selecionados, seguida por $P$. stratiotes e $S$. polyrrhiza.

EL-KHAIARY et al., (2009) submeteram a biomassa de Eichhornia crassipes a diversos tratamentos como lavagem com água quente, lavagem com solução diluída de $\mathrm{HCl}$ quente, imersão em $\mathrm{NaOH}$, imersão em $\mathrm{HNO}_{3}$ e sulfonação com o objetivo de aumentar a eficiência de remoção de íons em solução pela biomassa dessa macrófita. As isotermas de Langmuir e Freundlich foram aplicadas e o modelo de Langmuir apresentou o melhor ajuste aos dados experimentais, exceto para biomassa tratada com hidróxido de sódio, que seguiu o modelo de Freundlich.

SCHNEIDER (1995) utilizou biomassa das espécies de macrófitas Patamogeton lucens, Salvinia herzogii e Eichhornia crassipes para remoção dos íons dos metais $\mathrm{Ni}$, Cu e Zn em coluna de percolação. Neste estudo, foi realizado o tratamento químico com $\mathrm{HCl}$ para hidrogenar (ativar quimicamente) as biomassas e variações de $\mathrm{pH}$ de 2 a 12. A maior capacidade de adsorção ocorreu em pH 5,5 com agitação de 30 minutos com a espécie de macrófita Patamogeton lucens entre as três espécies estudadas, sendo que a eficiência de adsorção foi de 97\% para Ni, 95\% para $\mathrm{Cu}, 98 \%$ para $\mathrm{Zn}$. 


\section{OBJETIVOS}

\subsection{Objetivos gerais}

Este trabalho tem como objetivo a determinação da capacidade de remoção de íons metálicos dos elementos $\mathrm{Cd}, \mathrm{Pb}, \mathrm{Co}, \mathrm{Cr}$ e $\mathrm{Zn}$ em solução aquosa utilizando-se biomassa de Eichhornia crassipes obtida apenas por secagem e moagem do material e biomassa modificada por ativação com $\mathrm{HCl}$ e $\mathrm{NaOH}$.

Os elementos escolhidos para 0 estudo encontram-se entre aqueles que apresentam interesse do ponto de vista toxicológico, bem como, ambiental.

Para determinação das concentrações das soluções antes e após o tratamento para remoção dos íons bem como para a determinação da eficiência de adsorção, foram utilizadas as técnicas de Análise por Ativação Neutrônica Instrumental e Espectrometria de Absorção Atômica com forno de Grafite.

\subsection{Objetivos específicos}

- Estudar a capacidade adsorção da biomassa da raiz Eichhornia crassipes;

- Verificar qual melhor forma de ativar quimicamente a biomassa, com $\mathrm{HCl}$ ou $\mathrm{NaOH}$;

- Estabelecer parâmetros que favorecem a melhor capacidade de adsorção;

- Verificar a variações de pH, tempo de contato e concentrações e estabelecer o melhor método de adsorção. 


\section{MATERIAIS E MÉTODOS}

\subsection{Amostragem}

A biomassa a ser testada foi obtida a partir da macrófita Eichhornia crassipes que foi coletada às margens da represa Billings, São Bernardo do Campo localizada na região sudeste da Região Metropolitana de São Paulo, onde encontra-se em grade quantidade. Conforme ilustrado na figura 3.

Figura 3 - Vista aérea dos locais de coleta.

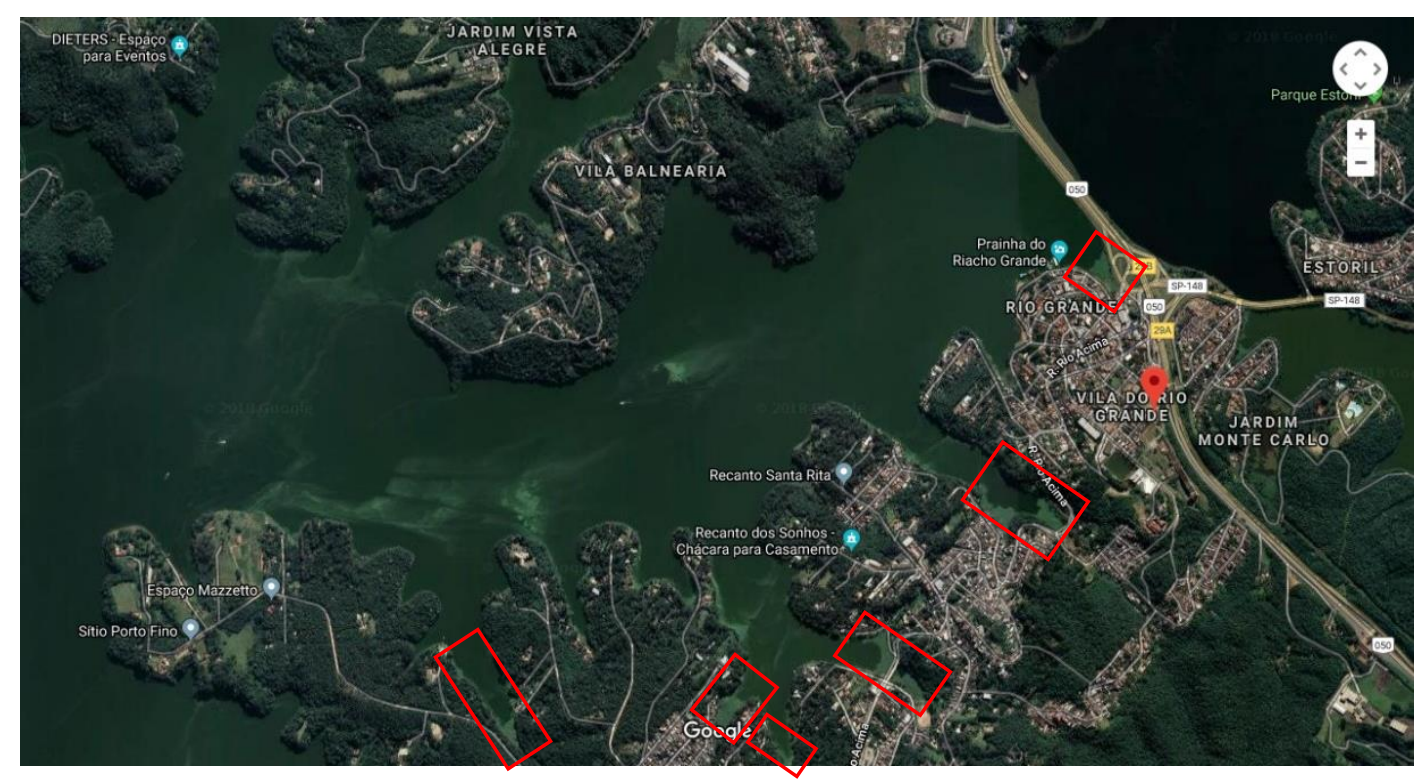

Fonte: https://www.google.com.br/maps

Nos pontos selecionados as manchas verdes mais claros, próxima as margens, são áreas de grande crescimento das espécies de macrófitas, coordenadas geográficas das proximidades da direita para esquerda.

Rio Grande São Bernardo do Campo - SP -23.776225, -46.529974

Rio Grande São Bernardo do Campo - SP -23.778561, -46.533364

Estr. do Rio Acima, 2509-2387 - Finco São Bernardo do Campo - SP, 09831-400 $-23.790254,-46.538632$

Unnamed Road - Finco São Bernardo do Campo - SP, 09831-400 -23.789783, -46.538546

Rio Grande São Bernardo do Campo - SP -23.778608, -46.533413

\subsection{Obtenção da biomassa}

Para obtenção da biomassa, as plantas coletadas foram separadas em caule, folhas e raiz no laboratório e lavadas com água em abundância para remoção de terra e 
insetos que estavam presentes nas mesmas. As partes separadas foram secas em estufa ventilada em temperatura entre 60 e $70 \stackrel{\circ}{\circ}$, até massa constante e foram trituradas com auxílio de um liquidificador com copo de processador de alimentos e o restante das fibras não transformadas em pó foi triturado com almofariz e pistilo até atingir uma granulometria de $150 \mu \mathrm{m}$. Todos os testes foram feitos com a biomassa seca e todos os cálculos, com base na massa seca das amostras. $\mathrm{Na}$ figura 4 está ilustrada na etapa de processo de divisão das partes da planta (raiz, caule e folhas).

Figura 4 - Etapas do processo de divisão da planta (raiz, caule e folha).

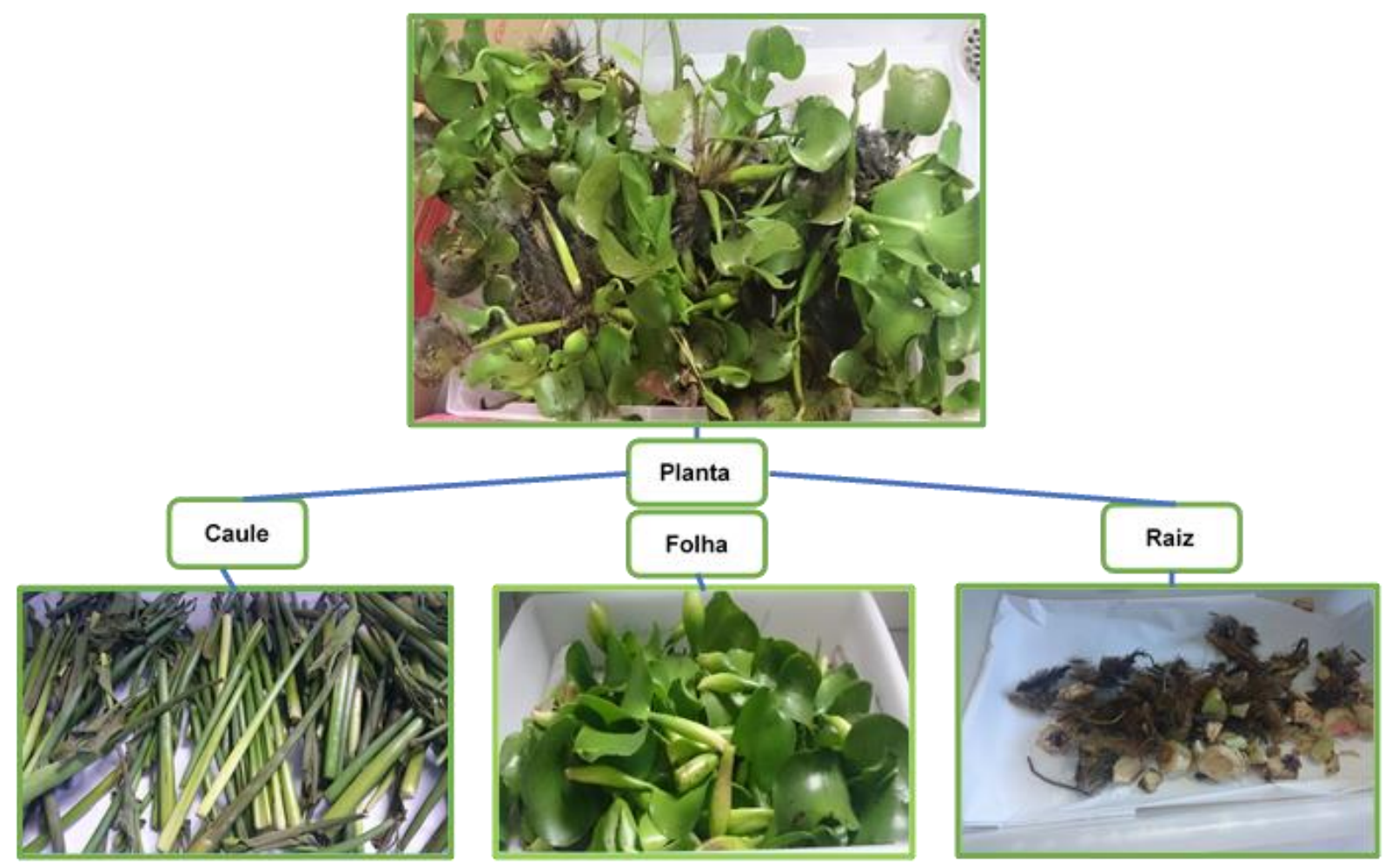

\subsubsection{Ativação ácida e básica}

Para modificação da biomassa por ativação química, foram realizados os tratamentos da mesma com $\mathrm{HCl} 0,1 \mathrm{~mol} / \mathrm{L}^{-1}$ e $\mathrm{NaOH} 0,1 \mathrm{~mol} / \mathrm{L}^{-1}$, na proporção 1:30 $(\mathrm{m} / \mathrm{V})$, deixada em repouso por um período de 24 horas à temperatura ambiente. Em seguida a biomassa foi colocada na centrifuga por 20 minutos em uma rotação de 3500 rpm, para separação do sobrenadante. Após a separação, a amostra foi levada 
a estufa para uma nova secagem, com temperatura entre $60^{\circ}$ a $70^{\circ} \mathrm{C}$ por 48 horas até massa constante, e novamente triturada e passada em peneira granulométrica de $150 \mu \mathrm{m}$.

As proporções utilizadas para ativação da biomassa na literatura foram encontradas com uma grande variação de estudo para estudo. No estudo de Rocker (2015) é utilizada uma proporção de 1:20 de $\mathrm{NaOH}$ e 1:8 de ácido cítrico. Mahamadi e Nharingo (2010) utilizaram uma proporção de 1:10 de $\mathrm{NaOH}$ para ativação. Em outro estudo desenvolvido por Pereira et al. (2008) foram utilizadas proporções diferentes para ativar a biomassa sendo 1:30 de $\mathrm{NaOH}, 1: 40$ de ácido acético. No estudo de Holanda (2010) utilizou-se ácido nítrico na proporção de 1:20 para o tratamento da biomassa.

\subsection{Preparação das soluções de metais}

As amostras das soluções contendo os íons metálicos foram preparadas em laboratório a partir da diluição de soluções padrão (SPEX Certiprep) com concentrações de $1000 \mathrm{mg} \mathrm{L}^{-1}$.

As concentrações das soluções que foram utilizadas são mostradas na tabela 1 . Estas concentrações correspondem a uma, duas e seis vezes, respectivamente, à concentração permitida para água doce de classe 1 de acordo com a resolução 357/2005, alterada pela 430/2011.

Tabela 1- Concentração permitida (coluna 1), duas (coluna 2) e seis (coluna 3) vezes o valor permitido para descarte em corpos hídricos que foram usadas neste trabalho.

\begin{tabular}{ccc}
\hline \multicolumn{2}{c}{ Elementos } & \multicolumn{2}{c}{ Concentrações $\left(\mathrm{mg} \mathrm{L}^{-1}\right)$} \\
\hline Cd $1,0 \times 10^{-3}$ & $2,0 \times 10^{-3}$ & $8,0 \times 10^{-3}$ \\
$\mathrm{~Pb} 1,0 \times 10^{-2}$ & $2,0 \times 10^{-2}$ & $8,0 \times 10^{-2}$ \\
Cr $5,0 \times 10^{-2}$ & $1,0 \times 10^{-1}$ & $4,0 \times 10^{-1}$ \\
Co $5,0 \times 10^{-2}$ & $1,0 \times 10^{-1}$ & $4,0 \times 10^{-1}$ \\
Zn $1,8 \times 10^{-1}$ & $3,6 \times 10^{-1}$ & 1,5 \\
\hline
\end{tabular}




\subsection{Caracterização físico-química das amostras}

Para a caracterização físico-química foram determinados o teor de cinzas e área superficial especifica por titulação com hidróxido de sódio e a caracterização elementar foi feita por análise por ativação neutrônica instrumental e espectrometria de absorção atômica com forno de grafite. Estes ensaios foram realizados com as amostras sem tratamento e com tratamento químico (ativação ácida), com solução de $\mathrm{HCl} 0,1 \mathrm{~mol} \mathrm{~L}^{-1}$.

\subsubsection{Determinação do teor de cinzas}

Para a determinação do teor de cinzas, $1,5 \mathrm{~g}$ de amostras de biomassa foram transferidas para cadinhos de porcelana previamente calcinados e pesados. Em seguida, foram levados à mufla com temperatura de $200^{\circ} \mathrm{C}$ por 2 horas.

\subsubsection{Análise de área superficial específica por titulação}

Análise de área superficial específica foi feita de acordo com o método proposto por SEARS (1956). Em um béquer de $200 \mathrm{~mL}$, uma alíquota de $1,5 \mathrm{~g}$ de amostra da biomassa seca foi adicionada a $50 \mathrm{~mL}$ de solução de $\mathrm{HCl} 0,1 \mathrm{~mol} \mathrm{~L}^{-1}$. Em seguida foram adicionados 30 gramas de $\mathrm{NaCl}$ e o volume foi completado até $150 \mathrm{~mL}$ com água ultrapura. Ajustou-se o pH a 4 com uma solução de $2 \mathrm{~mol} \mathrm{~L}^{-1}$ de $\mathrm{NaOH}$. Com o auxílio de uma bureta de $50 \mathrm{~mL}$ e solução padronizada de $\mathrm{NaOH}$ de $0,1 \mathrm{~mol} \mathrm{~L}^{-1}$, foi efetuada a titulação até $\mathrm{opH}$ ir de 4 a 9 e ficar estável. $\mathrm{O}$ cálculo foi efetuado utilizando a equação 7 .

$$
S=32 . V-25
$$

Sendo:

$S$ = superfície específica em metros quadrados por grama;

$\mathrm{V}=$ volume em mililitros de hidróxido de sódio necessário para elevar o pH de 4 a 9.

\subsubsection{Microscopia Eletrônica}

Para verificação dos aspectos morfológicos da biomassa obtida, as amostras foram colocadas em suporte metálico e pulverizadas com uma fina camada de ouro para torná-las condutoras e gerar uma imagem de melhor resolução. $O$ equipamento utilizado foi microscópio eletrônico de varredura (SEM), modelo XL-30, marca 
Phillips, com detector de espectroscopia de energia dispersiva (EDS) acoplado. Essa análise foi realizada no centro de Ciência e Tecnologia dos Materiais (CCTM) do Instituto de Pesquisas Energéticas e Nucleares (IPEN). Equipamento é ilustrado na figura 5 .

Figura 5 - Equipamento de microscopia eletrônica de varredura (SEM), modelo XL-30, marca Phillips, com detector de espectroscopia de energia dispersiva (EDS) acoplado.

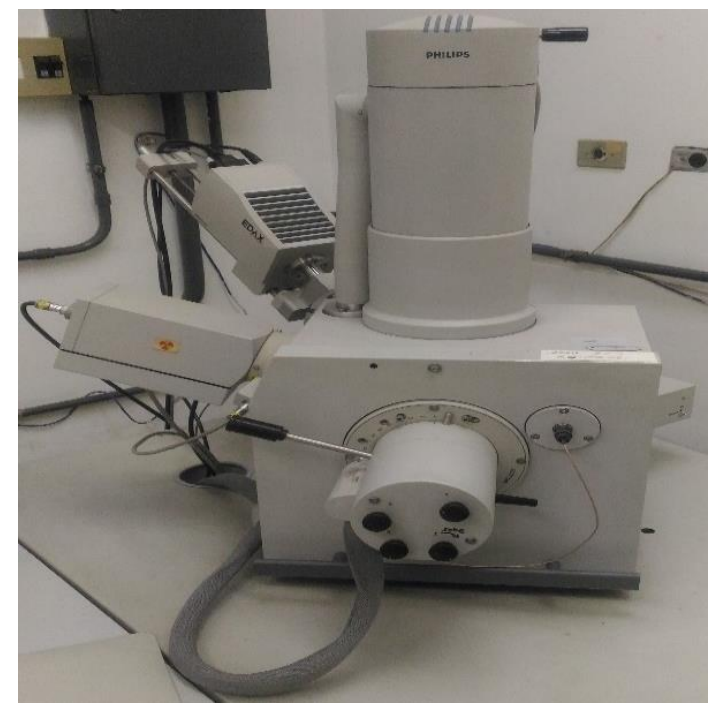

\subsubsection{Análise por ativação neutrônica instrumental (INAA)}

Esta técnica consiste no bombardeamento de um dado material por nêutrons, formando radionuclídeos artificiais, seguido da medida da radioatividade induzida. O método baseia-se em uma reação nuclear resultante da interação de um nêutron com um núcleo alvo produzindo um núcleo composto, em estado excitado, que irá decair de acordo com a meia vida do nuclídeo formado, através da emissão de um ou mais raios gama $(\mathrm{y})$ característicos, conforme ilustrado na Figura 6. 
Figura 6 - llustração da sequência de eventos para uma reação (n, y).

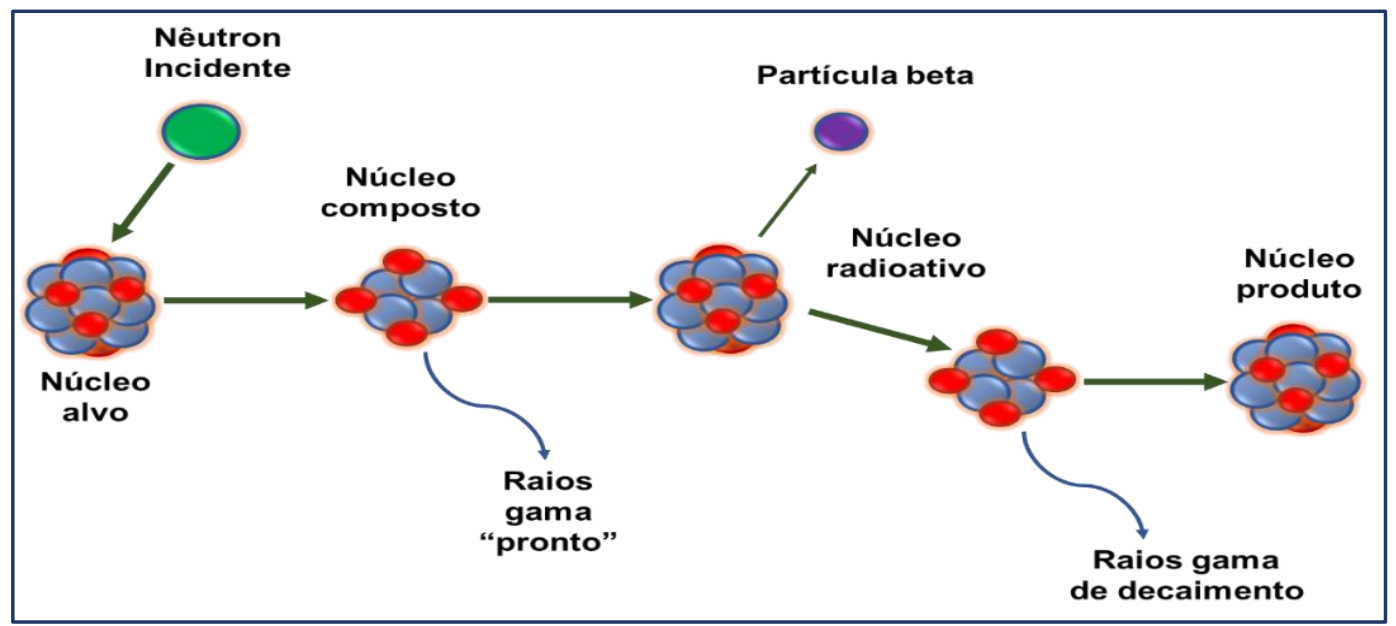

Fonte: Adaptado de ALI, 1999

Quando o nêutron colide com um núcleo, diversos tipos de reações podem ocorrer, tais como: espalhamento elástico $(n, n)$, espalhamento inelástico $\left(n, n^{\prime}\right)$, captura radioativa $(n, y)$, reações com liberação de partículas $(n, \alpha),(n, p)$ e $(n, 2 n)$, e reações de fissão $(n, f)$. Nêutrons térmicos e epitérmicos induzem principalmente a reação de captura radioativa $(n, y)$ e por esse motivo são considerados os mais importantes para NAA (IAEA, 2004).

A sequência de eventos que ocorrem numa reação nuclear típica utilizada na análise por ativação com nêutrons se inicia quando um nêutron interage com um núcleo alvo por meio de uma colisão inelástica, formando um núcleo composto num estado excitado. A energia de excitação do núcleo composto é devida à energia de ligação do nêutron com o núcleo. O núcleo composto formado quase que instantaneamente adquire uma configuração mais estável por meio da emissão de raios gama prontos. Em muitos casos, esta nova configuração produz um núcleo radioativo que também sofre um decaimento por emissão de raios gama retardados, mas a uma velocidade mais lenta, de acordo com o tempo de meia vida do núcleo radioativo (ALFASSI, 1990).

A intensidade da radiação emitida é proporcional à concentração do nuclídeo na amostra e, para cada radioisótopo produzido no processo de ativação (possuindo meia vida e energia gama características de sua emissão) é possível efetuar determinações por meio de comparação com a concentração em padrões certificados. 
O cálculo da concentração de um elemento desconhecido na amostra em relação ao padrão de comparação é feito utilizando-se a Equação 8

$$
C_{a i}=\frac{\left(A_{a i} m_{p} C_{p i}\right) e^{\lambda\left(\mathrm{t}_{\mathrm{a}}-\mathrm{t}_{\mathrm{p}}\right)}}{A_{p i} m_{a}}
$$

sendo:

$\mathrm{C}_{\mathrm{ai}}$ : concentração do elemento i na amostra $\left(\mathrm{mg} \mathrm{kg}^{-1} \mathrm{ou} \%\right)$

$\mathrm{C}_{\mathrm{pi}}$ : Concentração do elemento i no padrão $\left(\mathrm{mg} \mathrm{kg}^{-1}\right.$ ou \%)

$A_{a i}:$ Atividade do elemento i na amostra (cps)

$A_{p i}:$ Atividade do elemento i no padrão (cps)

$m_{a}$ e $m_{p}$ : massas da amostra e do padrão, respectivamente (g)

$\lambda$ : Constante de decaimento do radioisótopo $\left(\mathrm{min}^{-1}\right)$

$t_{a}-t_{p}$ : diferença de tempo (min) entre as contagens da amostra e padrão.

Como padrões, foram utilizados materiais de referência de matrizes de origem geológica e também padrões sintéticos provenientes de soluções padrão pipetados em papel de filtro para determinação das concentrações dos elementos nas amostras e para o controle da qualidade analítica.

Para determinação elementar e garantia da qualidade analítica foram utilizados materiais de referências certificados (MRC) JSO-1 do Japan Geological Reference Materials e MESS-3 do National Reasearch Council of Canada (NRC - CNRC) conforme tabela 2 .

Para as determinações por ativação neutrônica, aproximadamente $150 \mathrm{mg}$ das amostras moídas foram embaladas em sacos de polietileno e envolvidas com lâmina fina de alumínio, colocadas em capsulas cilíndricas de alumínio que foram encaminhadas para irradiação. Essas etapas são ilustradas na Figura 7. 
Tabela 2 - Elementos de interesse e suas concentrações (valor \pm incerteza), em mg $\mathrm{kg}^{-1}$ e valores calculados dos materiais de referência e dos padrões pipetados (P.P), utilizados para INAA.

\begin{tabular}{cccccc}
\hline Elementos & \multicolumn{2}{c}{ MESS-3 } & \multicolumn{2}{c}{ JSO $^{-1}$} & P.P \\
\cline { 2 - 6 } & $\begin{array}{c}\text { Conc. } \pm \text { incert. } \\
\text { no MRC }\end{array}$ & $\begin{array}{c}\text { Valores } \\
\text { calculados }\end{array}$ & $\begin{array}{c}\text { Conc. } \pm \text { incert. } \\
\text { no MRC }\end{array}$ & $\begin{array}{c}\text { Valores } \\
\text { calculados }\end{array}$ & Conc. \\
Co & $14,04 \pm 0,9$ & $13,7 \pm 0,9$ & $32 \pm 1$ & $33 \pm 1$ & 2,5 \\
\hline Zn & $159,0 \pm 8$ & $163,1 \pm 2$ & $105 \pm 2$ & $102 \pm 4$ & 100 \\
\hline Cr & $105,0 \pm 4$ & $104,1 \pm 0,5$ & $71 \pm 2$ & $72 \pm 1$ & 20
\end{tabular}

\subsubsection{Preparação das amostras para irradiação}

Figura 7 - llustração dos processos para preparação das amostras para irradiação: acondicionamento das amostras em saquinhos de polietileno (etapa 1), invólucros selados (etapa 2), embalados em lâmina de alumínio e acondicionados em cápsula de alumínio para irradiação (etapa 3).

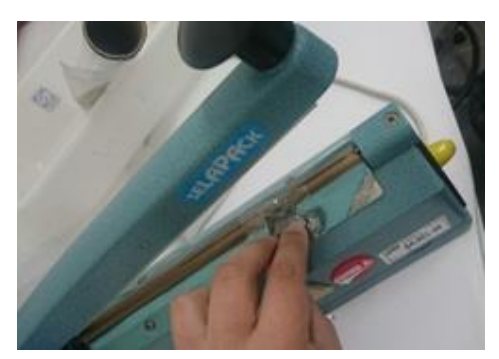

Etapa 1

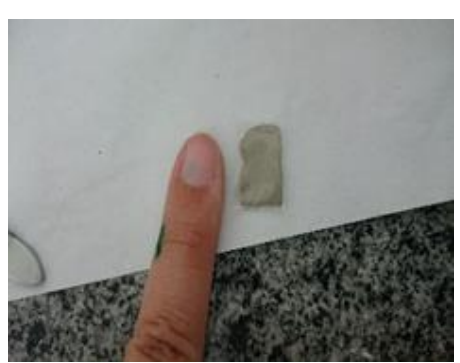

Etapa 2

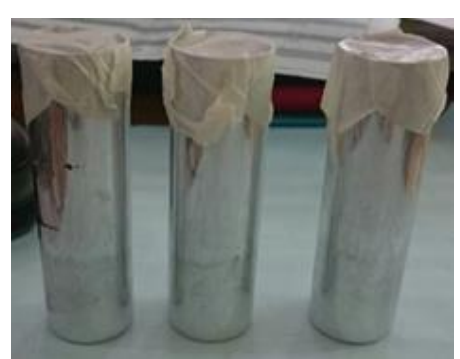

Etapa 3

\subsubsection{Irradiações e contagens}

Todas as amostras foram irradiadas no Reator Nuclear de Pesquisa IAE-R1 do IPEN/CNEN-SP sob um fluxo de nêutrons térmicos de 1 a $5 \times 1012 \mathrm{~cm}^{-2} \mathrm{~s}^{-1}$.

Para a irradiação, as amostras, os materiais de referência e os padrões sintéticos, acondicionados nas capsulas cilíndricas de alumínio, foram completamente vedados e posicionados próximos ao núcleo de reator e expostos ao fluxo de nêutrons especificado por um período de sete horas.

Para a determinação dos elementos de interesse deste trabalho, foi realizada uma série de contagem, feita após 15 dias de decaimento, para determinação dos 
elementos $\mathrm{Co}, \mathrm{Cr}$ e $\mathrm{Zn}$. A contagem da atividade gama induzida nas amostras, nos materiais de referência e nos padrões sintéticos foi feita utilizando um detector de Ge-Hiperpuro, EG\&G Ortec e equipamentos eletrônicos associados, com resolução de 0,88 keV e 2,09 keV para os picos de $122 \mathrm{keV}$ e $1332 \mathrm{keV}$ do ${ }^{57} \mathrm{Co}$ e ${ }^{60} \mathrm{Co}$, respectivamente. Na Figura 8 está ilustrado o sistema de detecção gama utilizado neste trabalho.

Figura 8 - Ilustração do sistema com detector de Germânio Hiperpuro e eletrônica associada do Laboratório de Análise por Ativação Neutrônica.

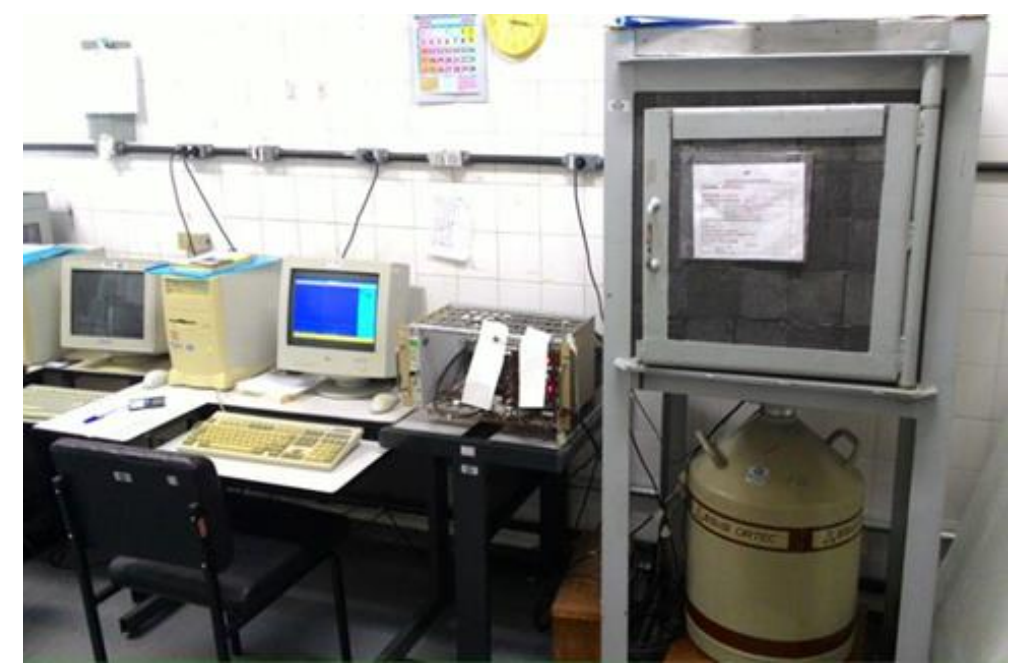

A análise dos espectros foi feita utilizando-se o programa VISPECT2 e os cálculos foram feitos em planilha de Microsoft Excel ${ }^{\circledR}$. O tempo de contagem para as amostras de biomassa e para os materiais de referência e os padrões pipetados sintéticos após 15 dias de decaimento foi de 60 minutos.

\subsubsection{Espectrometria de Absorção Atômica por Forno de Grafite (GF AAS)}

A análise pela técnica de espectrometria de absorção atômica por forno de grafite teve por objetivo a determinação da concentração de $\mathrm{Cd}$ e $\mathrm{Pb}$ nas amostras de biomassa e após os testes de adsorção.

Em espectrometria de absorção atômica, a amostra é exposta à radiação emitida por uma lâmpada com comprimentos de onda específico, cujas energias dos fótons são exatamente as mesmas que podem ser absorvidas pelos átomos livres do elemento de interesse. Existe uma lâmpada para cada elemento que se deseja determinar. A luz dirigida através da nuvem do elemento atomizado em uma chama ou cubeta de 
forno de grafite passa por um monocromador até atingir o detector. A quantidade de energia absorvida naquele comprimento de onda específico é diretamente proporcional à concentração do elemento na amostra (SHRIVER et al., 2006).

\subsubsection{Procedimento experimental para as analise de $\mathrm{Cd} \mathrm{e} \mathrm{Pb}$}

Para as determinações das concentrações dos elementos $\mathrm{Cd}$ e Pb nas amostras de biomassa, estas foram dissolvidas com ácidos concentrados em chapa aquecedora. Para as determinações após os experimentos de adsorção, a amostra foi centrifugada e o sobrenadante foi separado para análise.

As amostras foram analisadas no equipamento de GFAAS modelo Analyst 800 da Perkin Elmer, ilustrado na Figura 9, no Laboratório de Absorção Atômica (LAN/IPEN$\mathrm{SP})$.

Figura 9- Equipamento de GF AAS modelo AAnalyst 800 da Perkin Elmer para determinação de $\mathrm{Cd}$ e $\mathrm{Pb}$.

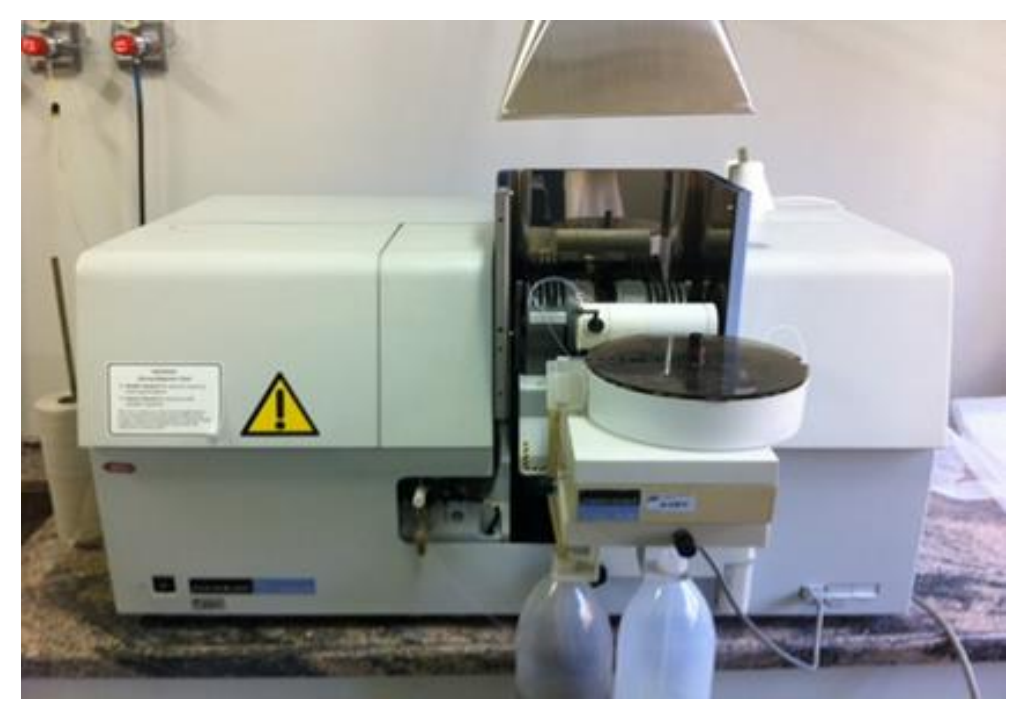

Antes da determinação de $\mathrm{Cd}$ e $\mathrm{Pb}$ nas amostras, foram preparadas soluções destes elementos a partir de soluções estoque e de solução de HNO3 0,2\% (v/v) (Merck), usado como diluente, para construção da curva de calibração do equipamento. As curvas de calibração obtidas para as determinações $\mathrm{Cd}$ e $\mathrm{Pb}$ são apresentadas nas Figuras 10. 
Figura 10- Curva de calibração obtida para análise de Cd e Pb por GF AAS.
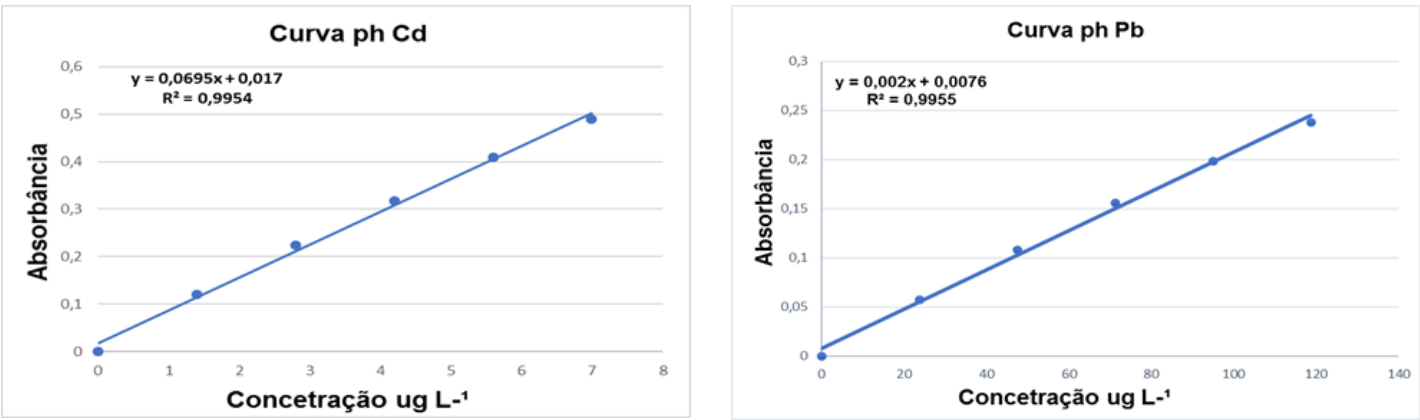

Para garantia da qualidade analítica das determinações de $\mathrm{Cd}$ e $\mathrm{Pb}$ foram utilizados materiais de referências certificados (MRC) Mixed Polish Herbs (INCT-MPH-2) do Institute of Nuclear Chemistry eTechnology e Oyster tissue (SRM 1566b) do National Institute of Standard e Thecnology. Foi utilizado desvio padrão para determinar a incertezas. Conforme tabela 3.

Tabela 3 - Elementos de interesse e suas concentrações (valor \pm desvio padrão), em $\mathrm{mg} \mathrm{kg}^{-1} \mathrm{e}$ valores calculados dos materiais de referência utilizados para FGASS.

\begin{tabular}{cccc}
\hline & MRC & $\begin{array}{c}\text { Valor } \\
\text { certificado }\end{array}$ & Valor obtido \\
& & & \\
\hline Pb & MPH-2 & $2,16 \pm 0,23$ & $2,01 \pm 0,03$ \\
Cd & $1566 b$ & $2,48 \pm 0,08$ & $1,86 \pm 0,02$ \\
\hline
\end{tabular}

\subsection{Estudo dos Parâmetros de Adsorção}

Com a biomassa de Eichornia crassipes obtida após o tratamento de ativação ácida, foi realizado o processo de adsorção dos íons dos metais para verificação dos efeitos de $\mathrm{pH}$, de tempo de contato e da concentração inicial. Todos os testes foram realizados em duplicata.

\subsubsection{Efeito do $\mathrm{pH}$}

Para verificação do efeito do $\mathrm{pH}, 0,5 \mathrm{~g}$ de amostra seca foram adicionados a $20 \mathrm{~mL}$ de uma solução cujo pH possuía valores iniciais de 2, 4, 6, 8 e 10, contendo individualmente os íons dos seguintes elementos $\mathrm{Cd}\left(1,0 \times 10^{-3} \mathrm{mg} \mathrm{L}^{-1}\right), \mathrm{Pb}\left(1,0 \times 10^{-2}\right.$ 
$\left.\mathrm{mg} \mathrm{L}^{-1}\right)$, $\operatorname{Cr}\left(5,0 \times 10^{-2} \mathrm{mg} \mathrm{L}^{-1}\right)$, Co $\left(5,0 \times 10^{-2} \mathrm{mg} \mathrm{L}^{-1}\right)$ e $\mathrm{Zn}\left(1,8 \times 10^{-1} \mathrm{mg} \mathrm{L}^{-1}\right)$. Cada mistura foi agitada por $20 \mathrm{~min}$ a $60 \mathrm{rpm}$. Em seguida, foram centrifugadas por $20 \mathrm{~min}$ a 3500 rpm e o sólido foi separado do líquido, seco em temperatura entre 60 e 70 ${ }^{\circ} \mathrm{C}$, até peso constante, triturado e embalado para INAA para análise de $\mathrm{Cr}$, Co e $\mathrm{Zn}$ e no caso do $\mathrm{Cd}$ e $\mathrm{Pb}$ foi utilizada a fase líquida para análise por FGAAS.

\subsubsection{Efeito do tempo de contato}

Para avaliação do efeito do tempo de contato, $0,5 \mathrm{~g}$ de amostra foram adicionados a $20 \mathrm{~mL}$ de solução, contendo os íons de interesse, ajustada a pH 6 e agitadas pelos tempos de 10, 20, 30, 60 e $120 \mathrm{~min}$. Após o período de agitação, as amostras foram centrifugadas por $20 \mathrm{~min}$ a $3500 \mathrm{rpm}$ e o sólido foi separado do líquido, seco em temperatura entre 60 a $70^{\circ} \mathrm{C}$, até peso constante, triturado e embalado para determinação de $\mathrm{Cr}$, Co e Zn por INAA e a fase líquida foi usada para determinação de $\mathrm{Cd}$ e $\mathrm{Pb}$ por FGAAS.

\subsubsection{Efeito da concentração inicial}

Para avaliação do efeito de concentração inicial, $0,5 \mathrm{~g}$ de amostra de biomassa foram adicionado a $20 \mathrm{~mL}$ de solução, ajustou-se $\circ \mathrm{pH}$ para 6 e agitou-se por 30 minutos em $60 \mathrm{rpm}$. Em seguida a mistura foi levada à centrifuga por 20 minutos em rotação de $3500 \mathrm{rpm}$. O sólido foi separado do líquido e levado a estufa em temperatura de 60 a $70^{\circ} \mathrm{C}$ até massa constante. Após a secagem o sólido foi triturado e preparado para determinação de $\mathrm{Cr}$, Co, Zn por INAA. A fase líquida foi utilizada para determinação de $\mathrm{Cd}$ e $\mathrm{Pb}$ por FGAAS. Todas as soluções de íons metálicos $\mathrm{Co}, \mathrm{Cr}, \mathrm{Zn}, \mathrm{Pb}$ e Cd foram feitas em três concentrações diferentes para cada elemento testado, todas concentrações encontra-se em $\mathrm{mg} \mathrm{L}^{-1}$ conforme tabela 1.

\subsubsection{Determinação da Capacidade de Adsorção e porcentagem de remoção}

A capacidade de adsorção (qe) (mg do metal por g do adsorvente) e a eficiência de adsorção (Ead\%) do adsorvente foram calculadas a partir das Equações 9 e 10.

$$
\begin{aligned}
q_{e} & =\frac{\left(C_{0}-C e\right)}{m} \cdot V \\
E_{a d \%} & =\frac{\left(C_{0}-C e\right)}{C_{o}} \cdot 100 \%
\end{aligned}
$$


Sendo

Co é a concentração inicial do íon metálico $\left(\mathrm{mg} \mathrm{L}^{-1}\right)$;

Ce é a concentração no equilíbrio do íon metálico $\left(\mathrm{mg} \mathrm{L}^{-1}\right)$;

V é o volume da solução aquosa (L);

m é a massa do adsorvente usado (g). 


\section{RESULTADOS E DISCUSSÃO}

\subsection{Teor de cinzas}

$\mathrm{Na}$ Tabela 4 estão apresentados os teores de cinza encontrados para as amostras de biomassa analisadas neste trabalho. $O$ teor de cinzas é um indicativo da quantidade de resíduo que poderá ser gerado com a queima da biomassa após o seu uso como adsorvente.

Tabela 4 - Teor de cinzas de amostras de biomassa.

\begin{tabular}{cc}
\hline Amostras & teor de cinzas (\%) \\
\hline Caule e folhas & 18 \\
\hline Raiz & 25 \\
\hline Caule & 22 \\
\hline Folha & 16
\end{tabular}

Observa-se que em termos de gerenciamento de rejeitos, pode-se obter uma redução de 75 a $82 \%$ na quantidade de biomassa após a sua utilização, o que facilita seu armazenamento ou disposição final.

Outra possibilidade de destinar a biomassa após a adsorção seria a recuperação dos metais, a escolha do método de recuperação depende do mecanismo de acumulação do metal. Se a acumulação ocorrer por adsorção extracelular, pode ser utilizado um processo não destrutivo, se a acumulação ocorrer por processos metabólico os metais ficam retidos intracelularmente, a recuperação só pode ser realizada por processos destrutivos. Exemplos de métodos de extração desses metais seriam coluna de percolação, reatores de leitos fluidizados e reatores em bateladas (SCHNEIDER, 1995).

\section{2 Área superficial específica (S)}

As análises para determinação de área superficial específica foram feitas em triplicata, para todas as biomassas avaliadas neste estudo: raiz, caule, folhas e uma mistura de caule e folhas nas amostras sem tratamento e ativadas quimicamente com $\mathrm{HCl} 0,1 \mathrm{~mol} \mathrm{~L}^{-1}$ e $\mathrm{NaOH} 0,1 \mathrm{~mol} \mathrm{~L}^{-1}$. Os resultados estão apresentados na Tabela 5. 
Tabela 5 - Área superficial específica, em $\mathrm{m}^{2} \mathrm{~g}^{-1}$, das biomassas não ativadas.

\begin{tabular}{ccccc}
\hline Amostras & Caule e Folha & Folha & Raiz & Caule \\
\hline Media & 343 & 277 & 346 & 209 \\
\hline Desvio padrão & 11 & 10 & 6 & 3 \\
\hline
\end{tabular}

Inicialmente foram determinadas as áreas superficiais das amostras sem tratamento prévio, apenas trituradas e peneiradas. Observou-se que a raiz foi a parte da planta que apresentou a maior área superficial e, desta forma, esta parte foi selecionada para a próxima etapa, que foi o tratamento com solução de $\mathrm{HCl}$ e $\mathrm{NaOH}$. Os resultados da biomassa obtida das raízes, após tratamento ácido e básico, estão descritos na tabela 6 .

Tabela 6: Área superficial, em $\mathrm{m}^{2} \mathrm{~g}^{-1}$, da biomassa (raiz) avaliada após tratamento de $\mathrm{HCl}$ e $\mathrm{NaOH}$.

\begin{tabular}{|c|c|}
\hline \multicolumn{2}{|c|}{$\mathrm{HCl} \mathrm{0,1} \mathrm{mol} \mathrm{L}^{-1}$} \\
\hline Média & $405 \mathrm{~m}^{2} \mathrm{~g}^{-1}$ \\
\hline Desvio padrão & 2 \\
\hline NaOH 0,1 mol L L $^{-1}$ \\
\hline Média & $405 \mathrm{~m}^{2} \mathrm{~g}^{-1}$ \\
\hline Desvio padrão & 16 \\
\hline
\end{tabular}

Com os resultados obtidos nas análises de área superficial verificou-se que a raiz tratada com $\mathrm{HCl}$ e $\mathrm{NaOH}$ apresentaram valores semelhantes e superiores aos obtidos para a biomassa não tratada. Em razão da facilidade de processar o material obtido, foi escolhida a raiz com o tratamento ácido para próximas etapas de testes de adsorção.

\subsection{Microscopia eletrônica}

A técnica de microscopia eletrônica de varredura foi utilizada nesse trabalho para uma melhor observação das superfícies da biomassa não tratada e após os tratamentos efetuados com $\mathrm{HCl}$ e $\mathrm{NaOH}$. 
Nas figuras 11 (a, b, c e d) são mostradas as superfícies da raiz sem tratamento com ampliações de 25, 100 e 500 vezes.

Figura 11- Imagens por microscopia eletrônica da raiz sem tratamento.

a

b
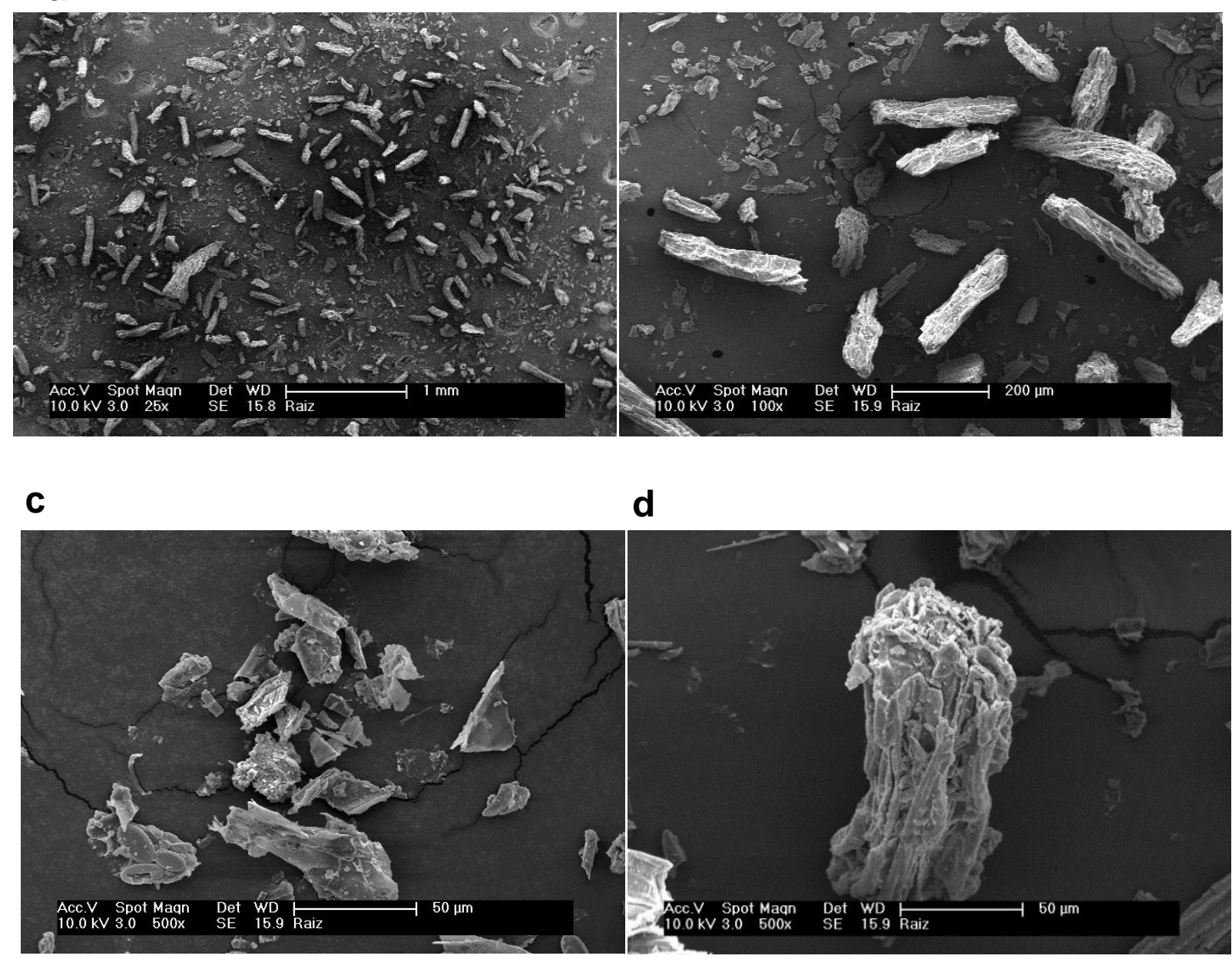

Nas figuras 12 (a, b e c) são mostradas as superfícies das raízes tratadas com $\mathrm{HCl}$ $0,1 \mathrm{~mol} \mathrm{~L}^{-1}$ em ampliações de 25 e 500 vezes e nas figuras 13 (a, b e c) são

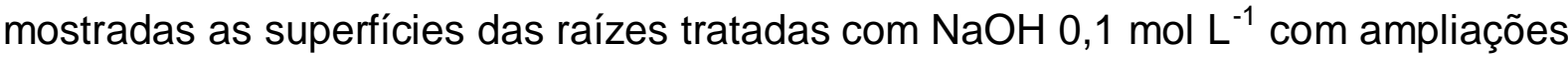
de 25,100 e 500 vezes.

Comparando-se as imagens obtidas por MEV, nota-se que o tratamento da raiz com $\mathrm{HCl}$ 0,1 mol L-1 aparentemente acentua a porosidade da biomassa não tratada,

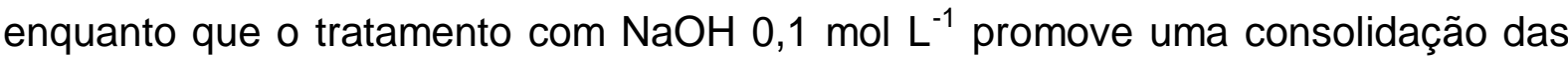
partículas formando aglomerados mais densos. Este resultado justifica o fato do material obtido após o tratamento básico apresentar maior dureza e resistência mecânica que o obtido após o tratamento ácido. Apesar das diferenças observadas, 
ambos os materiais apresentaram área superficial específica semelhante, quando reduzidos a uma granulometria inferior a 100 mesh, conforme discutido no item 4.2.

Figura 12- Imagens por microscopia eletrônica da raiz com tratamento com $\mathrm{HCl}, 1 \mathrm{~mol}$ $\mathrm{L}^{-1}$.

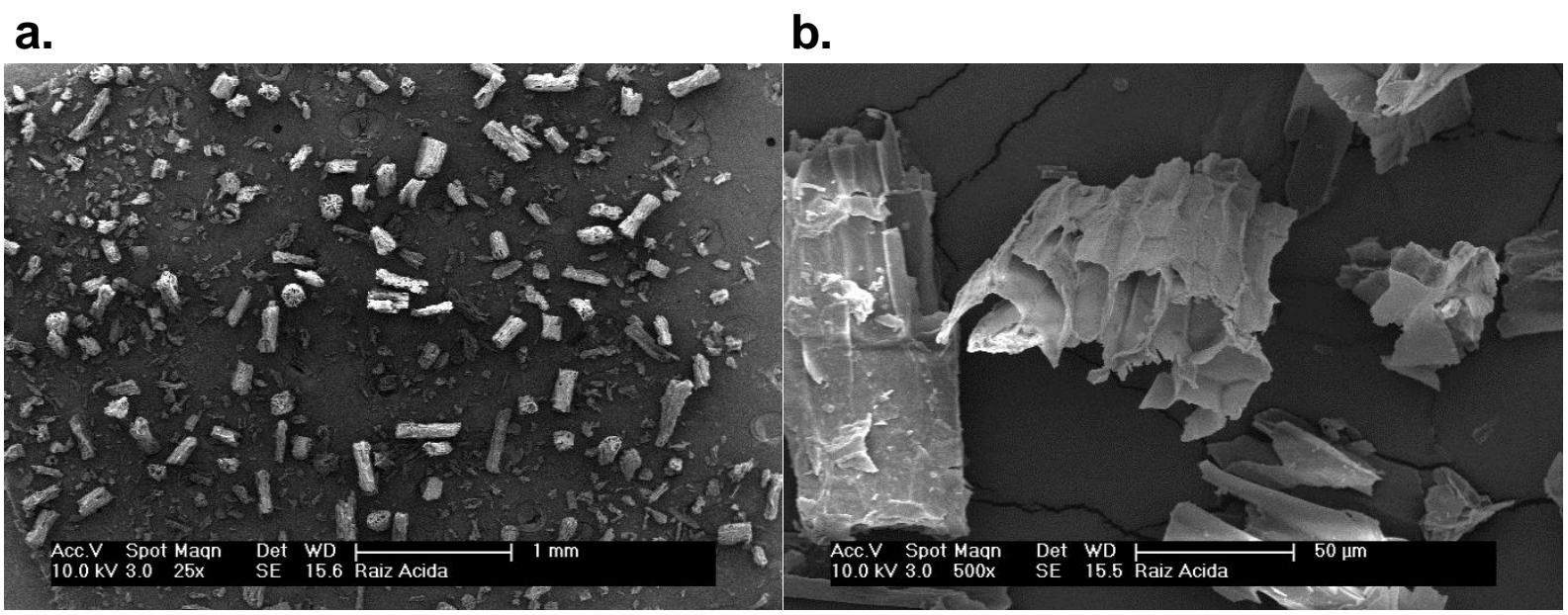

c.

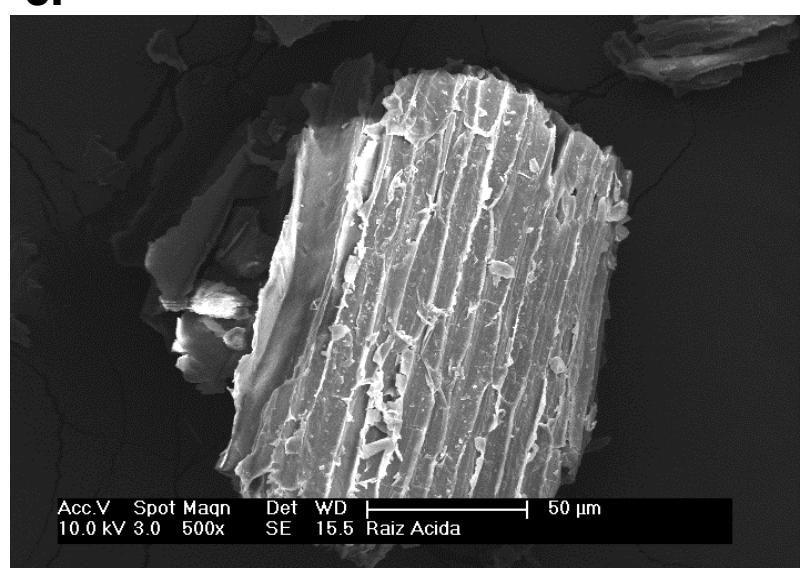


Figura 13- Imagens por microscopia eletrônica da raiz tratada com $\mathrm{NaOH} 0,1 \mathrm{~mol} \mathrm{~L}^{-1}$.

a.

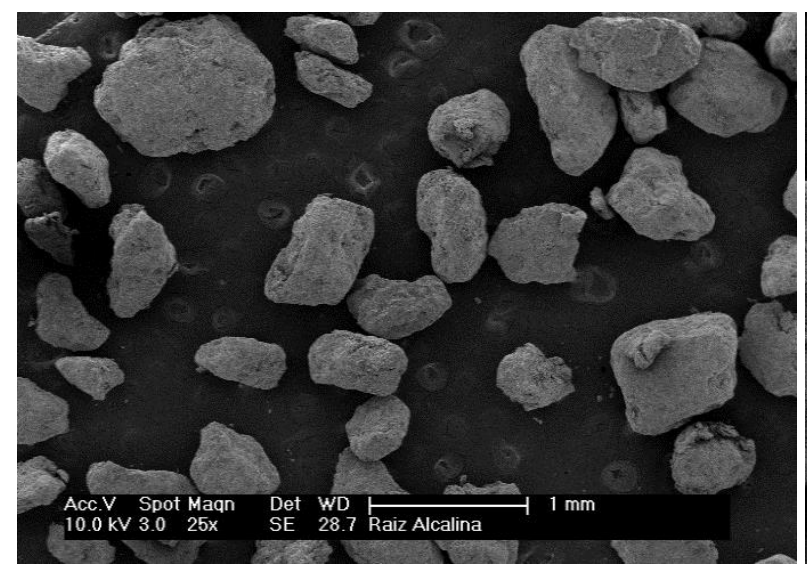

b.

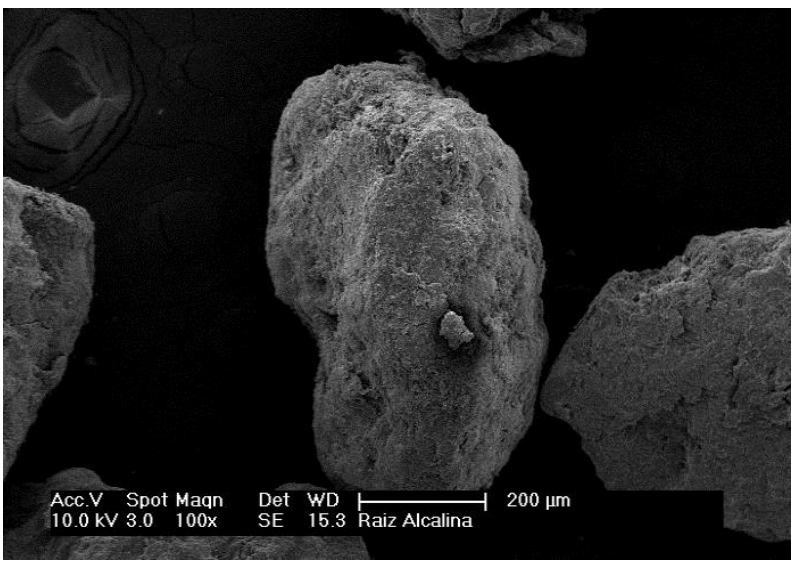

C.

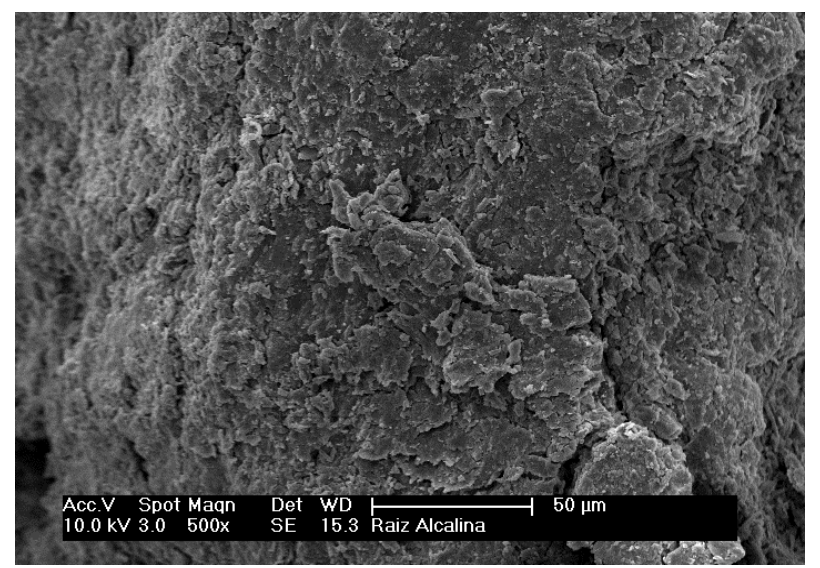

\subsection{Caracterização elementar dos metais na biomassa}

\subsubsection{Análise por ativação}

Foram determinadas as concentrações dos elementos de interesse nas amostras de

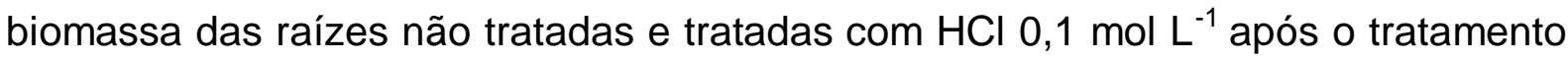
houve redução de massa. Uma vez que foram feitas diferentes coletas, o material obtido em cada uma delas e utilizado nos diferentes testes de adsorção foi caracterizado quanto à concentração dos elementos de interesse e os resultados são apresentados na Tabela 7. 
Verifica-se que os elementos Co e $\mathrm{Zn}$ apresentam uma menor concentração nas amostras após o tratamento com ácido, enquanto que para $\mathrm{Cr}$, observou-se um aumento da concentração.

\subsubsection{Absorção Atômica}

As concentrações de $\mathrm{Cd}$ e $\mathrm{Pb}$, obtidas por absorção atômica, foram determinadas apenas nas raízes tratadas com $\mathrm{HCl} 0,1 \mathrm{~mol} \mathrm{~L}^{-1}$ e raiz sem tratamento. Os resultados são apresentados na Tabela 8.

Observa-se que o tratamento ácido diminui a concentração de $\mathrm{Pb}$ nas amostras de biomassa, no entanto não causam efeito sobre a concentração do $\mathrm{Cd}$.

Tabela 7 - Concentrações determinadas por NAA, em mg kg-1, para os elementos de interesse, nas amostras utilizadas para estudo do efeito do $\mathrm{pH}$ e do tempo de contato.

\begin{tabular}{|c|c|c|c|c|c|c|}
\hline \multicolumn{7}{|c|}{ Efeito do $\mathrm{pH}$} \\
\hline & Co & & $\mathrm{Cr}$ & & $\mathrm{Zn}$ & \\
\hline$\overline{\mathrm{R} 1}$ & 0,98 & $\pm 0,09$ & 9,3 & $\pm 0,6$ & $45 \pm$ & \\
\hline $\mathrm{R} 2$ & 1,10 & $\pm 0,08$ & 11,8 & $\pm 0,7$ & $46 \pm$ & \pm 3 \\
\hline RA1 & 0,77 & $\pm 0,08$ & 15,3 & $\pm 0,7$ & $16 \pm$ & \pm 1 \\
\hline RA2 & 0,95 & $\pm 0,09$ & 15,8 & $\pm 0,7$ & $20 \pm$ & \pm 2 \\
\hline \multicolumn{7}{|c|}{ Efeito do tempo de contato } \\
\hline & Co & & $\mathrm{Cr}$ & & $\mathrm{Zn}$ & \\
\hline$\overline{\mathrm{R} 1}$ & $\sqrt{1,4}$ & $\overline{0,05}$ & 12,5 & $\pm 0,6$ & $170 \pm$ & \pm 6 \\
\hline R2 & 1,26 & $\pm 0,05$ & 17,9 & $\pm 0,7$ & $156 \pm$ & \pm 5 \\
\hline RA1 & 0,88 & $\pm 0,05$ & 22,5 & $\pm 0,7$ & $28 \pm$ & \pm 2 \\
\hline RA2 & 0,74 & $\pm 0,05$ & 29,0 & $\pm 0,9$ & $35 \pm$ & \pm 2 \\
\hline \multicolumn{7}{|c|}{ Efeito da concentração inicial } \\
\hline & Co & & $\mathrm{Cr}$ & & $\mathrm{Zn}$ & \\
\hline R1 & 1,42 & $\pm 0,05$ & 12,5 & $\pm 0,6$ & $170 \pm$ & \\
\hline $\mathrm{R} 2$ & 1,26 & $\pm 0,05$ & 17,9 & $\pm 0,7$ & $156 \pm$ & \pm 5 \\
\hline RA1 & 0,88 & $\pm 0,05$ & 22,5 & $\pm 0,7$ & $28 \pm$ & \pm 2 \\
\hline RA2 & 0,74 & $\pm 0,05$ & 29,0 & $\pm 0,9$ & $35 \pm$ & \pm 2 \\
\hline
\end{tabular}

$\mathrm{R}=$ amostra de raiz sem tratamento, $\mathrm{RA}=$ raiz com tratamento ácido. 
Tabela 8 - Concentrações de $\mathrm{Cd}$ e Pb, em mg kg ${ }^{-1}$, obtidas por absorção atômica.

\begin{tabular}{cc}
\hline \multicolumn{2}{c}{ Raízes sem tratamento } \\
\hline $\mathrm{Pb}$ & $0,51 \pm 0,17$ \\
$\mathrm{Cd}$ & $0,43 \pm 0,02$ \\
\hline \multicolumn{2}{l}{ Raízes ativadas com $\mathbf{~ H C l ~ 0 , 1 ~ \mathrm { mol } \mathrm { L } ^ { - 1 }}$} \\
\hline $\mathrm{Pb}$ & $0,224 \pm 0,002$ \\
\hline $\mathrm{Cd}$ & $0,436 \pm 0,003$ \\
\hline
\end{tabular}

\subsection{Estudos de Adsorção}

\subsubsection{Efeito pH inicial da solução}

Nas Figuras 14 e 15 são mostradas a capacidade de adsorção e a porcentagem de remoção de íons cobalto como função do $\mathrm{pH}$ e na tabela 9 que antecede os gráficos são exibidos os valores encontrados. Pode ver-se que tanto $q_{e}$ quanto Ead\% apresentam baixos valores abaixo do $\mathrm{pH}$ inicial 8 .

Tabela 9 - Valores de $\mathrm{q}_{\mathrm{e}}$ obtidos para o efeito de $\mathrm{pH}$ para o Co.

\begin{tabular}{ccc}
\hline & qe & Incerteza \\
\hline \multicolumn{2}{c}{$\mathrm{mg} \mathrm{g}^{-1}$} \\
\hline pH 2 & $2,2.10^{-4}$ & $9,8 \cdot 10^{-5}$ \\
\hline pH 4 & $5,0.10^{-4}$ & $2,3 \cdot 10^{-5}$ \\
\hline pH 6 & $5,8 \cdot 10^{-4}$ & $2,6.10^{-5}$ \\
\hline pH 8 & $9,5 \cdot 10^{-4}$ & $5,3 \cdot 10^{-5}$ \\
\hline pH10 & $4,2.10^{-3}$ & $8,5 \cdot 10^{-4}$ \\
\hline
\end{tabular}

Estudos sobre a adsorção de Co em biomassa mostraram que o processo de adsorção é maior em pH 6 (Foroutan et al., 2017). Os resultados aqui observados devem estar relacionados ao fato de que o pH da solução foi ajustado e a biomassa 
da raiz de Eichhornia crassipes foi posteriormente adicionada. Portanto, o pH durante o experimento de adsorção deve ter sido baixado para valores inferiores ao inicial.

Figura 14 - Capacidade de adsorção $\left(q_{e}, \mathrm{mg} \mathrm{g}^{-1}\right)$ em função do $\mathrm{pH}$ para o íon cobalto.

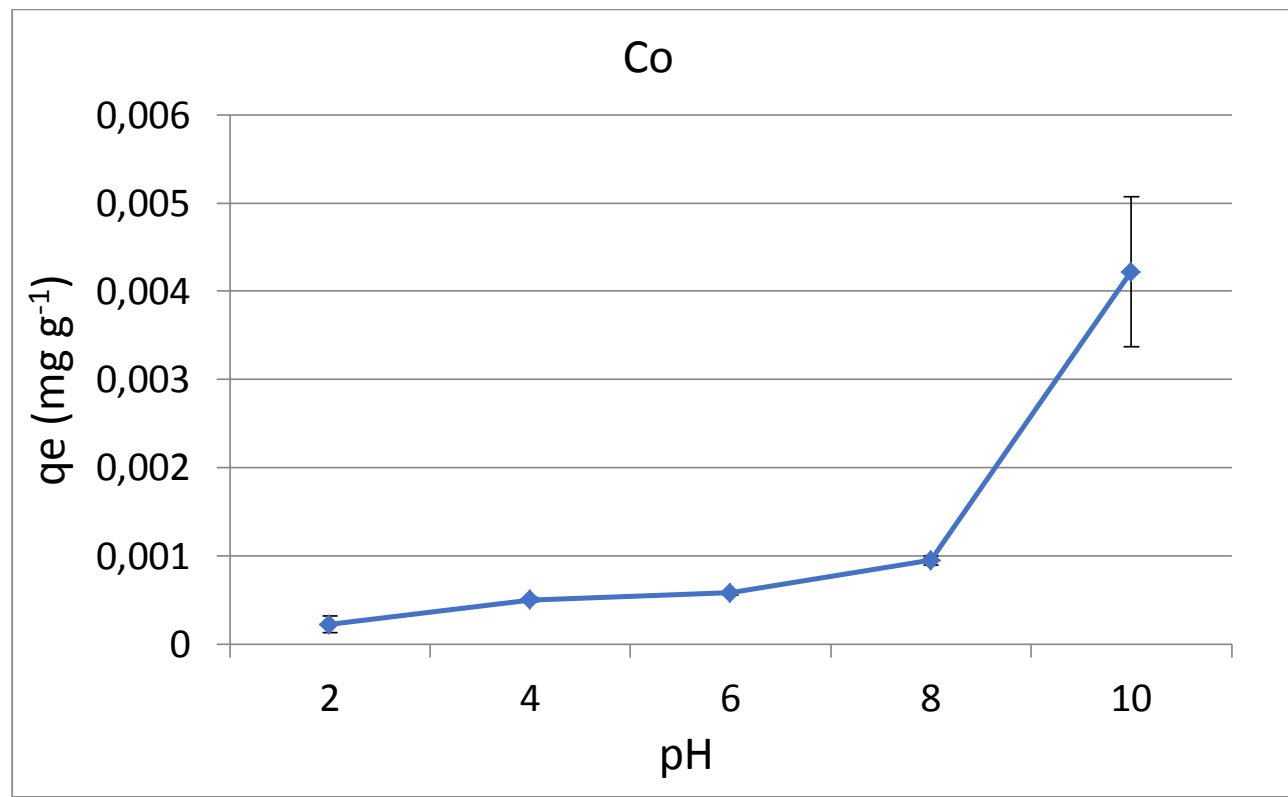

Figura 15 - Eficiência de remoção (\%) em função do pH para o íon cobalto.

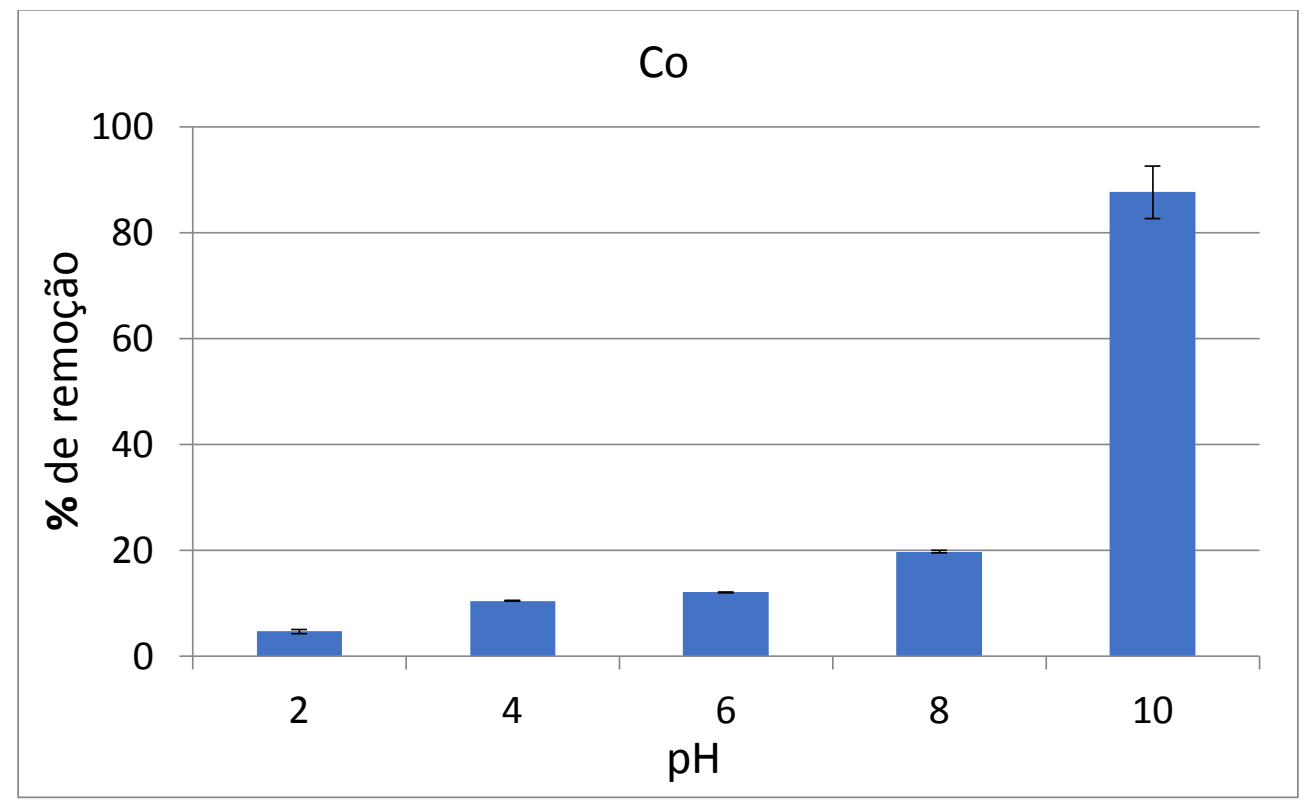

Nas Figuras 16 e 17 são mostradas a capacidade de adsorção e a eficiência de remoção de íons zinco como função do pH e na tabela 10 que antecede os gráficos são exibidos os valores encontrados. Os valores de $q_{e}$ mostraram o mesmo 
comportamento que o observado para o cobalto. No entanto, a porcentagem de remoção, para este íon, foi próxima de $100 \%$ em todos os valores de $\mathrm{pH}$, indicando que a adsorção de zinco foi independente do pH da solução.

Tabela 10 - Valores de $\mathrm{q}_{\mathrm{e}}$ obtidos para o efeito de $\mathrm{pH}$ para o $\mathrm{Zn}$.

\begin{tabular}{ccc}
\hline & $\mathrm{q}_{\mathrm{e}}$ & Incerteza \\
\hline \multicolumn{3}{c}{$\mathbf{m g ~ g}^{-1}$} \\
\hline pH 2 & - & - \\
\hline pH 4 & $2,3.10^{-3}$ & $2,2.10^{-4}$ \\
\hline pH 6 & $1,6.10^{-3}$ & $1,5.10^{-4}$ \\
\hline pH 8 & $2,2.10^{-3}$ & $2,0.10^{-4}$ \\
\hline pH10 & $3,4.10^{-2}$ & $1,5.10^{-2}$ \\
\hline
\end{tabular}

Figura 16 - Capacidade de adsorção $\left(q_{e}, \mathrm{mg} \mathrm{g}^{-1}\right)$ em função do $\mathrm{pH}$ para o íon zinco.

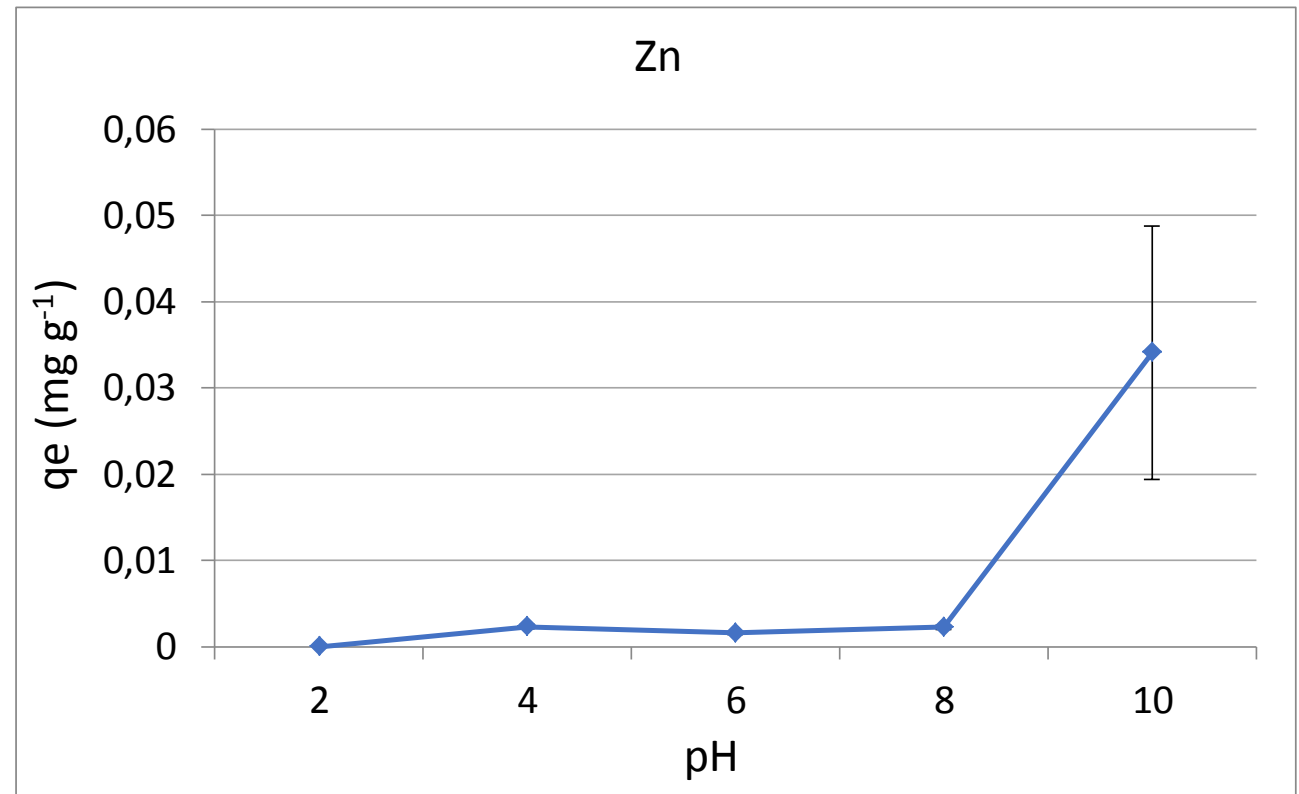


Figura 17 - Eficiência de remoção (\%) em função do pH para o íon zinco.

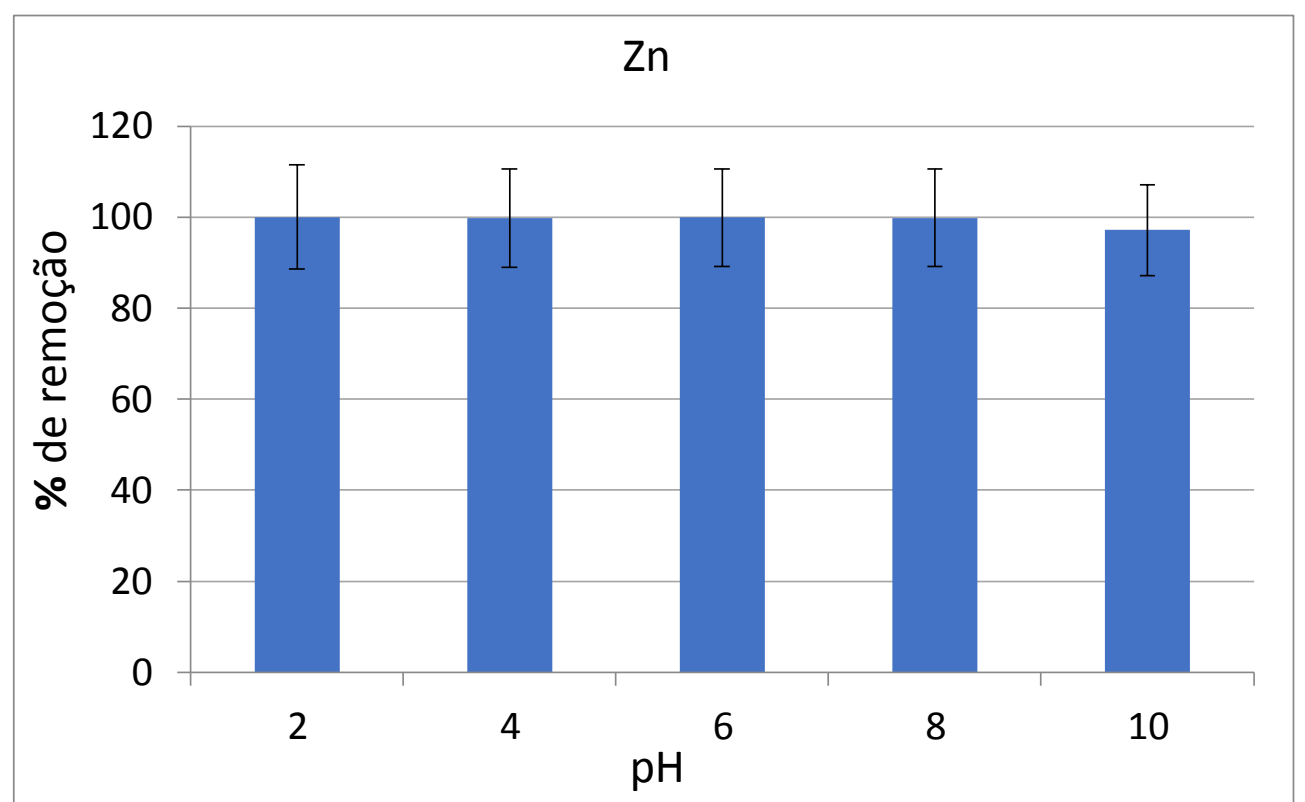

Nas Figuras 18 e 19 são mostradas a capacidade de adsorção e a eficiência de remoção de íons cromo como função do pH e na tabela 11 que antecede os gráficos são exibidos os valores encontrados. Os valores mostraram que a melhor adsorção do cromo foi no pH inicial 4. No entanto, a porcentagem de remoção, para este íon, foi baixa, inferior a $30 \%$ em todos os valores de $\mathrm{pH}$.

Tabela 11 - Valores de $\mathrm{q}_{\mathrm{e}}$ obtidos para o efeito de $\mathrm{pH}$ para o $\mathrm{Cr}$.

\begin{tabular}{ccc}
\hline & \multicolumn{1}{c}{$q_{\mathrm{e}}$} & Incerteza \\
\hline \multicolumn{3}{c}{$\mathbf{m g ~ g}^{-1}$} \\
\hline pH 2 & $2,2.10^{-4}$ & $9,8.10^{-5}$ \\
\hline pH 4 & $5,0.10^{-4}$ & $2,3.10^{-5}$ \\
\hline pH 6 & $5,8.10^{-4}$ & $2,6.10^{-5}$ \\
\hline pH 8 & $9,5.10^{-4}$ & $5,3.10^{-5}$ \\
pH10 & $4,2.10^{-3}$ & $8,5.10^{-4}$ \\
\hline
\end{tabular}


Figura 18 - Capacidade de adsorção ( $\left.q_{e}, \mathrm{mg} \mathrm{g}^{-1}\right)$ em função do pH para o íon cromo.

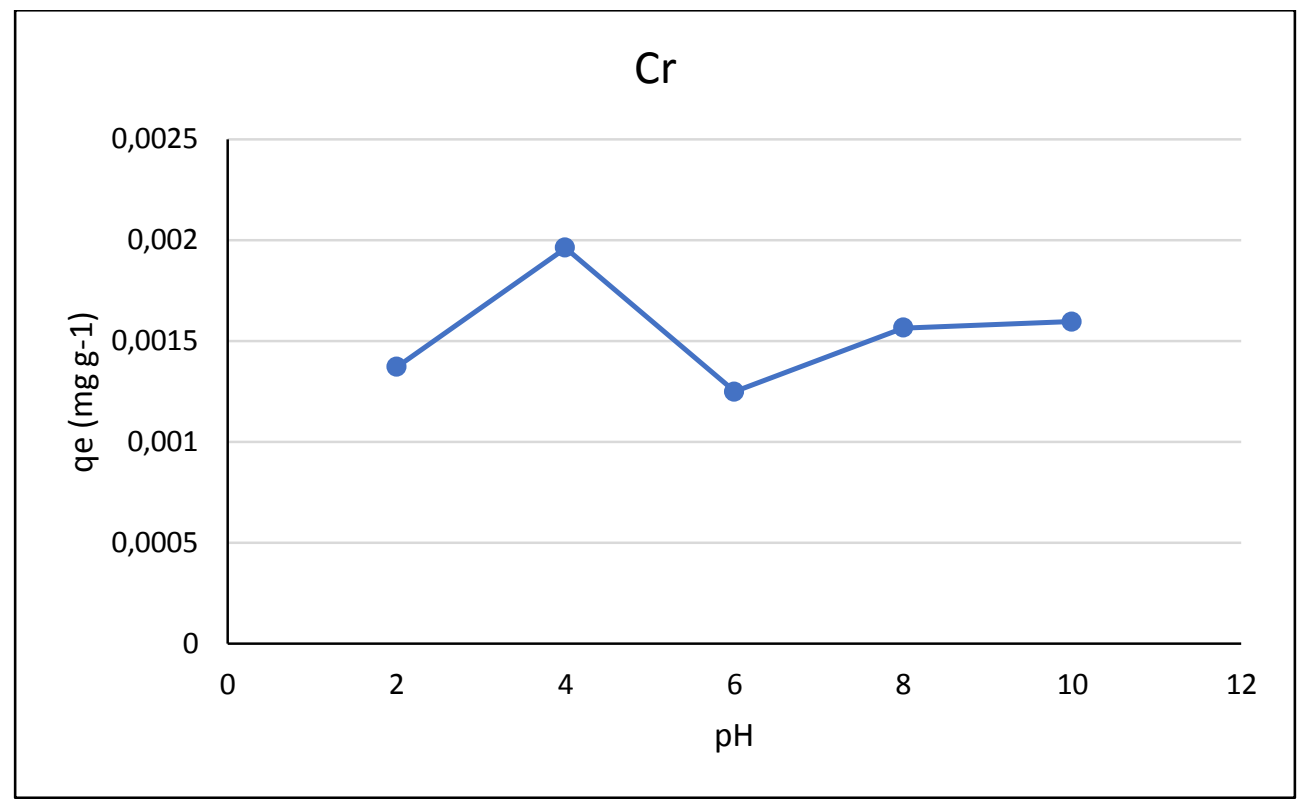

Figura 19 - Eficiência de remoção (\%) em função do pH para o íon cromo.

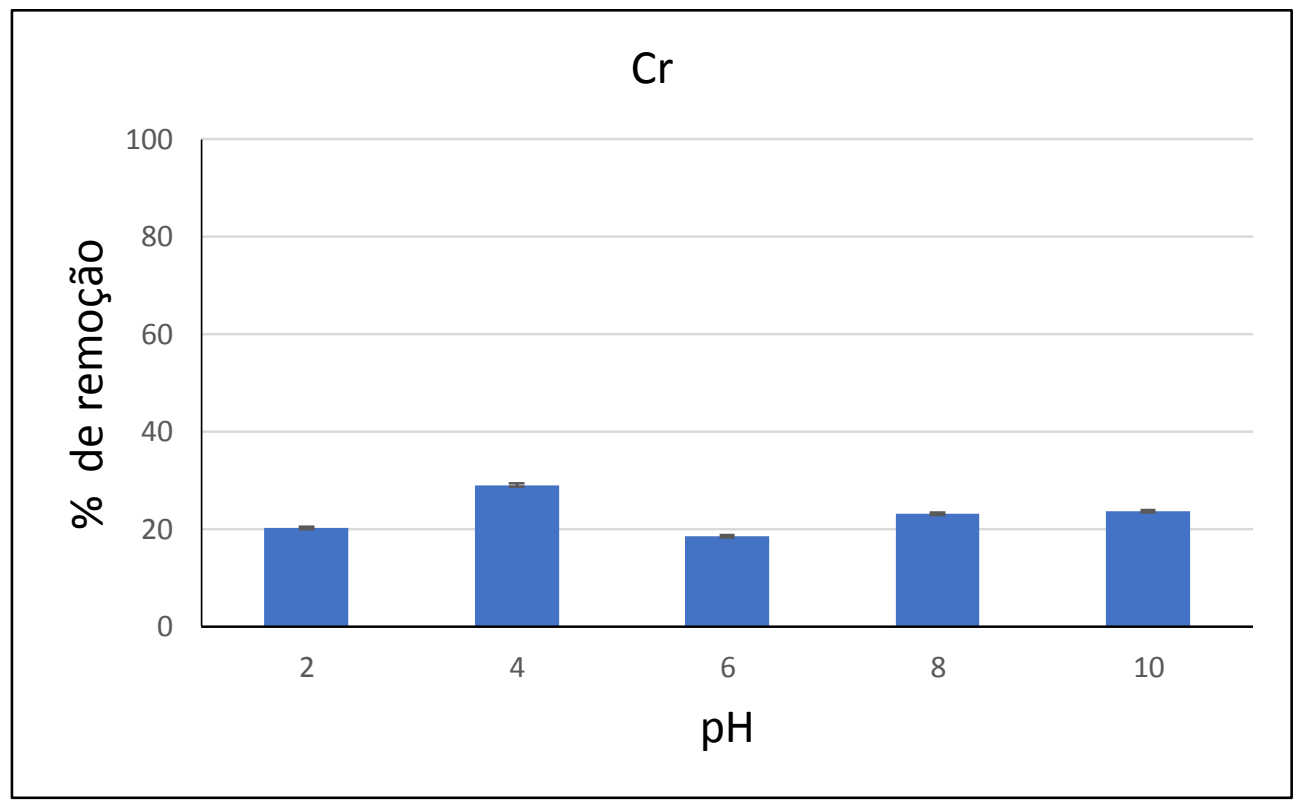

Este resultado pode estar relacionado ao fato do teste de verificação da influência do $\mathrm{pH}$ ter sido realizado em um tempo de contato de $20 \mathrm{~min}$, indicando que a adsorção de cromo não foi eficiente neste período de tempo. No trabalho de SARASWAT e RAl (2010) observou-se que o cromo não teve boa adsorção em tempo abaixo de 120 minutos, apresentando um melhor rendimento acima de 180 minutos. 
Nas Figuras 20 e 21 são mostrados os resultados obtidos para a eficiência de remoção (Ead\%) e capacidade de adsorção (qe) do $\mathrm{Cd}$ em função do pH e na tabela 12 que antecede os gráficos são exibidos os valores encontrados. Exceto para o pH inicial 2, verifica-se um aumento tanto na porcentagem de remoção quanto em qe com ou aumento do $\mathrm{pH}$. O processo de adsorção é influenciado por fatores tais como o pH inicial e final da solução, carga superficial do adsorvente e especiação do metal (RAO e KASHIFUDDIN, 2014). Observou-se durante os experimentos que a adição da biomassa ativada com ácido reduzia significativamente os valores de $\mathrm{pH}$ da solução inicial, o que pode justificar a maior adsorção em pH inicial 10.

Tabela 12 - Valores de $\mathrm{q}_{\mathrm{e}}$ obtidos para o efeito de $\mathrm{pH}$ para o $\mathrm{Cd}$.

\begin{tabular}{ccc}
\hline & $\mathrm{q}_{\mathrm{e}}$ & Incerteza \\
\hline \multicolumn{3}{c}{$\mathbf{m g ~ g}^{-1}$} \\
\hline pH 2 & $4,9.10^{-2}$ & $4,6 \cdot 10^{-3}$ \\
\hline pH 4 & $2,5.10^{-2}$ & $9,1.10^{-3}$ \\
\hline pH 6 & $3,0.10^{-2}$ & $4,3 \cdot 10^{-3}$ \\
\hline pH 8 & $4,0.10^{-2}$ & $9,2 \cdot 10^{-3}$ \\
\hline pH10 & $8,0.10^{-2}$ & $5,9 \cdot 10^{-3}$ \\
\hline
\end{tabular}


Figura 20 - Capacidade de adsorção em $\mathrm{mg} \mathrm{g}^{-1}$, em função do pH inicial da solução de íons de cádmio.

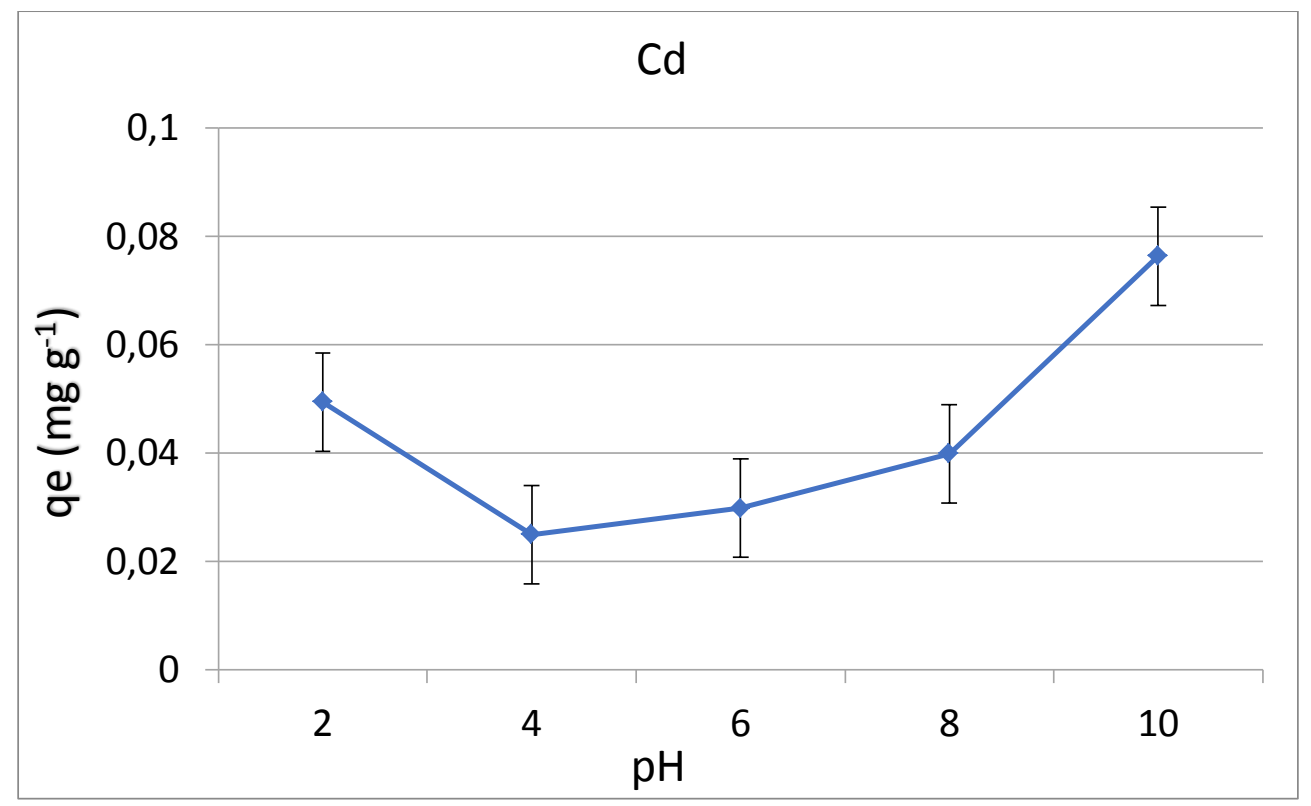

Figura 21 - Eficiência de remoção (\%) em função do pH para os íons da solução de cádmio.

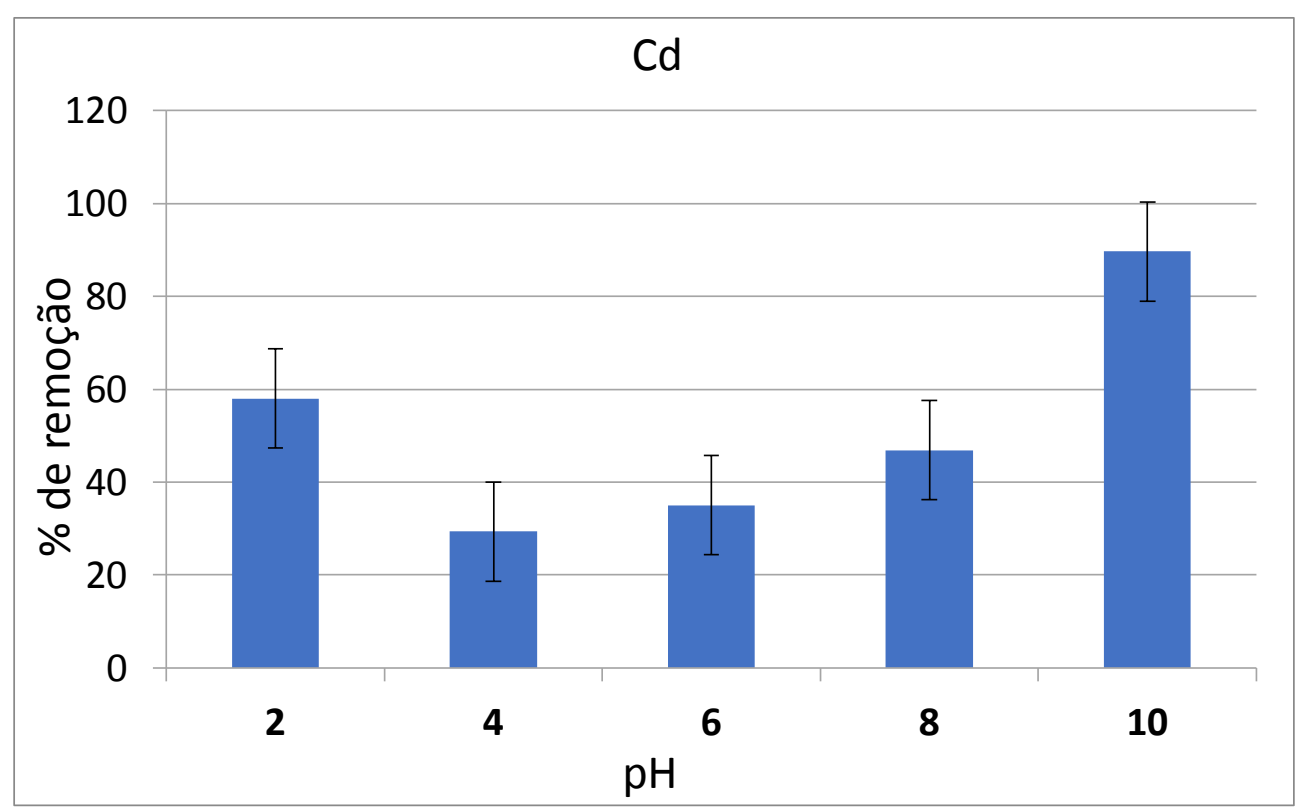

Nas Figuras 22 e 23 são mostradas a eficiência de remoção em (\%) e a capacidade e adsorção para o $\mathrm{Pb}$ e na tabela 13 que antecede os gráficos são exibidos os 
valores encontrados. Verifica-se que a porcentagem de remoção do $\mathrm{Pb}$ da solução é maior que $80 \%$ em pH inicial superior a 4 , mantendo-se praticamente constante a partir deste valor. A capacidade de adsorção, por sua vez aumenta significativamente do $\mathrm{pH} 4$ para 6 . Resultados semelhantes foram obtidos por THE et al. (2017) utilizando um compósito de folhas de eucalipto e polianilina, sendo que determinaram valores de qe da ordem de $8 \mathrm{mg} \mathrm{g}^{-1}$, a partir de uma solução inicial de concentração $1 \mathrm{mg} \mathrm{L}^{-1}$.

Tabela 13 - Valores de $\mathrm{q}_{\mathrm{e}}$ obtidos para o efeito de $\mathrm{pH}$ para o $\mathrm{Pb}$.

\begin{tabular}{ccc}
\hline & $\mathbf{q}_{\mathrm{e}}$ & Incerteza \\
\hline \multicolumn{3}{c}{$\mathbf{m g ~ g}^{-1}$} \\
\hline $\mathbf{p H ~ 2}$ & $2,6.10^{-02}$ & $3,0.10^{-3}$ \\
\hline $\mathbf{p H} 4$ & $1,1.10^{-01}$ & $1,0.10^{-2}$ \\
\hline $\mathbf{p H ~ 6}$ & 3,41 & 0,4 \\
\hline $\mathbf{p H 8}$ & 3,57 & 0,4 \\
\hline
\end{tabular}

Figura 22 - Capacidade de adsorção, em $\mathrm{mg} \mathrm{g}^{-1}$, de chumbo em função do $\mathrm{pH}$ inicial da solução.

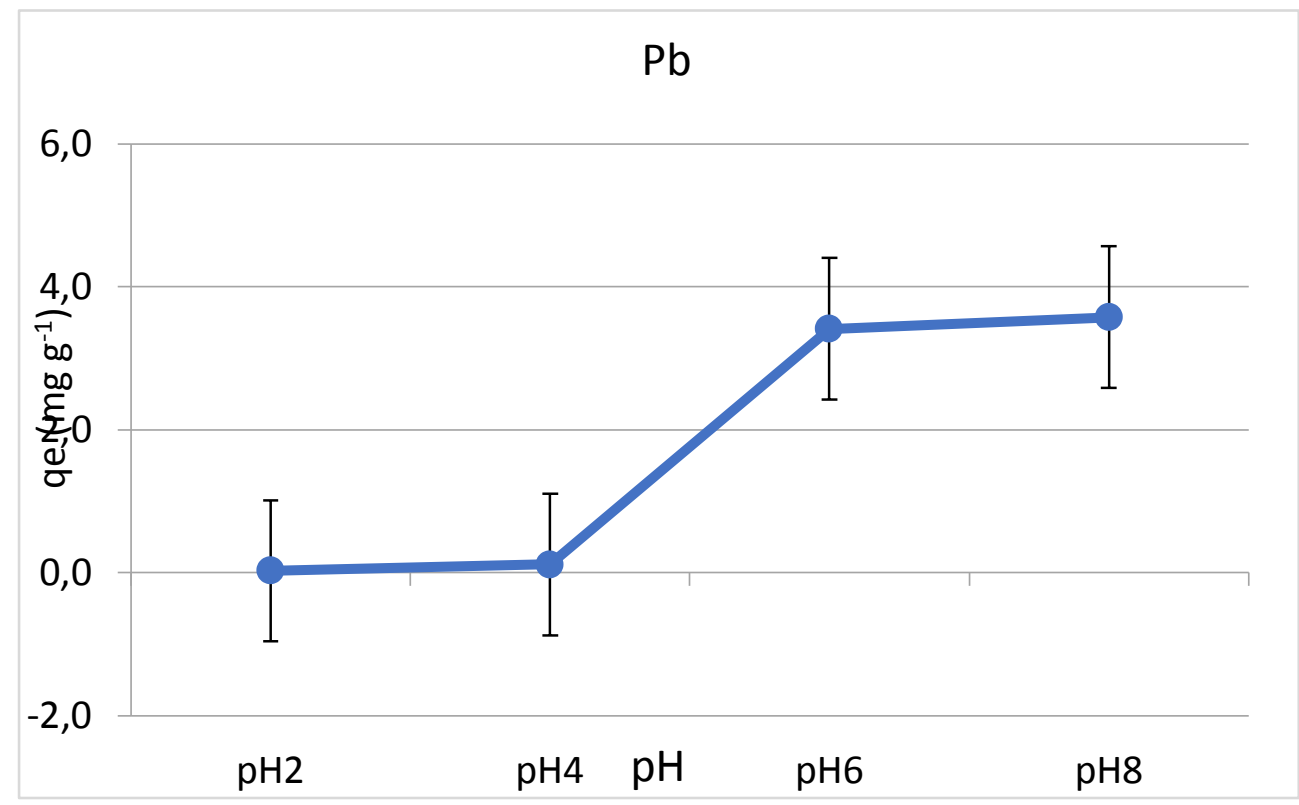


Figura 23 - Eficiência de remoção (\%) em função do pH inicial para solução de íons de chumbo.

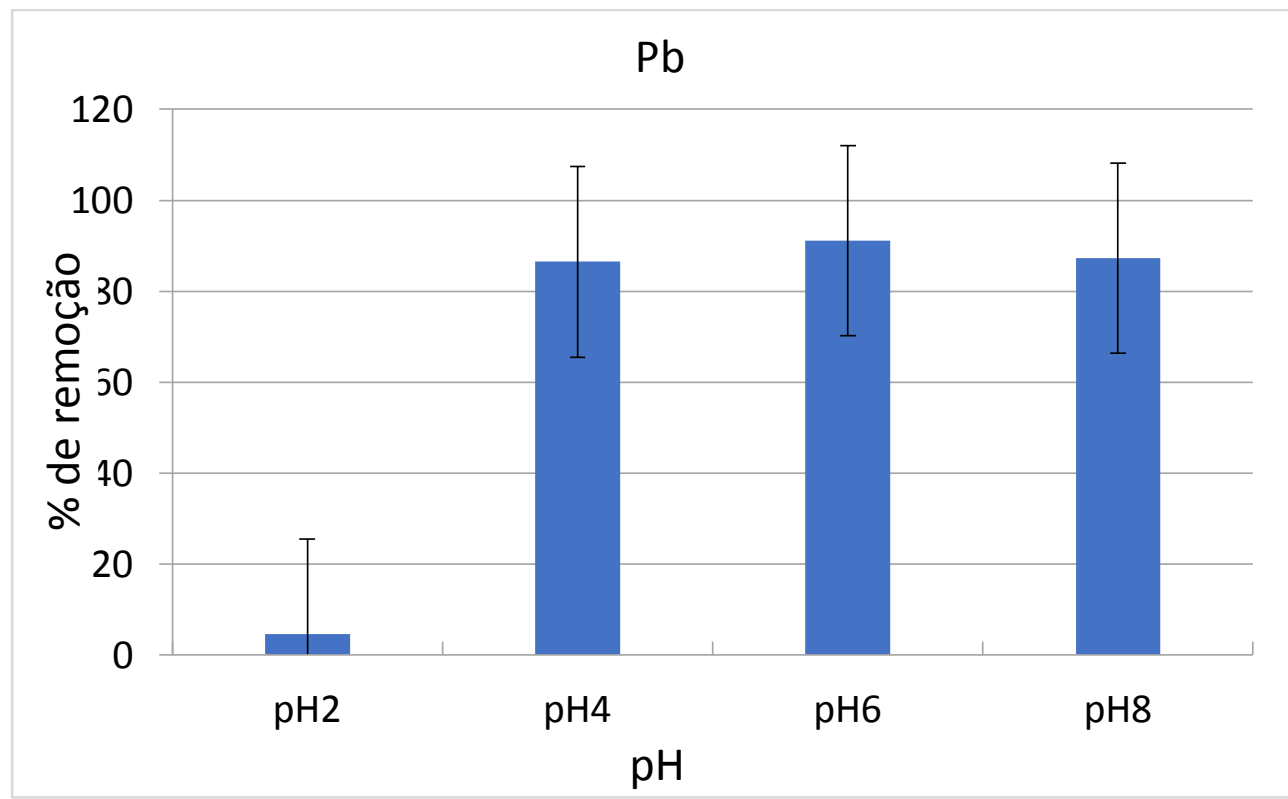

\subsubsection{Efeito do tempo de contato}

Nos testes para verificação do tempo de contato, os íons Co apresentaram valores médios mais altos para a capacidade de adsorção qe antes de $30 \mathrm{~min}$. Os resultados obtidos para capacidade de adsorção e porcentagem de remoção são mostrados nas Figuras 24 e 25 e na tabela 14 que antecede os gráficos são exibidos os valores encontrados.

Tabela 14 - Valores de $\mathrm{q}_{\mathrm{e}}$ obtidos para o efeito de TC para o Co.

\begin{tabular}{ccc}
\hline & qe & Incerteza \\
\hline \multicolumn{3}{c}{$\mathbf{m g ~ s}^{-1}$} \\
\hline TC 10 & $4,7.10^{-3}$ & $6,2.10^{-4}$ \\
\hline TC 20 & $4,5.10^{-3}$ & $6,0.10^{-4}$ \\
\hline TC 30 & $4,1.10^{-3}$ & $5,4.10^{-4}$ \\
TC 60 & $4,0.10^{-3}$ & $5,12.10^{-4}$ \\
\hline TC 120 & $4,1.10^{-3}$ & $5,4.10^{-4}$ \\
\hline
\end{tabular}


Figura 24 - Capacidade de adsorção (qe, $\mathrm{mg} \mathrm{g}^{-1}$ ) em função do tempo de contato para o íon cobalto.

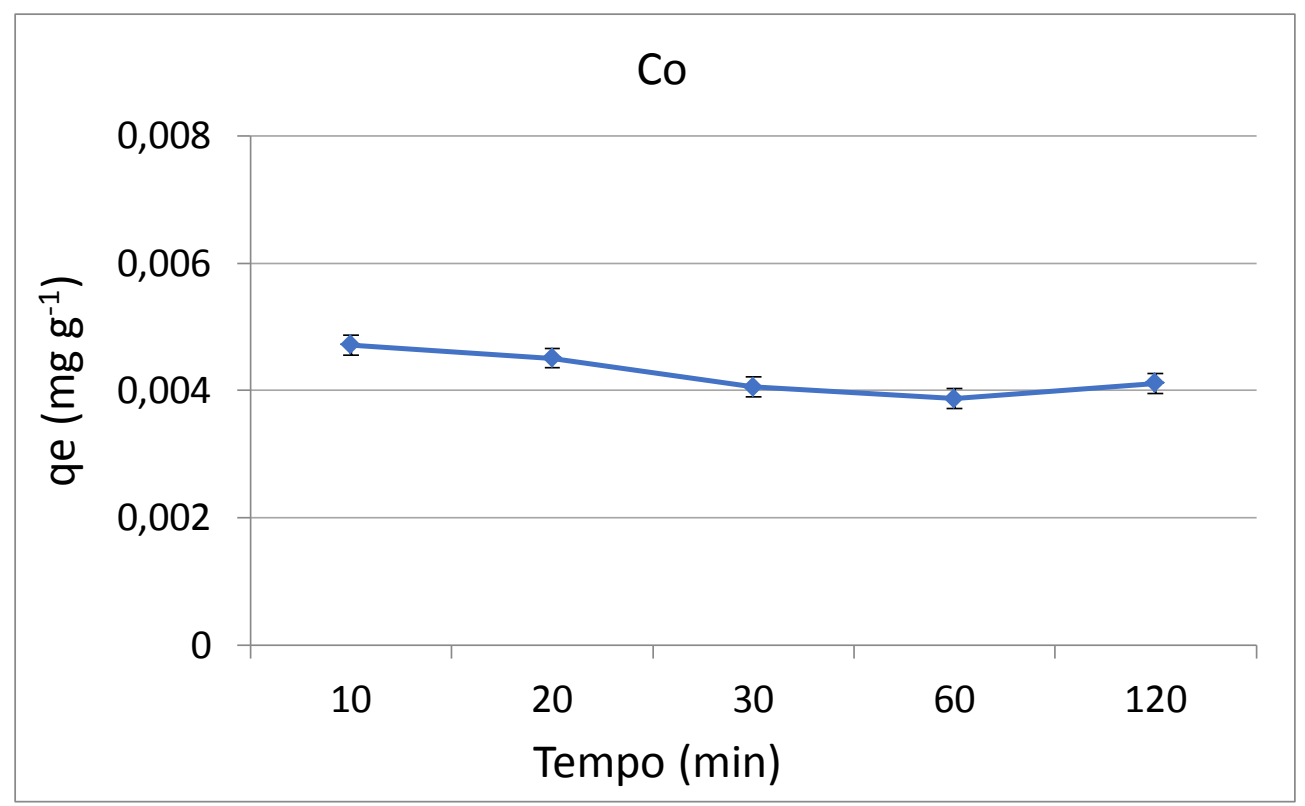

Figura 25 - Eficiência de remoção, em \%, em função do tempo de contato para o íon cobalto..

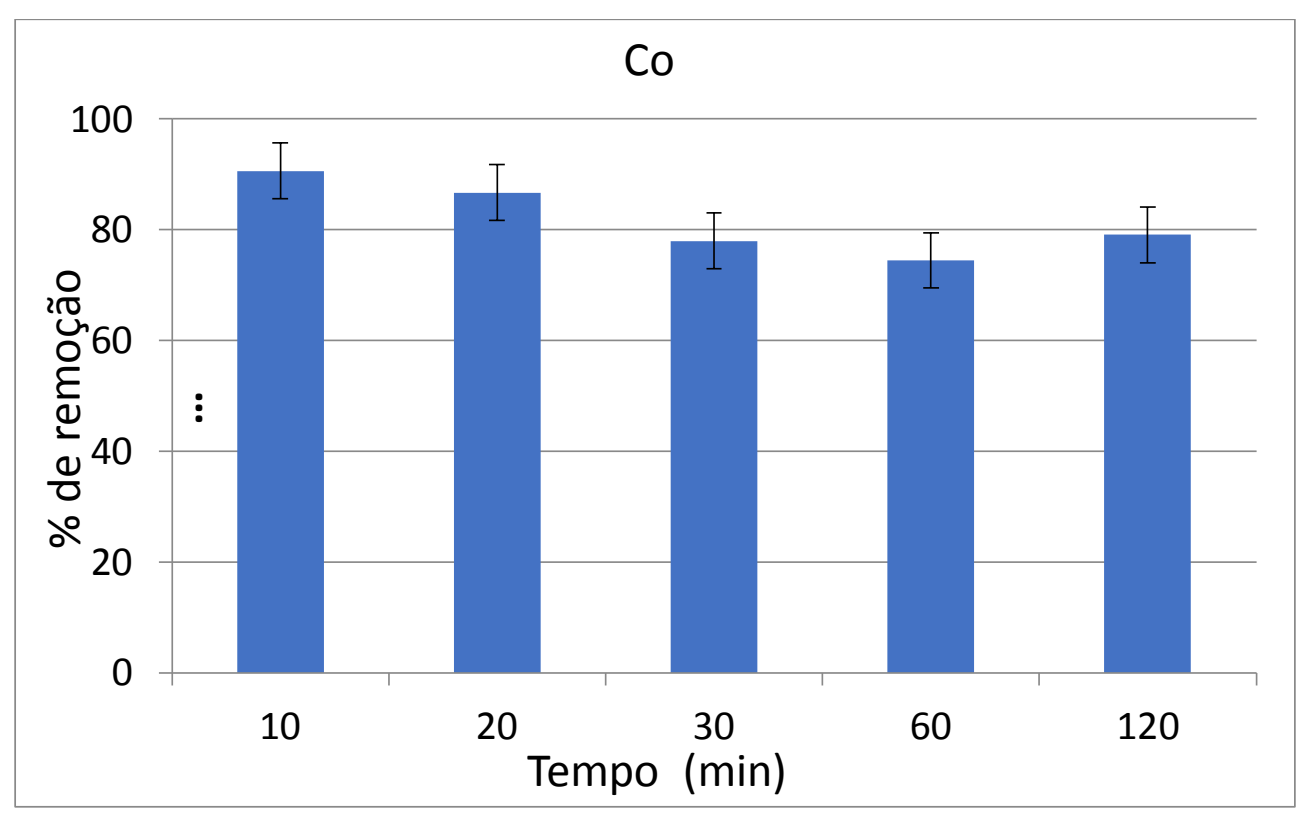

Para a remoção de íons de zinco em função do tempo de contato, os resultados de qe e Ead\% de remoção são mostrados nas Figura 26 e 27 e na tabela 15 que antecede os gráficos são exibidos os valores encontrados. A eficiência média de remoção observada diminuiu com o tempo, indicando que a adsorção de $\mathrm{Zn}$ foi menos dependente do $\mathrm{pH}$, mas dependente do tempo de contato. 
Tabela 15 - Valores de qe obtidos para o efeito de TC para o Zn.

\begin{tabular}{ccc}
\hline & $\mathrm{q}_{\mathrm{e}}$ & Incerteza \\
\hline \multicolumn{3}{c}{$\mathrm{mg} \mathrm{g}^{-1}$} \\
\hline TC 10 & $2,1.10^{-2}$ & $1,9.10^{-2}$ \\
TC 20 & $1,7.10^{-2}$ & $4,4.10^{-3}$ \\
\hline TC 30 & $2,2.10^{-02}$ & $1,5.10^{-2}$ \\
\hline TC 60 & $1,4.10^{-02}$ & $2,8.10^{-3}$ \\
\hline TC 120 & $1,5.10^{-02}$ & $3,2.10^{-3}$
\end{tabular}

Figura 26 - Capacidade de adsorção $\left(q_{e}, \mathrm{mg} \mathrm{g}^{-1}\right)$ em função do tempo de contato para o íon de zinco.

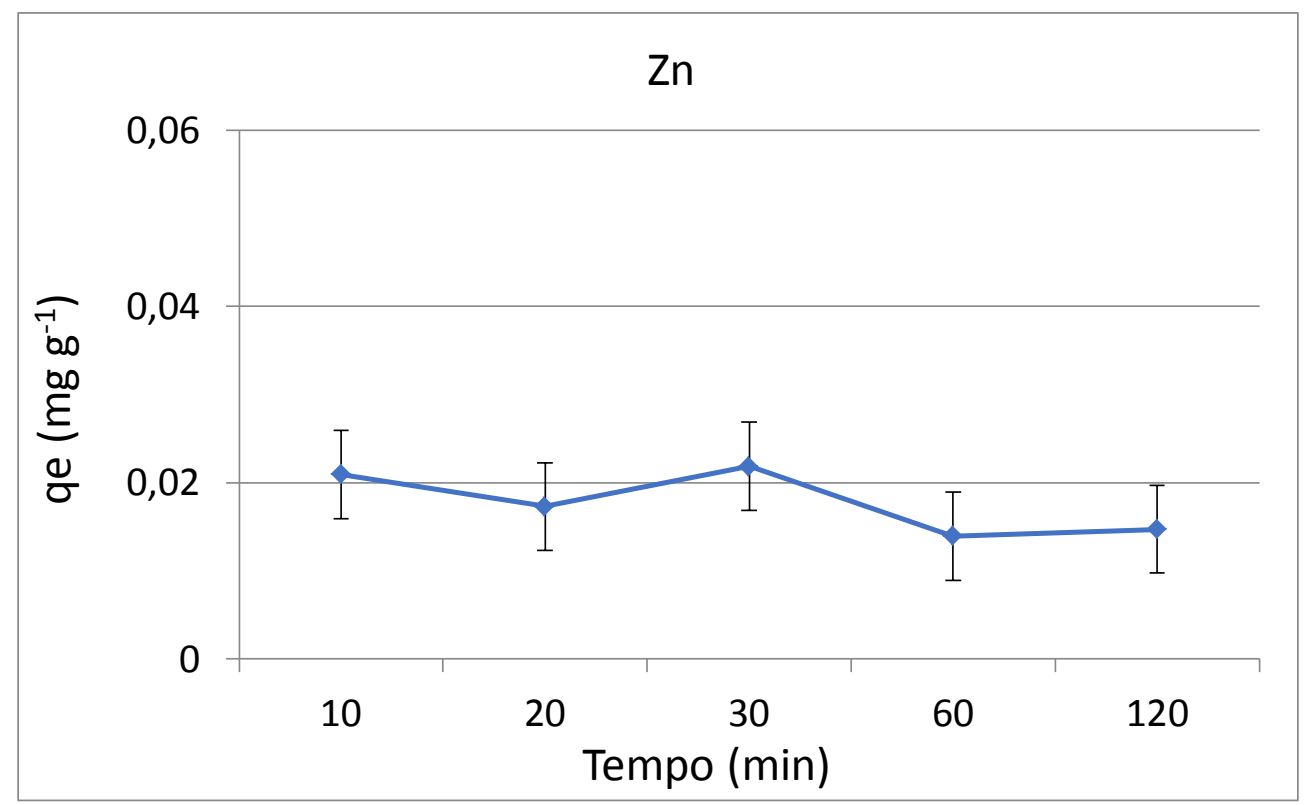


Figura 27 - Eficiência de remoção, em \%, em função do tempo de contato para o íon de zinco.

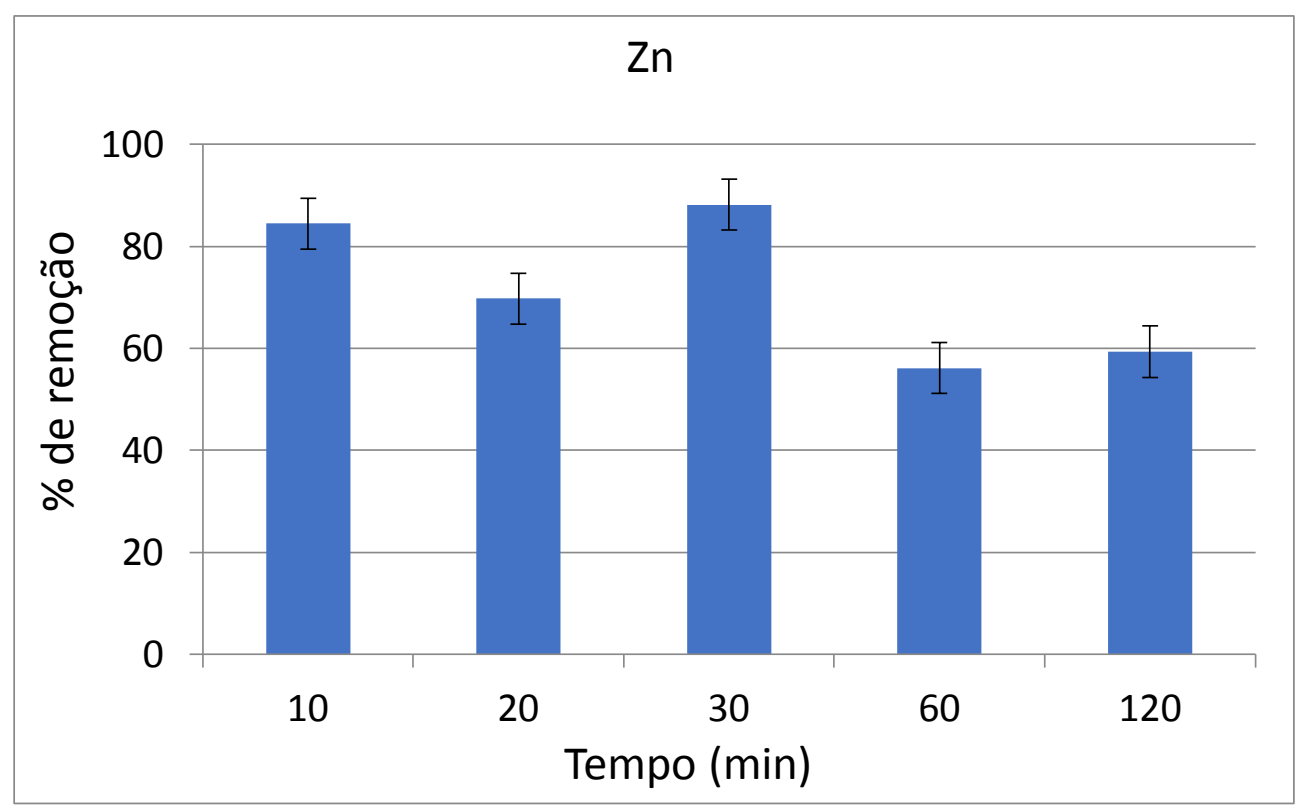

Para os experimentos em tempo de contato, o pH foi ajustado para 6 após a adição do adsorvente na solução. A capacidade de adsorção e a porcentagem de remoção de íons de cobalto e zinco, em função do tempo de contato, indicam que os valores mais elevados de qe e Ead\% foram observados nos tempos iniciais, inferiores a 30 $\min$.

Para os íons de cromo, não houve remoção da solução nos tempos inferiores a 120 minutos e pH ajustado para 6 após a dição da biomassa. Apenas no experimento realizado com tempo de 120 min foi possível determinar um valor de qe de 0,0016 $\mathrm{mg} \mathrm{g}^{-1}$, representando aproximadamente $26 \%$ de remoção dos íons da solução, resultado semelhante ao obtido no teste para verificação da influência do $\mathrm{pH}$.

O efeito do tempo de contato na porcentagem de remoção e na capacidade de adsorção do Cd é mostrado nas Figuras 28 e 29 e na tabela 16 que antecede os gráficos são exibidos os valores encontrados. Verifica-se que maior capacidade de adsorção e eficiência de remoção ocorrem antes de 10 minutos de tempo de contato e foram mantidas em todos os tempos do experimento. 
Tabela 16 - Valores de $q_{\mathrm{e}}$ obtidos para o efeito de TC para o Cd.

\begin{tabular}{ccc}
\hline & qe & Incerteza \\
\hline \multicolumn{3}{c}{ mg g $^{-1}$} \\
\hline TC 10 & $5,92 \cdot 10^{-2}$ & $1,27.10^{-3}$ \\
\hline TC 20 & $5,98 \cdot 10^{-2}$ & $7,07.10^{-3}$ \\
\hline TC 30 & $5,95.10^{-2}$ & $5,66 \cdot 10^{-3}$ \\
\hline TC 60 & $5,93 \cdot 10^{-2}$ & $8,49 \cdot 10^{-3}$ \\
\hline TC 120 & $5,87.10^{-2}$ & $2,12.10^{-3}$ \\
\hline
\end{tabular}

Figura 28 - Capacidade de adsorção, em mg g ${ }^{-1}$, de Cd em função do tempo de contato.

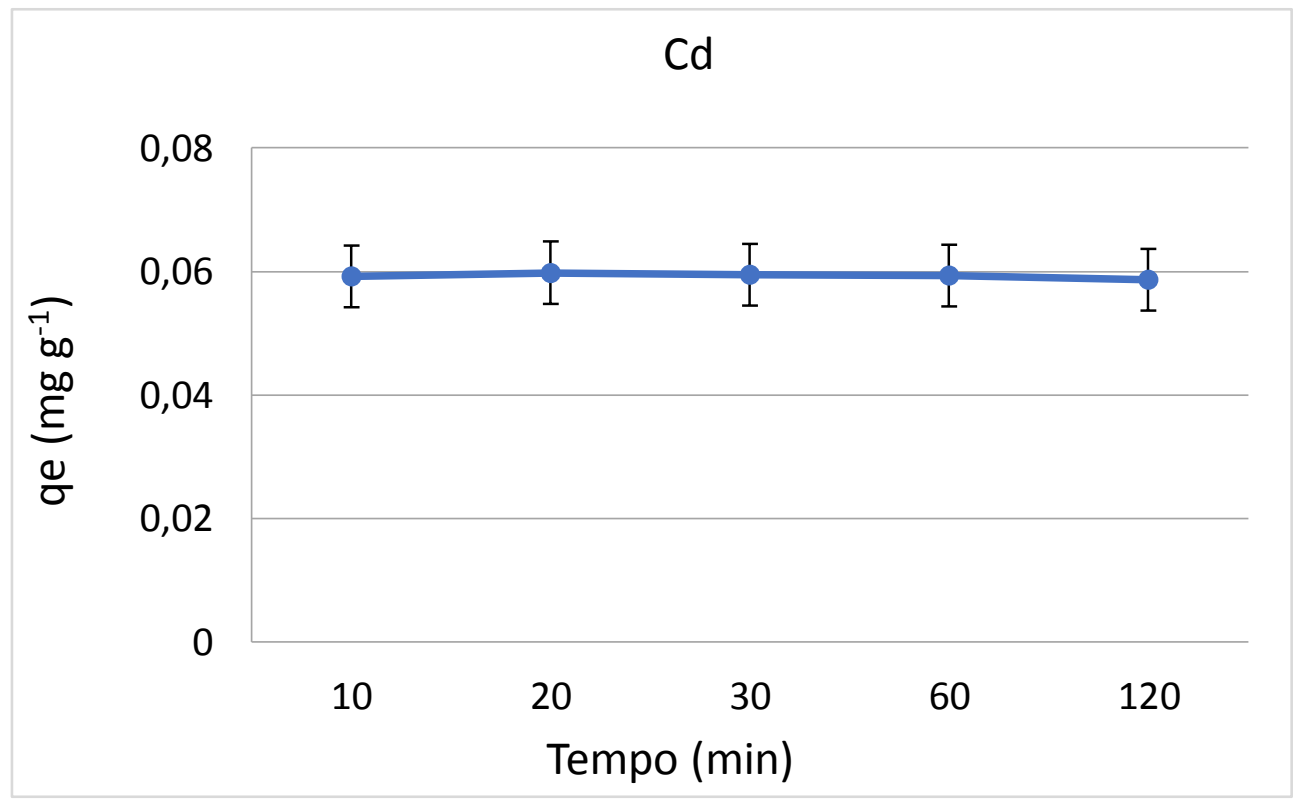


Figura 29 - Eficiência de remoção, em \%, de Cd em função do tempo de contato.

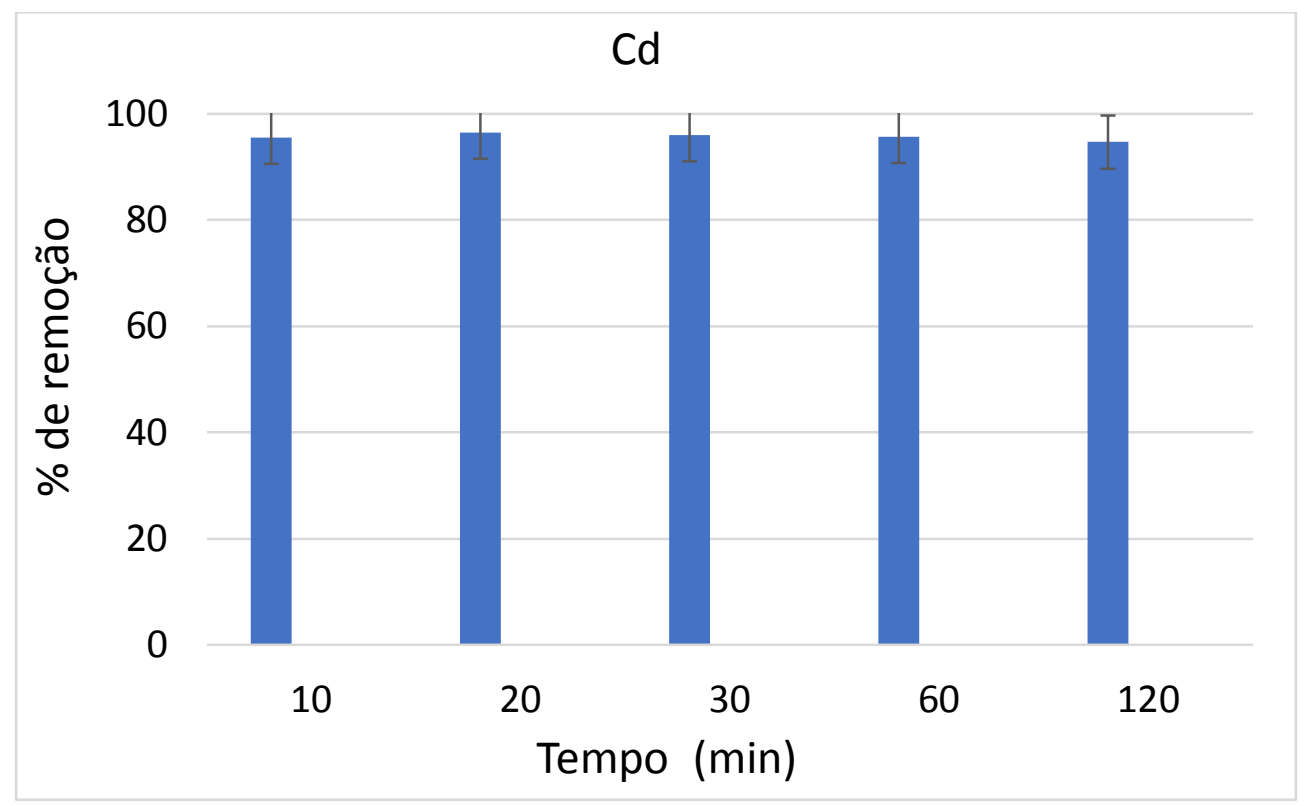

Nas Figuras 30 e 31 e na tabela 16 que antecede os gráficos são exibidos os valores encontrados. São apresentados os resultados obtidos para $0 \mathrm{~Pb}$ em relação à capacidade de adsorção e eficiência de remoção. Verifica-se que para este elemento os maiores valores de qe e Ead\% ocorrem após 60 min e que estes tendem a estabilidade após esse tempo.

Tabela 17 - Valores de $\mathrm{q}_{\mathrm{e}}$ obtidos para o efeito de TC para o Pb.

\begin{tabular}{ccc}
\hline & $\mathbf{q}_{\mathbf{e}}$ & Incerteza \\
\hline & \multicolumn{3}{c}{$\mathrm{mg} \mathrm{g}^{-1}$} \\
\hline TC 10 & 1,64 & 0,19 \\
\hline TC 20 & 1,68 & 0,15 \\
\hline TC 60 & 1,87 & 0,11 \\
TC 120 & 1,86 & 0,49
\end{tabular}


Figura 30 - Capacidade de adsorção, em mg g ${ }^{-1}$, de $\mathrm{Pb}$ em função do tempo de contato.

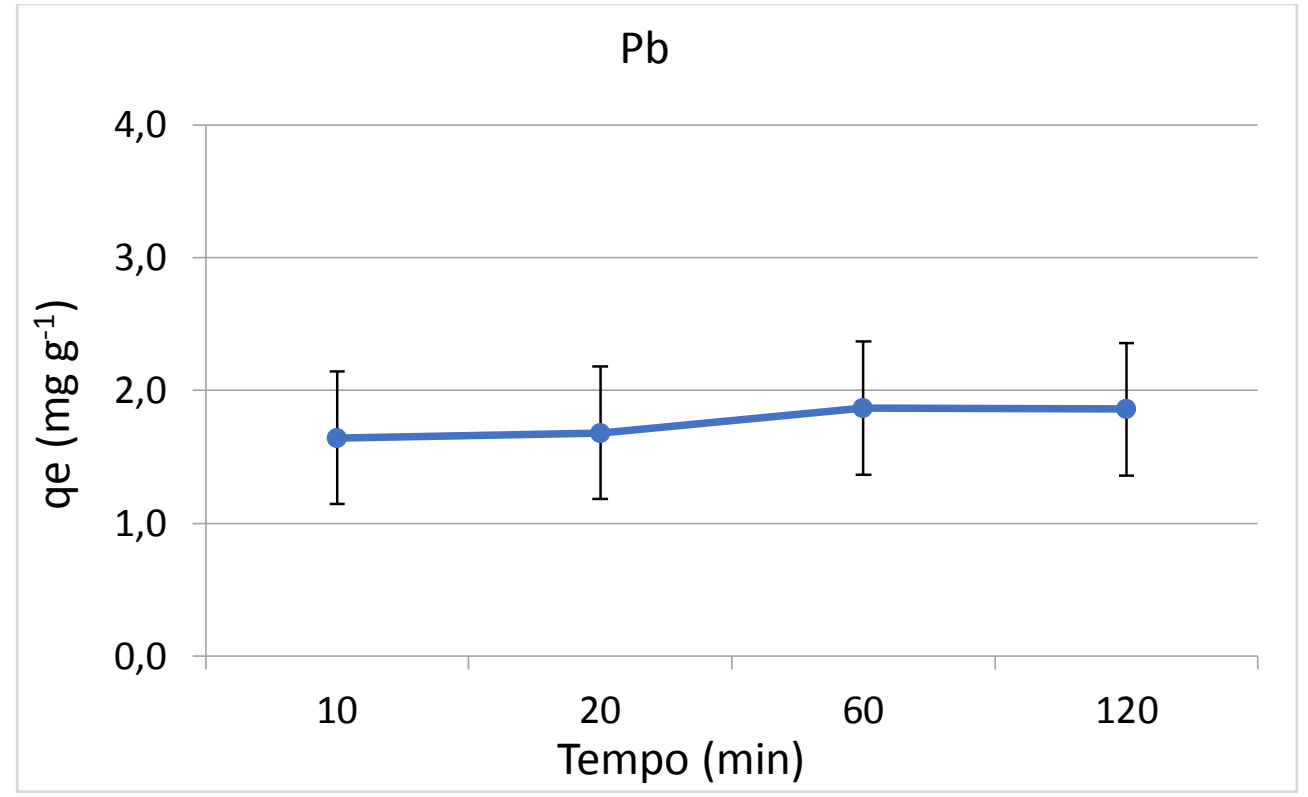

Figura 31 - Eficiência de remoção, em \%, de Pb em função do tempo de contato.

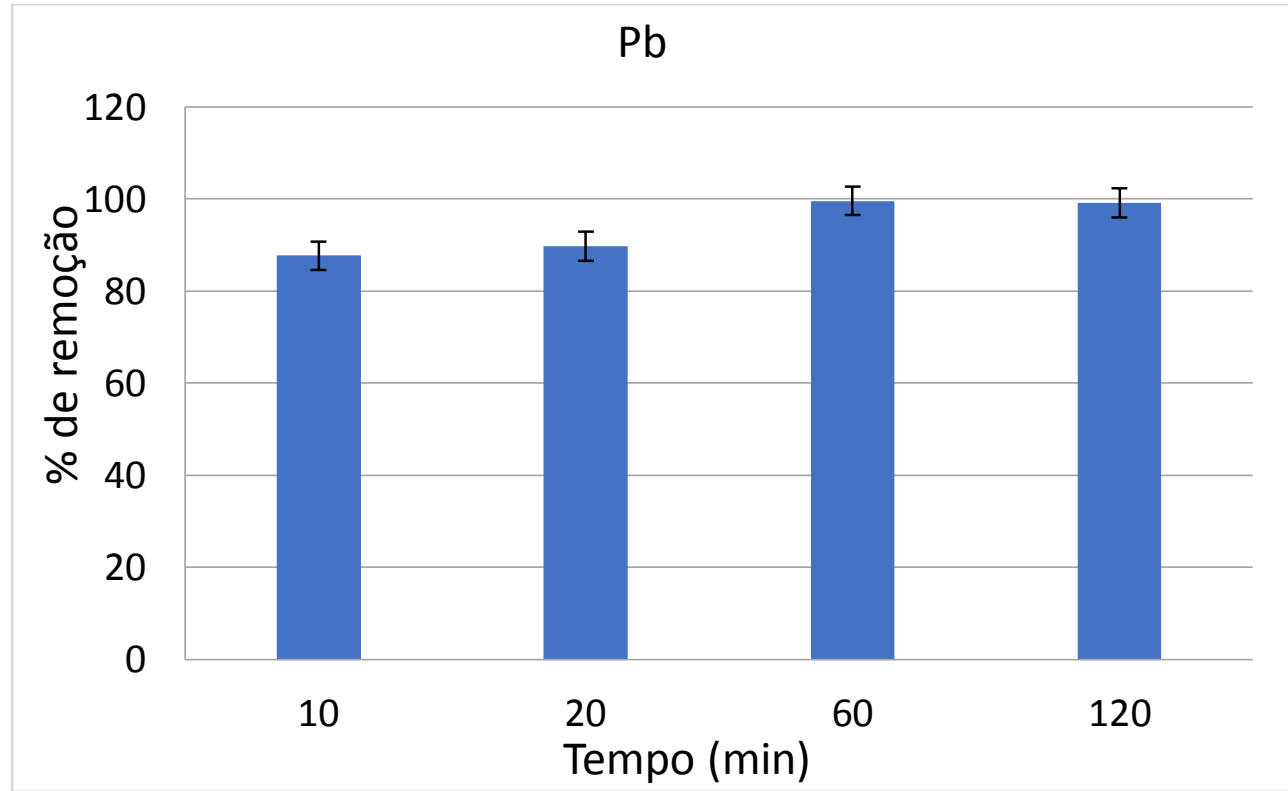

A estabilidade, ou diminuição, da eficiência de remoção e capacidade de adsorção com o tempo depende do número de sítios ativos na superfície do adsorvente. Uma vez que estes sítios se tornam saturados o processo de adsorção tende a entrar em equilíbrio (LEHMAN e HARTER, 1984). 


\subsubsection{Efeito das concentrações iniciais}

Para os experimentos para verificação do efeito das concentrações iniciais, foram testadas três concentrações diferentes, o pH foi ajustado para 6 após a adição de biomassa na solução contendo o íon de interesse e o tempo de agitação foi de 30 minutos.

Os íons Co apresentaram valores maiores para a capacidade de adsorção qe na concentração maior, mas em todas concentrações a porcentagem de remoção foi superior a $80 \%$. Os resultados obtidos são mostrados nas Figuras 32 e 33 e na tabela 18 que antecede os gráficos são exibidos os valores encontrados.

Tabela 18 - Valores de $\mathrm{q}_{\mathrm{e}}$ obtidos para o efeito de Concentração para o Co.

\begin{tabular}{|c|c|c|}
\hline & $\overline{q_{e}}$ & Incerteza \\
\hline & \multicolumn{2}{|c|}{$\mathrm{mg} \mathrm{g}^{-1}$} \\
\hline 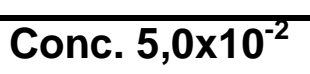 & $9,88 \cdot 10^{-3}$ & $1,02.10^{-3}$ \\
\hline Conc. $1,0 \times 10^{-1}$ & $5,35.10^{-3}$ & $1,36.10^{-3}$ \\
\hline Conc. $4,0 \times 10^{-1}$ & $3,71.10^{-2}$ & $2,79.10^{-3}$ \\
\hline
\end{tabular}

Figura 32 - Capacidade de adsorção, em $\mathrm{mg} \mathrm{g}^{-1}$, de cobalto em função da variação concentração.

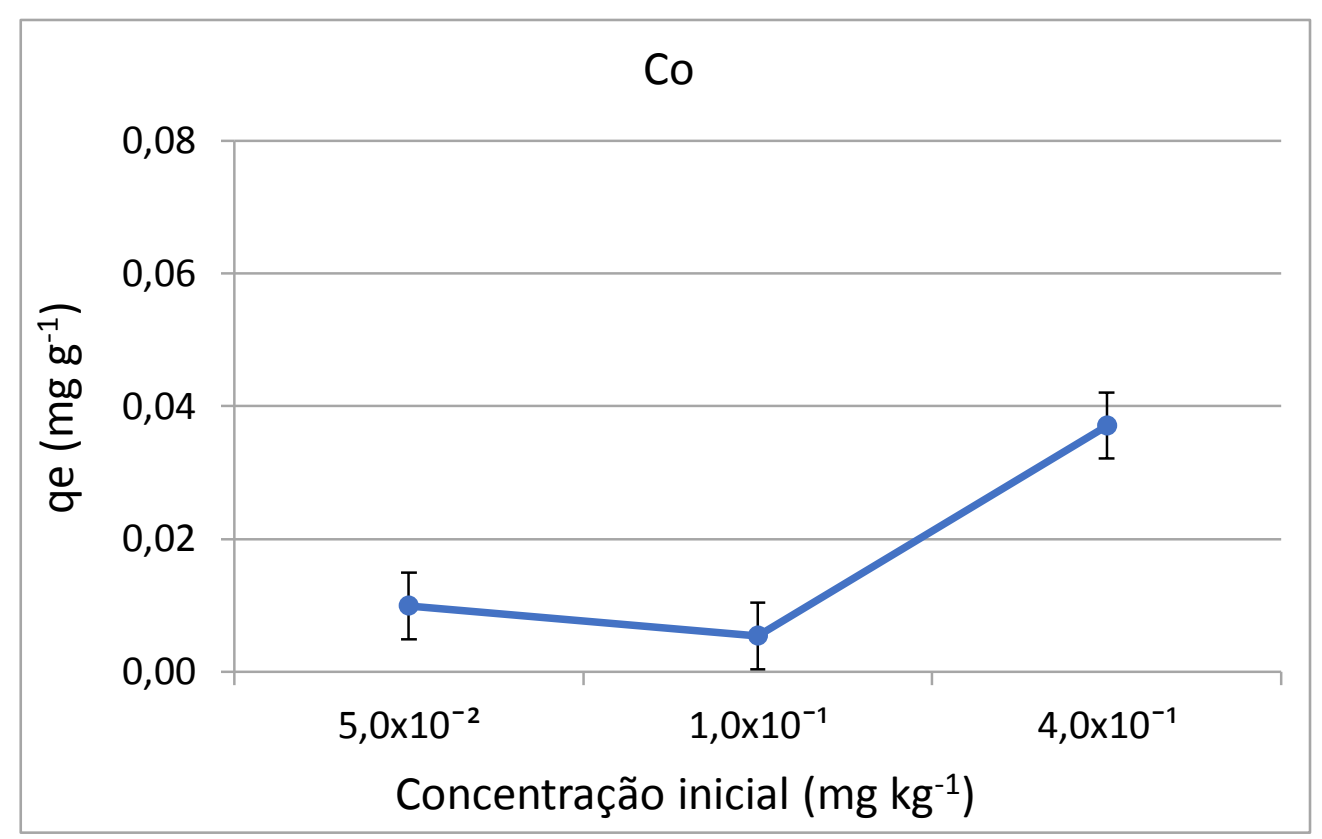


Figura 33 - Eficiência de remoção, em \%, em função da variação da concentração para os íons cobalto.

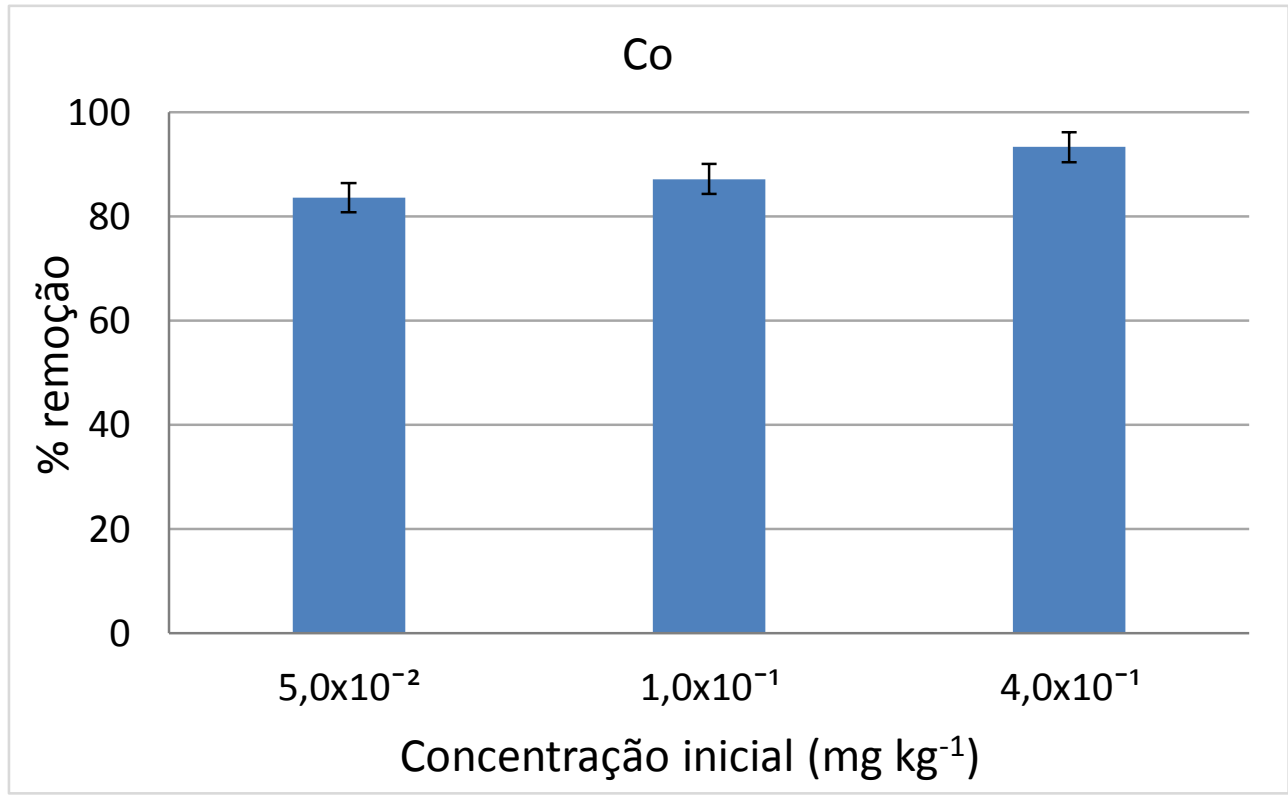

Para o elemento zinco verifica-se que a capacidade de adsorção aumenta com o aumento da concentração. A porcentagem de remoção para todas as concentrações foi superior a $90 \%$. Os resultados obtidos são mostrados nas figuras 34 e 35 e na tabela 19 que antecede os gráficos são exibidos os valores encontrados.

Tabela 19 - Valores de $q_{e}$ obtidos para o efeito de Concentração para o Zn.

\begin{tabular}{|c|c|c|}
\hline & $q_{e}$ & Incerteza \\
\hline & \multicolumn{2}{|c|}{$\mathrm{mg} \mathrm{g}^{-1}$} \\
\hline Conc. $1,8 \times 10^{-1}$ & - & - \\
\hline Conc. $3,6 \times 10^{-1}$ & $1,4.10^{-2}$ & $2,1.10^{-3}$ \\
\hline Conc. 1,5 & $7,4 \cdot 10^{-2}$ & $1,4.10^{-2}$ \\
\hline
\end{tabular}


Figura 34 - Capacidade de adsorção, em $\mathrm{mg} \mathrm{g}^{-1}$, de zinco em função da concentração.

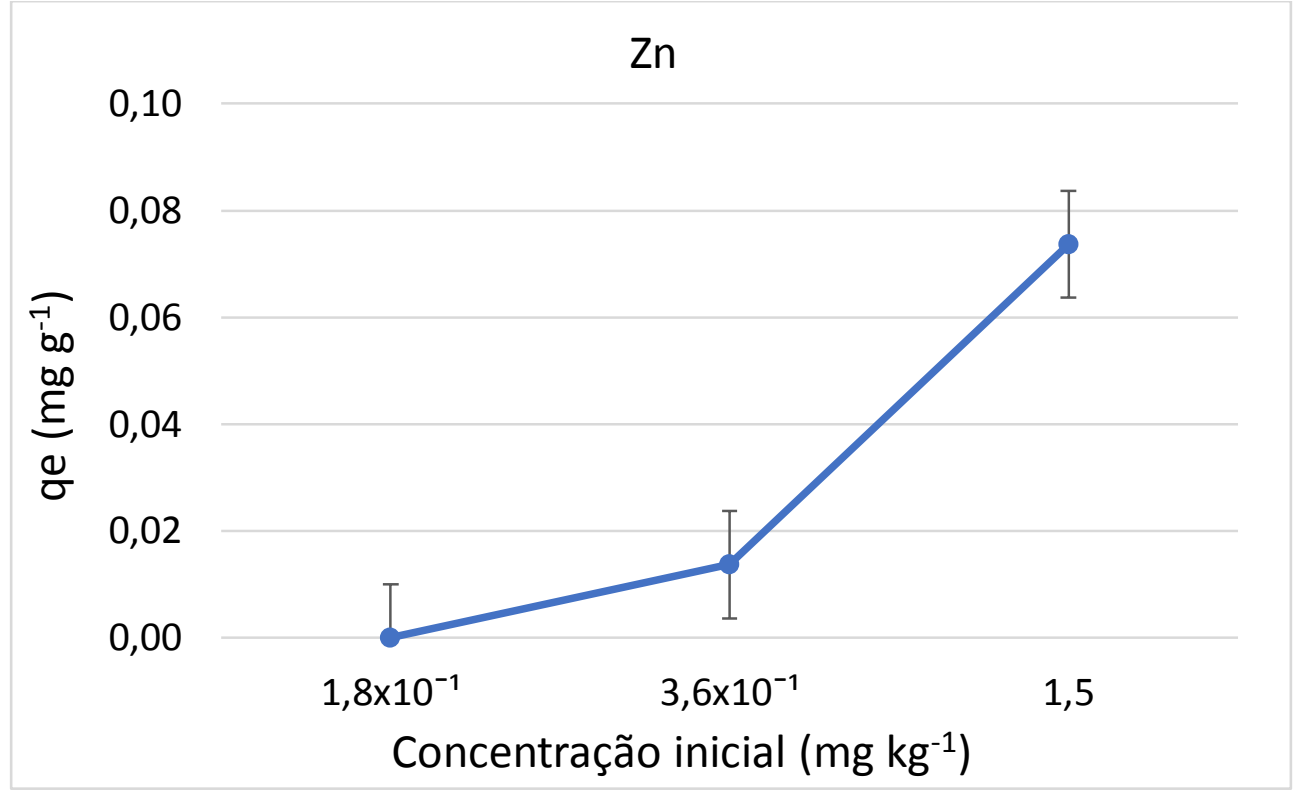

Figura 35 - Eficiência de remoção, em \%, em função da variação de concentração para íons de Zinco.

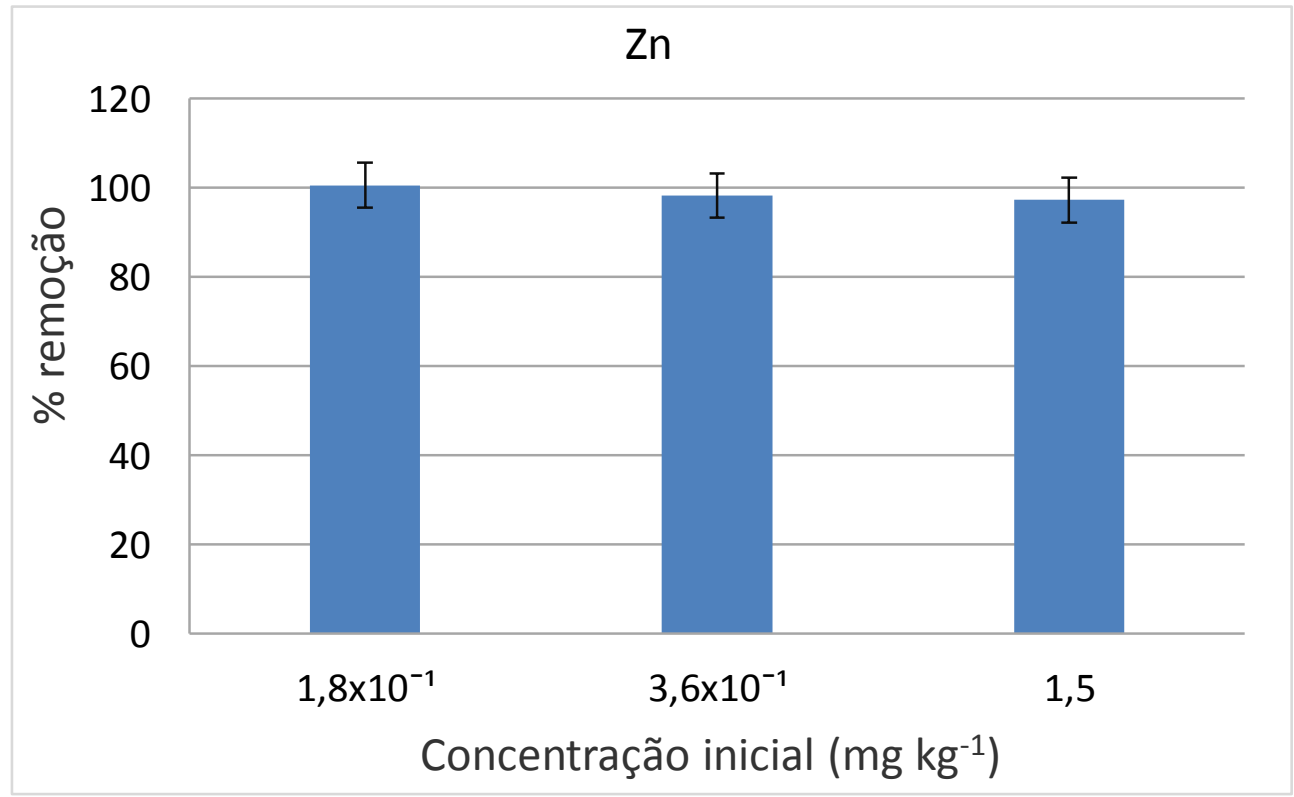

A capacidade de adsorção em função da concentração inicial da solução para o elemento cromo só foi determinada na solução de maior concentração $\left(4,0 \times 10^{-1}\right)$. A eficiência de remoção para este caso foi de $36 \%$, assim como observado nos testes anteriores. 
Para cádmio todas concentrações tiveram boa capacidade de adsorção nas três variações de concentração, na porcentagem de remoção a concentração $1,0 \times 10^{-3}$ teve $100 \%$ de adsorção nas demais concentrações a remoção foi acima de $90 \%$. Os resultados obtidos estão ilustrados nas figuras 36 e 37 e na tabela 20 que antecede os gráficos são exibidos os valores encontrados.

Tabela 20 - Valores de $q_{e}$ obtidos para o efeito de Concentração para o Cd.

\begin{tabular}{|c|c|c|}
\hline & $q_{e}$ & Incerteza \\
\hline \multicolumn{3}{|c|}{$\mathrm{mg} \mathrm{g}^{-1}$} \\
\hline Conc. $1,0 \times 10^{-3}$ & $5,8.10^{-2}$ & $9,3.10^{-3}$ \\
\hline Conc. $2,0 \times 10^{-3}$ & $1,3.10^{-1}$ & $2,1.10^{-2}$ \\
\hline Conc. $8,0 \times 10^{-3}$ & $2,5.10^{-1}$ & $3,8.10^{-2}$ \\
\hline
\end{tabular}

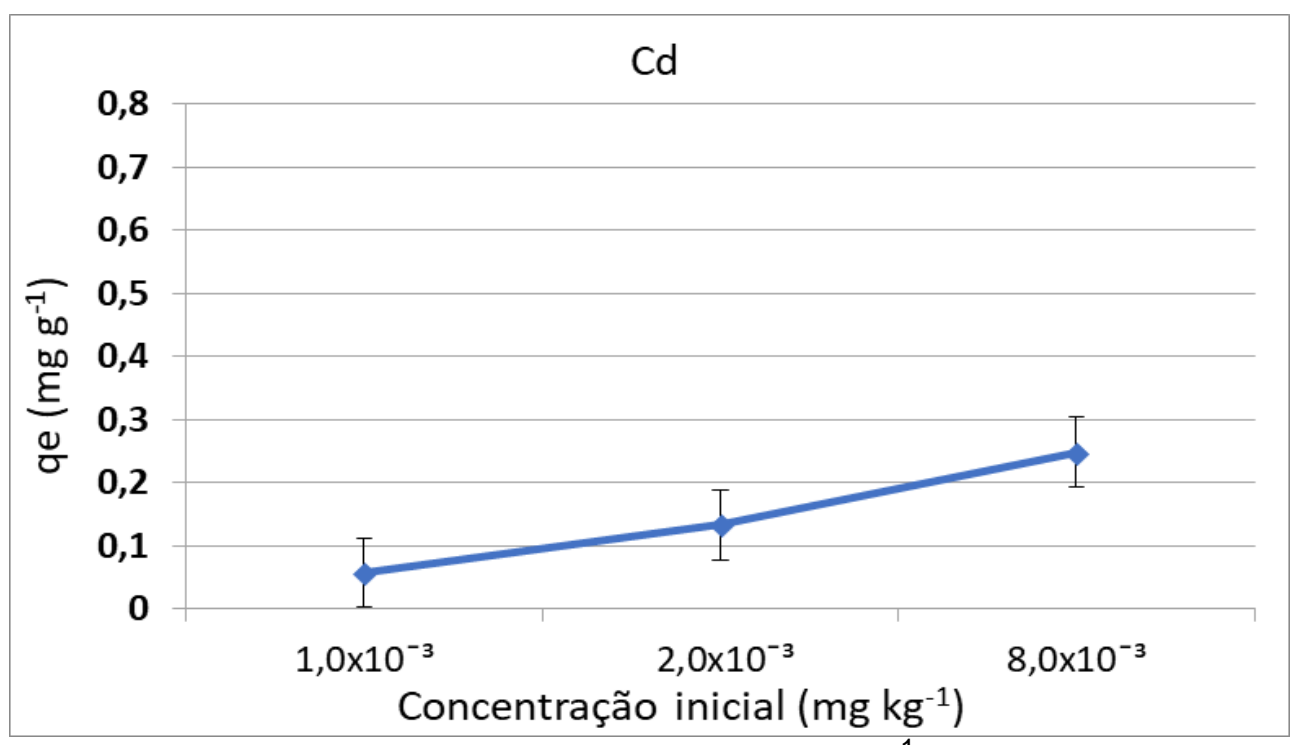

Figura 36 - Capacidade de adsorção, em $\mathrm{mg} \mathrm{g}^{-1}$, de cádmio em função da concentração. 
Figura 37 - Eficiência de remoção, em \%, em variação de concentração para íons de cádmio.

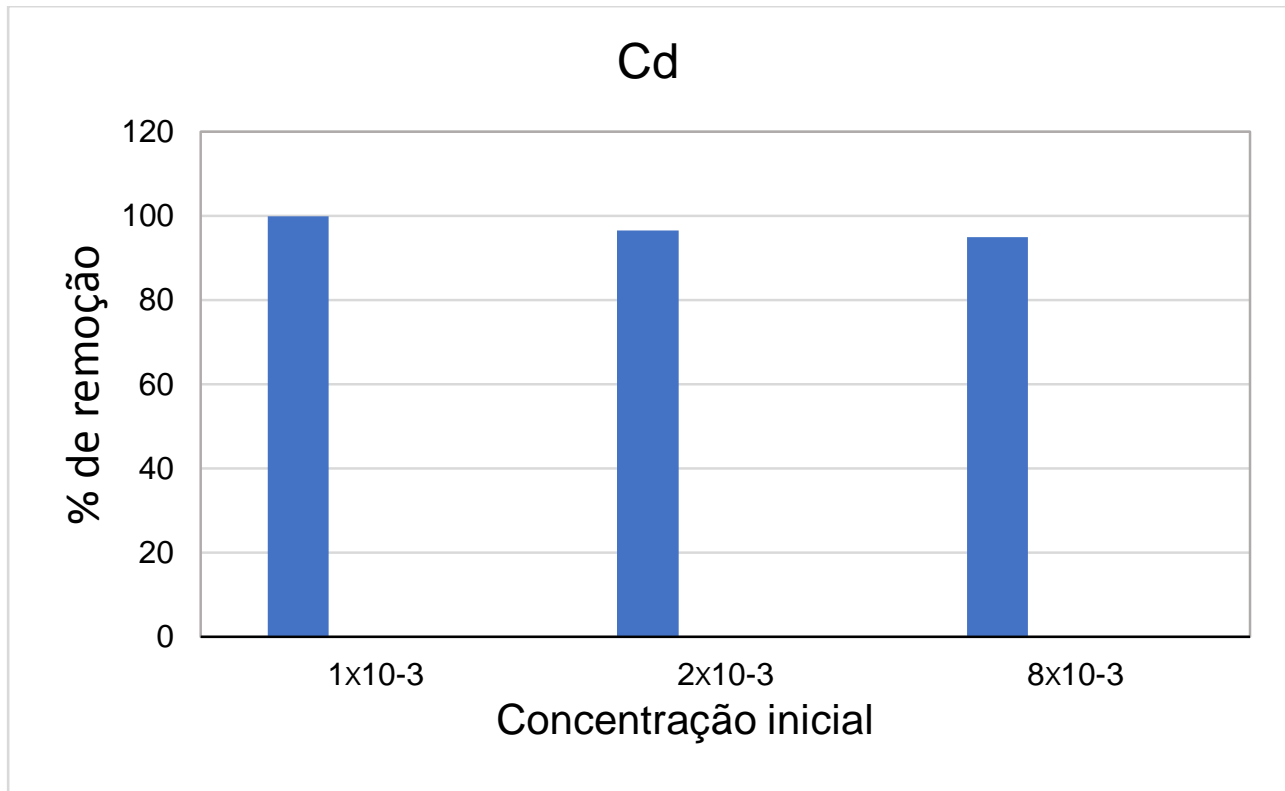

Os resultados obtidos para a capacidade de adsorção e porcentagem de remoção para o íon $\mathrm{Pb}$ estão ilustrados nas figuras 38 e 39 e na tabela 21 que antecede os gráficos são exibidos os valores encontrados.

Tabela 21 - Valores de $q_{e}$ obtidos para o efeito de Concentração para o Cd.

\begin{tabular}{|c|c|c|}
\hline & $q_{e}$ & Incerteza \\
\hline \multicolumn{3}{|c|}{$\mathrm{mg} \mathrm{g}^{-1}$} \\
\hline Conc. $1,0 \times 10^{-2}$ & 1,0 & 0,1 \\
\hline Conc. $2,0 \times 10^{-2}$ & 1,9 & 0,2 \\
\hline Conc. $8,0 \times 10^{-2}$ & 4,4 & 0,4 \\
\hline
\end{tabular}


Figura 38 - Capacidade de adsorção, em $\mathrm{mg} \mathrm{g}^{-1}$, de $\mathrm{Pb}$ em função da concentração.

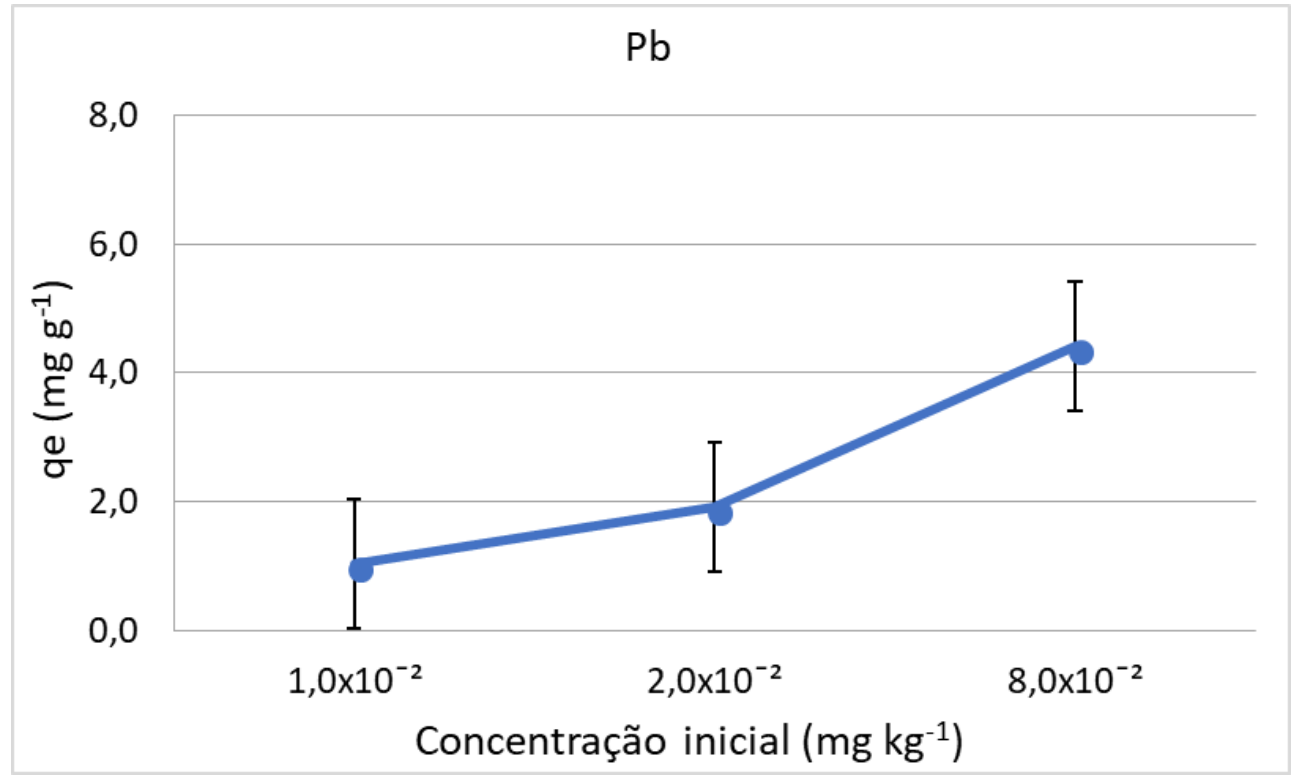

Figura 39 - Eficiência de remoção em (\%) em função da variação de concentração íons de chumbo.

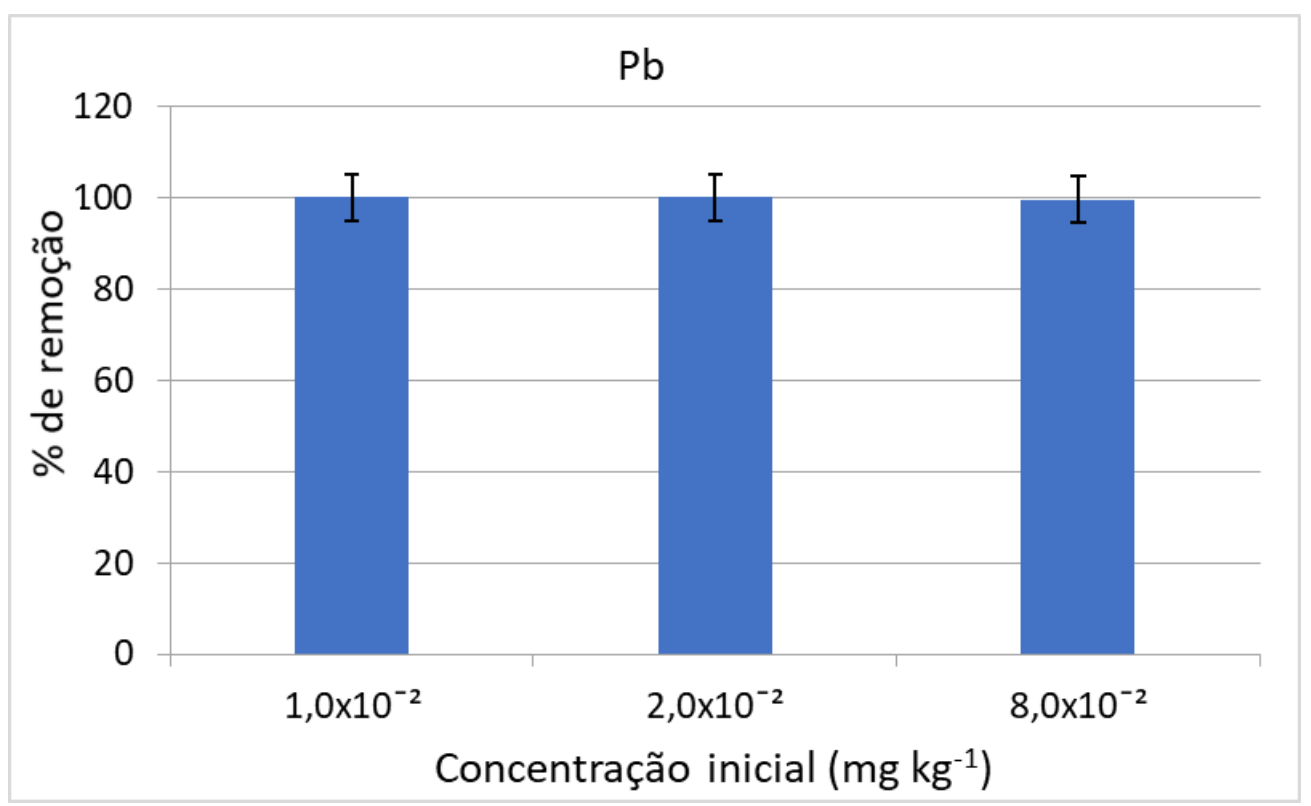

Para chumbo verifica-se também um aumento da capacidade de adsorção com o aumento da concentração inicial da solução. A capacidade de remoção do íon $\mathrm{Pb}$ da solução foi próxima a 100\% em todas as concentrações avaliadas. 


\subsection{Isotermas de adsorção}

Com os resultados obtidos nos testes de efeito da concentração inicial foram calculadas as isotermas de adsorção de Langmuir e Freundlich. Os parâmetros dos modelos obtidos neste trabalho são apresentados na Tabela 22. Os parâmetros para chumbo não foram calculados devido ao fato da concentração final da solução após o procedimento de adsorção ter ficado abaixo do limite de detecção para as duas concentrações iniciais mais baixas e para o cromo, não houve adsorção significativa devido ao tempo de contato em que os experimentos foram realizados, como discutido anteriormente.

Em cada caso os coeficientes de determinação obtidos foram avaliados por meio do teste t. Se o valor calculado $(T)$ é maior que o valor tabelado $(t)$, o coeficiente de determinação é significativo a $95 \%$ de confiança $(p<0,05)$.

Tabela 22 - Parâmetros das isotermas de Langmuir e Freundlich.

\begin{tabular}{|c|c|c|c|c|c|}
\hline \multicolumn{6}{|c|}{ Isoterma de Langmuir } \\
\hline & $\begin{array}{c}\mathrm{Q} 0 \\
\left(\mathrm{mg} \mathrm{g}^{-1}\right)\end{array}$ & $\begin{array}{c}\mathrm{KL} \\
\left(\mathrm{L} \cdot \mathrm{mg}^{-1}\right)\end{array}$ & $\mathrm{RL}$ & $\mathrm{R} 2$ & significância \\
\hline Co & $-0,0310$ & $-6,605$ & $-0,18$ a $-77,25$ & 0,24 & $T>t$ \\
\hline $\mathrm{Cd}$ & 0,26 & 21,83 & 0,007 a 0,031 & 0,879 & $T>t$ \\
\hline \multicolumn{6}{|c|}{ Isoterma de Freundlich } \\
\hline & $\begin{array}{c}\mathrm{Kf} \\
\left(\mathrm{mg} \mathrm{g}^{-1}\right)\end{array}$ & $\mathrm{n}$ & $\mathrm{R} 2$ & \multicolumn{2}{|c|}{ significância } \\
\hline Co & 1,096 & 0,72 & 0,79 & \multicolumn{2}{|r|}{$T>t$} \\
\hline $\mathrm{Zn}$ & 0,025 & $-0,521$ & 0,23 & \multicolumn{2}{|r|}{$T<t$} \\
\hline $\mathrm{Cd}$ & 0,08 & $-2,47$ & 0,345 & \multicolumn{2}{|r|}{$T<t$} \\
\hline
\end{tabular}

Verifica-se pelos resultados que para o cobalto, o ajuste de Langmuir não foi satisfatório, visto que todos os coeficientes foram negativos. Pelo ajuste para a isoterma de Freundlich o coeficiente de determinação foi significativo com valor de $n$ inferior a 1. O valor de $\mathrm{n}$ indica que a reação é favorável quando se encontra no intervalo de 1 a 10 Sposito (1980). Este resultado está de acordo com os baixos valores de capacidade de adsorção observados para este elemento, embora a porcentagem de remoção tenha sido da ordem de $80 \%$. 
Os coeficientes de determinação para zinco não foram significativos em ambos os modelos. Para este elemento, o modelo de Langmuir indica que a adsorção é favorável (RL entre 0 e 1) porém com baixa energia de ligação $(K L)$.

A isoterma de Langmuir também foi a que apresentou os melhores resultados para o $\mathrm{Cd}$. De acordo com esse modelo a reação é espontânea e com alta energia de ligação (KL). 


\section{CONCLUSÕES}

O estudo de viabilidade do uso da macrófita Eichhornia crassipes como biomassa para adsorção de íons metálicos em solução mostrou indicou que:

A queima da biomassa obtida por duas horas a $200 \stackrel{\circ}{\circ}$ reduz em $75 \%$ a $84 \%$ o material caso este venha a ser incinerado após o uso para fins de estocagem.

As diferentes partes da planta, raiz, caule e folhas, apresentam alta área superficial específica, sendo a raiz a de maior valor. A ativação ácida ou básica da raiz com ácido clorídrico ou hidróxido de sódio, ambos em concentração de $0,1 \mathrm{~mol} \mathrm{~L}^{-1}$, provocam um aumento da área superficial, porém o tratamento ácido produz um material de mais fácil moagem.

O tratamento ácido diminui a concentração dos elementos $\mathrm{Co}, \mathrm{Zn}$ e $\mathrm{Pb}$ no produto obtido em relação às concentrações observadas na biomassa não tratado. $A$ concentração do $\mathrm{Cd}$ praticamente não se altera, enquanto que a de $\mathrm{Cr}$ aumenta após o tratamento.

Adsorção de todos os íons, exceto o de cromo, foi favorecida pelo aumento do $\mathrm{pH}$ da solução inicial.

A adsorção dos íons dos elementos $\mathrm{Cd}$, $\mathrm{Co}, \mathrm{Pb}$ e $\mathrm{Zn}$ praticamente não foi influenciada em função do tempo de contato, porém o cromo somente apresentou alguma adsorção no tempo de 120 min de contato.

O efeito da concentração inicial mostra um aumento da capacidade de adsorção a medida que aumenta a concentração nas condições em que foram realizados os experimentos.

A maior capacidade de adsorção foi verificada com relação ao íon chumbo, em torno de $4 \mathrm{mg} \mathrm{g}^{-1}$. Apesar dos baixos valores de qe verificados para os íons de $\mathrm{Cd}$, Co e $\mathrm{Zn}$, as porcentagens de remoção obtidas indicam que a biomassa de Eichornia crassipes é eficiente em sua remoção a partir de soluções aquosas.

Pode-se concluir que a biomassa obtida da raiz de Eichhornia Crassipes tratada com ácido clorídrico $0,1 \mathrm{molL}^{-1}$ apresenta-se como uma alternativa rápida, barata $\mathrm{e}$ eficiente para remoção dos íons metálicos considerados neste trabalho, sendo que a eficiência de remoção presentou a seguinte ordem decrescente: $\mathrm{Pb}>\mathrm{Cd}>\mathrm{Zn}>\mathrm{Co}$. 


\section{REFERÊNCIAS BIBLIOGRÁFICAS}

ALFASSI, Z. B. Activation analysis. Department of Nuclear Engineering Ben Gurion University of the Negev Beer Sheva Israel, Vol. 1, 1990.

ALI, M. A. A. Brief Overview of Neutron Activation Analyses Methodology e Applications. 2ed Conference on Nuclear e Particle Physics, 13 -17 Nov.1999, Cairo, Egypt.

ASSOCIAÇÃO BRASILEIRA DE NORMAS TÉCNICAS. NBR 10703: Degradação do solo: Terminologia. Rio de Janeiro: ABNT, 1989. 45 p.

BRAGA, B. et al. Introdução à engenharia ambiental. 2. ed. São Paulo: Pearson, 2005. 628 p.

BRASIL. Resolução CONAMA nํ 430, de 13 de maio de 2011. CONAMA: O CONSELHO NACIONAL DO MEIO AMBIENTE. Disponível em: <http://www.mma.gov.br/port/conama/legiabre.cfm?codlegi=646>. Acesso em: 31 jul. 2017.

BROOKS, R. R. Plants that hyperaccumulate heavy metals their role in phytoremediation, microbiology, archaeology, mineral exploration e phytomining. New York: Oxford Cab International, 1998. 380 p. Organização.

CASARIN, J. Adsorção de íons metálicos utilizo a casca de semente de castanha do brasil (Bertholletia excelsa H.B.K.) como biossorvente. 2014. 150 p. Dissertação (Mestrado) - Curso de Agronomia, Universidade Estadual do Oeste do Paraná, Marechal Cândido Rondon, 2014.

CAVINATTO, V. M. Saneamento Básico: Fonte de Saúde e Bem-Estar. [s.i.]: Moderna, 1994. 62 p.

COSTA, Y. J. et al. Estudo cinético e de equilíbrio da biossorção de $\mathrm{Cr}$ (VI) de solução aquosas usando mesocarpo de maracujá-amarelo como biossorvente. Scientia Plena, v. 11, n. 12, p.1-13, 4 dez. 2015. Mensal. Associacao Sergipana de Ciencia. http://dx.doi.org/10.14808/sci.plena.2015.124201. Disponível em: <https://www.scientiaplena.org.br/sp/article/view/2637/1355>. Acesso em: 03 out. 2017. 
DEMIRBAS, A. (2008). Heavy metal adsorption onto agro-based waste materials: A review. J. Hazard. Mater., 157, 220-229.

ELKHAIARY, M. Kinetics and mechanism of adsorption of methylene blue from aqueous solution by nitric-acid treated water-hyacinth. Journal of Hazardous Materials, v. 147, n. 1-2, p.28-36, 17 ago. 2007. Elsevier BV. http://dx.doi.org/10.1016/i.jhazmat.2006.12.058. Disponível em: <http://www.sciencedirect.com/science/article/pii/S0304389406015160>. Acesso em: 10 jul. 2017.

ESTEVES, F. A. Fundamentos de Limnologia. 2. ed. Rio de Janeiro: Interciência, 1998. $226 \mathrm{p}$.

FLORES-CANO, J. V. et al. Sorption mechanism of Cd (II) from water solution onto chicken eggshell. Applied Surface Science, v. 276, p.682-690, jul. 2013. Elsevier BV. http://dx.doi.org/10.1016/j.apsusc.2013.03.153. Disponível em: <http://www.sciencedirect.com/science/article/pii/S016943321300651X>. Acesso em: 03 out. 2017.

FOO, K.Y.; HAMEED, B.H. Preparation and characterization of activated carbon from sunflower seed oil residue via microwave assisted $\mathrm{K}_{2} \mathrm{CO}_{3}$ activation. Bioresource Technology, [s.I.], v. 102, n. 20, p.9794-9799, out. 2011. Elsevier BV. http://dx.doi.org/10.1016/j.biortech.2011.08.007. Disponível em:<https://www.sciencedirect.com/science/article/pii/S0960852411010935?via=ihub >. Acesso em: 25 jan. 2018.

FONTANA, K. B. et al. Biossorption of pb (ii) by urucum shells (bixa orellana) in aqueous solutions: kinetic, equilibrium and thermodynamic study. Química Nova, v. 39, n. 9, p.1078-1084, 17 jun. 2016. GN1 Genesis Network. http://dx.doi.org/10.5935/0100-4042.20160113. Disponível em: <http://quimicanova.sbq.org.br/detalhe artigo.asp?id=6469>. Acesso em: 03 out. 2017.

FOROUTAN, R. et al. Zinc, nickel, and cobalt ions removal from aqueous solution and plating plant wastewater by modified Aspergillus flavus biomass: A dataset. Data In Brief, v. 12, p.485-492, 12 jun. 2017. Elsevier 
BV. http://dx.doi.org/10.1016/i.dib.2017.04.031.

Disponível

em:

<https://doi.org/10.1016/j.dib.2017.04.031>. Acesso em: 04 out. 2017.

HENRY-SILVA, G.G.; CAMARGO, A.F.M. Composição química de macrófitas aquáticas flutuantes utilizadas no tratamento de efluentes de aqüicultura. Planta Daninha, v. 24, n. 1, p.21-28, fev. 2006. Fap UNIFESP (SciELO). http://dx.doi.org/10.1590/s0100-83582006000100003. Disponível em: $<$ http://www.scielo.br/scielo.php?pid=S0100$83582006000100003 \&$ script=sci abstract\&tlng=pt>. Acesso em: 02 jan. 2018.

HYPOLITO, R.; ANDRADE, S.; EZAKI, S. Geoquímica da interação água, rocha, solo: estudos preliminares. São Paulo: All Print, 2011. 450 p.

I.EL-KHAIARY, M. Kinetics and mechanism of adsorption of methylene blue from aqueous solution by nitric-acid treated water-hyacinth. Journal of Hazardous Materials, v. 147, n. 1-2, p.28-36, 17 ago. 2007. Elsevier BV. http://dx.doi.org/10.1016/i.jhazmat.2006.12.058. Disponível em: $<$ http://www.sciencedirect.com/science/article/pii/S0304389406015160\#!>. Acesso em: 10 jul. 2017.

IAEA. International atomic Energy Agency. Uncertainty evaluation in instrumental and radio-chemical neutron activation analysis. Vienna, 2004 Disponível em: Acesso em: 10 outubro 2017.

HASHEM, A.; AKASHA, R. A.; GHITH, A.; HUSSEIN, D. A. (2007). Adsorbent based on agricultural wastes for heavy metal and dye removal: a review. Energy Edu. Sci. Technol., 19, 69-86.

HUSSEIN, H.; IBRAHIM S. F.; KANDEEL, K.; MOAWAD, H. (2004): "Biosorption of heavy metals from waste water using pseudomonas specie. Electronic Journal of Biotechnology. Vol. 7 pp $1-11$.

THE, L. C.; TAN, V. M.; BINH, P. T. REMOVAL OF Pb2+ FROM AQUEOUS SOLUTION BY ADSORPTION ONTO COMPOSITE BASED ON EUCALYPTUS LEAF AND POLYANILINE. Vietnam Journal Of Science And Technology, [s.I.], v. 55, n. 1, p.54-63, 9 fev. 2017. Publishing House for Science and Technology, Vietnam Academy of Science and Technology. http://dx.doi.org/10.15625/0866-708x/55/1/8360. 
LEHMAN R. G.; Harter, R.D. (1984) Assessment of copper-soil bond strength by desorption kinetics. Soil Sci Soc Am J 48:769-772.

LIMONS, R. S. Avaliação do Potencial de Utilização da Macrófita Aquática Seca Salvinia sp. no Tratamento de Efluentes de Fecularia. 2008, 101f. Dissertação Universidade Estadual do Oeste do Paraná. Disponível em: $<$ http://projetos.unioeste.br/pos/media/File/eng_quimica/rafaela_da_silva_limons.pd> Acesso em fev. 2016.

KAÍSA, B; CHRISTOPHER, D. K. C. Aquatic plant book. v. 27, n. 2, p.196-196, jun. 1992. Springer Nature. http://dx.doi.org/10.1007/bf02856255. Disponível em:<https://link-springercom.ez67.periodicos.capes.gov.br/article/10.1007/BF02856255>. Acesso em: 03 jan. 2018.

KAWAI, H.; GRIECO, V. M. Utilização de aguapé para tratamento de esgoto doméstico. São Paulo: Dae, 1983. 45 p. (153). CETESB.

KHORAMZADEH, E.; NASERNEJAD, B.; HALLADJ, R. Mercury biosorption from aqueous solutions by Sugarcane Bagasse. Journal of The Taiwan Institute of Chemical Engineers, v. 44, n. 2, p.266-269. Elsevier BV. http://dx.doi.org/10.1016/i.jtice.2012.09.004. Disponível em: $<$ http://www.sciencedirect.com/science/article/pii/S1876107012001277>. Acesso em: 03 out. 2017.

MAHAMADI, C.; NHARINGO, T. Competitive adsorption of $\mathrm{Pb}^{2+}, \mathrm{Cd}^{2+}$ and $\mathrm{Zn}^{2+}$ ions onto Eichhornia crassipes in binary and ternary systems. Bioresource Technology, v. 101, n. 3, p.859-864. Elsevier BV. http://dx.doi.org/10.1016/j.biortech.2009.08.097. MIMURA, A. M. S.; VIEIRA, T. V. A.; MARTELLI, P. B.; GORGULHO, H. F. Aplicação da casca de arroz na adsorção dos íons $\mathrm{Cu}^{2+}, \mathrm{Al}^{3+}, \mathrm{Ni}^{2+}$ e $\mathrm{Zn}^{2+}$. Química Nova, [s.I.], $\quad$ v. $\quad 33, \quad$ n. $\quad 6, \quad$ p.1279-1284, 2010. Fap UNIFESP (SciELO). http://dx.doi.org/10.1590/s0100-40422010000600012.

MISHRA, V. K.; TRIPATHI, B.D. Concurrent removal and accumulation of heavy metals by the three aquatic macrophytes. Bioresource Technology, v. 99, n. 15, p.7091-7097, outubro, 2008.2 Elsevier BV. http://dx.doi.org/10.1016/j.biortech.2008.01.002. Disponível em: 
$<$ http://www.sciencedirect.com/science/article/pii/S0960852408000072>. Acesso em: 29 dez. 2017.

MOHAMED Ahmed Mahmoud, Mohamed Mohamed El-Halwany, Adsorption of Cadmium onto Orange Peels: Isotherms, Kinetics, and Thermodynamics. J Chromatogr Sep Tech, v. 5, p $1-6$.

PINO, Gabriela Alejandra Huamán. Biossorção de Metais Pesados Utilizando Pó da Casca de Coco Verde (Cocos nucifera). 2005. 113 p. Dissertação (Mestrado) - Curso de Engenharia Metalúrgica do Departamento de Ciência dos Materiais e Metalurgia, Puc-rio, Rio de Janeiro, 2005. Disponível em: <http://www.nima.pucrio.br/cursos/pdf/036 gabriela.pdff. Acesso em: 01 out. 2017.

POMPÊO, M. Monitoramento e manejo de macrófitas aquáticas. 2008, 19p. Artigo Oecologia Australis. Disponível em: $<$ <ttp://www.oecologiaaustralis.org/ojs/index.php/oa/article/viewArticle/114>. Acesso em fev. 2016.

RAHMAN, M. Azizur et al. Influence of phosphate and iron ions in selective uptake of arsenic species by water fern (Salvinia natans L.). Chemical Engineering Journal, v. 145, n. 2, p.179-184, dez. $2008 . \quad$ Elsevier BV. http://dx.doi.org/10.1016/i.cej.2008.03.014. Disponível em: $<$ https://www.sciencedirect.com/science/article/pii/S1385894708001745>. Acesso em: 29 dez. 2017.

RANDALL, J. M.; HAUTALA, E.; MCDONALD, G. Binding of heavy metal ions by formaldehyde-polymerized peanut skins. Journal of Applied Polymer Science, v. 22, n. 2, p.379-387, fevereiro. $1978 . \quad$ WileyBlackwell. http://dx.doi.org/10.1002/app.1978.070220207.

RIFAQAT A. K. R.; MOHAMMAD K. Kinetics and isotherm studies of Cd (II) adsorption from aqueous solution utilizing seeds of bottlebrush plant (Callistemon chisholmii), Appl Water Sci (2014) 4:371-383.

ROCKER, C. Biossorção de íons cromo de solução aquosa sintética e efluente de cortume utilizando macrófitas aquáticas. 2015. 97 p. Dissertação (Mestrado) - Curso de Ciências Ambientais, Universidade Estadual do Oeste do Paraná, Toledo, 2015. Disponível em: <http://tede.unioeste.br/handle/tede/1820>. Acesso em: 03 out. 2017. 
SAI, P. M.; KRISHNAIAH, K. Development of the Pore-Size Distribution in Activated Carbon Produced from Coconut Shell Char in a Fluidized-Bed Reactor. Industrial \& Engineering Chemistry Research, v. 44, n. 1, p.51-60, janeiro. 2005. American Chemical Society (ACS). http://dx.doi.org/10.1021/ie0400090. Disponível em: <http://pubs.acs.org/doi/abs/10.1021/ie0400090>. Acesso em: 25 jan. 2018.

SANTANA, H. S. Bioadsorção de íons de $\mathrm{Cd}^{2+}, \mathrm{Cu}^{2+}, \mathrm{Pb}^{2+}, \mathrm{Ni}^{2+}$ e $\mathrm{Zn}^{2+}$ pela macrófita aquática Limnobium spongia. 2012. 78 p. Dissertação (Mestrado) - Curso de Engenharia Química, Área de Concentração em Engenharia de Processos - Acep, Universidade Estadual de Campinas, Campinas, 2012. Disponível em: <http://repositorio.unicamp.br/bitstream/REPOSIP/266699/1/Santana HarrsonSilva M.pdf>. Acesso em: 31 dez. 2017.

SARASWAT, S.; RAI, J.P.N. Heavy metal adsorption from aqueous solution using Eichhornia crassipes dead biomass. International Journal of Mineral Processing, v. 94, n. 3-4, p.203-206, abr. 2010. Elsevier BV. http://dx.doi.org/10.1016/i.minpro.2010.02.006.

SARKAR, M.; RAHMAN, A.K.M.L.; BHOUMIK, N.C. Remediation of chromium and copper on water hyacinth (E. crassipes) shoot powder. Water Resources And Industry, [s.I.], $\quad$ v. $17, \quad$ p.1-6, jun. $2017 . \quad$ Elsevier BV. http://dx.doi.org/10.1016/j.wri.2016.12.003. Disponível em: <https://www.sciencedirect.com/science/article/pii/S2212371716301585>. Acesso em: 26 dez. 2017.

SARIN, V.; PANT, K. K. (2006). Removal of chromium from industrial waste by using eucalyptus bark. Bioresour.Technol., 97, 15-20.

SEARS, G. W. Jr. Determonation of specific surface area of colloidal silica by titration with sodium hydrorxide. Grasselli Chemicals Department, Experimental 21

SCHMAL, M.. Cinética dos Reatores: Aplicação na Engenharia Química. Rio de Janeiro: Synergia, 2009. 611 p.

STTTION, E. I. Du Pont de Nemours \& Co., Inc., Wilmington, Del. VOLUME 28, № 12, DECEMBER 1956. 
SINGH, K. K.; TALAT, M.; HASAN, S. H. (2006). Removal of lead from aqueous solutions by agricultural waste maize bran. Bioresour.Technol., 97, 2124-2130.

SCHNEIDER, I. A. H. Biossorção de Metais Pesados com a Biomassa de Macrófitos Aquáticos. 1995. 158 p. Tese (Doutorado) - Curso de Engenharia Metalúrgica e dos Materiais (PPGEMM), Escola de Engenharia, Universidade Federal do Rio Grande do Sul (UFRS), Porto Alegre, 1995. Disponível em:<https://www.lume.ufrgs.br/bitstream/handle/10183/96089/000202084.pdf?seque nce=1>. Acesso em: 10 dez. 2016

SCHVARTSMAN, S. Intoxicações agudas. São Paulo: 1985. 443 p.

SILVA, G. S.; CAPRI NETO, Â.; CAPRI, M. R. BIOSSORÇÃO DE Cr (VI) PELA CASCA DE BANANA NANICA NO TRATAMENTO DE EFLUENTES. Interfaces Científicas - Saúde e Ambiente, [s.I.], v. 5, n. 1, p.153-162, 1 out. 2016. Universidade Tiradentes. http://dx.doi.org/10.17564/2316-3798.2016v5n1p153-162.

SPOSITO, G.; Soil Science Society America Journal, 44:1980, 652p.

TIWARI, S.; DIXIT, S.; VERMA, N. An Effective Means of Biofiltration of Heavy Metal Contaminated Water Bodies Using Aquatic Weed Eichhornia crassipes. Environmental Monitoring and Assessment, [s.I.], v. 129, n. 1-3, p.253256, 28 out. 2006. Springer Nature. http://dx.doi.org/10.1007/s10661-006-9358-7.

ZHANG, F. et al. Efficiency and mechanisms of Cd removal from aqueous solution by biochar derived from water hyacinth (Eichornia crassipes). Journal of Environmental Management, v. 153, p.68-73, abr. $2015 . \quad$ Elsevier BV. http://dx.doi.org/10.1016/j.jenvman.2015.01.043. Disponível em: <http://www.sciencedirect.com/science/article/pii/S0301479715000596>. Acesso em: 27 dez. 2017.

WANYONYI, W. C.; ONYARI, J. M.; SHIUNDU, P. M., (2014) Adsorption of Congo Red Dye from Aqueous Solutions Using Roots of Eichhornia Crassipes: Kinetic and Equilibrium Studies, Energy Procedia, 50, 862-869. 
INSTITUTO DE PESQUISAS ENERGÉTICAS E NUCLEARES

Diretoria de Pesquisa, Desenvolvimento e Ensino

Av. Prof. Lineu Prestes, 2242 - Cidade Universitária CEP: 05508-000

Fone/Fax(0XX11) 3133-8908

SÃO PAULO - São Paulo - Brasil

http://www.ipen.br

O IPEN é uma Autaquia vinculada à Secretaria de Desenvolvimento, associada à Universiade de São Paulo e gerida técnica e administrativamente pela Comissão Nacional de Energia Nuclear, órgão do Ministério da Ciência, Tecnologia e Inovação. 